NBER WORKING PAPER SERIES

\title{
CASH-ON-HAND AND COMPETING MODELS OF INTERTEMPORAL BEHAVIOR: NEW EVIDENCE FROM THE LABOR MARKET
}

\author{
David Card \\ Raj Chetty \\ Andrea Weber \\ Working Paper 12639 \\ http://www.nber.org/papers/w12639 \\ NATIONAL BUREAU OF ECONOMIC RESEARCH \\ 1050 Massachusetts Avenue \\ Cambridge, MA 02138 \\ October 2006
}

We are extremely grateful to Rudolph Winter-Ebmer and Jospeh Zweimuller for assistance in obtaining the data used in this study. Thanks to George Akerlof, Joe Altonji, David Autor, Richard Blundell, Peter Diamond, Caroline Hoxby, David Lee, David Romer, Emmanuel Saez, Adam Szeidl, Robert Shimer, and numerous seminar participants for comments and suggestions. Thanks to Sepp Zuckerstatter and Andreas Buzek for help with institutional details. Matthew Grandy provided excellent research assistance and Josef Fersterer provided excellent assistance with data processing. Funding was provided by the Center for Labor Economics at UC Berkeley. The views expressed herein are those of the author(s) and do not necessarily reflect the views of the National Bureau of Economic Research.

(C) 2006 by David Card, Raj Chetty, and Andrea Weber. All rights reserved. Short sections of text, not to exceed two paragraphs, may be quoted without explicit permission provided that full credit, including $(\odot$ notice, is given to the source. 
Cash-on-Hand and Competing Models of Intertemporal Behavior: New Evidence from the

Labor Market

David Card, Raj Chetty, and Andrea Weber

NBER Working Paper No. 12639

October 2006

JEL No. D91,E6,H5,J6

\section{$\underline{\text { ABSTRACT }}$}

This paper presents new tests of the permanent income hypothesis and other widely used models of household behavior using data from the labor market. We estimate the "excess sensitivity" of job search behavior to cash-on-hand using sharp discontinuities in eligibility for severance pay and extended unemployment insurance (UI) benefits in Austria. Analyzing data for over one-half million job losers, we obtain three empirical results: (1) a lump-sum severance payment equal to two months of earnings reduces the job-finding rate by $8-12 \%$ on average; (2) an extension of the potential duration of UI benefits from 20 weeks to 30 weeks similarly lowers job-finding rates in the first 20 weeks of search by 5-9\%; and (3) increases in the duration of search induced by the two programs have little or no effect on subsequent job match quality. Using a search theoretic model, we show that estimates of the relative effect of severance pay and extended benefits can be used to calibrate and test a wide set of intertemporal models. Our estimates of this ratio are inconsistent with the predictions of a standard permanent income model, as well as naive "rule of thumb" behavior. The representative job searcher in our data is $70 \%$ of the way between the permanent income benchmark and credit-constrained behavior in terms of sensitivity to cash-on-hand.

David Card

Department of Economics

549 Evans Hall, \#3880

UC Berkeley

Berkeley, CA 94720-3880

and NBER

card@econ.berkeley.edu

Raj Chetty

Department of Economics

UC- Berkeley

521 Evans Hall \#3880

Berkeley, CA 94720

and NBER

chetty@econ.berkeley.edu
Andrea Weber

University of California, Berkeley

Department of Economics

549 Evans Hall \#3880

andrea.weber@ihs.ac.at 


\section{Introduction}

Does disposable income ("cash-on-hand") affect household behavior? The answer to this basic question has implications for many areas of economics. In macroeconomics, the answer distinguishes between a set of widely used models, ranging from the permanent income hypothesis (where changes in disposable income have small effects on current consumption) to "rule of thumb" models (where consumption rises dollar-for-dollar with income). In public finance, the answer matters for optimal tax and social insurance policies. Temporary tax cuts can only be effective as a fiscal stimulus if households are sensitive to cash-on-hand. Similarly, the benefits of temporary income support programs such as unemployment insurance and welfare depend on the extent to which individuals can smooth short-term income fluctuations on their own (Baily 1978, Chetty 2006a).

The effects of cash-on-hand have been studied since the 1950s in the macroeconomics literature, where researchers have estimated the effects of windfall cash grants on consumption (see section II for a brief summary of this literature). However, there is still no firm consensus on the extent to which individuals can smooth consumption, due in part to limitations of the available data. As a result, the issue of which model best describes household behavior remains controversial. ${ }^{1}$

In this paper, we provide new evidence on the validity of alternative dynamic models by estimating the effects of cash-on-hand on labor market behavior. In particular, we study whether lump-sum severance payments for job losers in Austria affect unemployment durations and subsequent job outcomes. Conceptually, our analysis is similar to existing studies of sensitivity to cash-on-hand. We simply use a different measure of "consumption" - search intensity instead of purchased goods. Excess sensitivity of search intensity to cash-on-hand distinguishes between the permanent income hypothesis (PIH) and other dynamic models in the same way as excess sensitivity of consumption. Indeed, using a simple job search model, we show that the effects of cash-on-hand on consumption can be inferred from its effects on search behavior.

Our labor market approach complements existing consumption-based studies in three ways. First, the institutional features of the labor market we study allow a sharper research design. Eligibility for severance pay in Austria is based on a simple discontinuous rule that applies to nearly all workers: people with 3 or more years of job tenure are eligible, whereas those with shorter tenures are not. In addition, administrative wage and employment data are available for the universe of private sector workers, providing a sample of 650,000 job losers. The sharp

\footnotetext{
${ }^{1}$ The lack of consensus is underscored in the review by Browning and Lusardi (1996), who note that they personally disagree on importance of liquidity constraints.
} 
discontinuity and large sample size allow us to obtain more precise estimates of the effects of cash-on-hand than consumption-based studies, which are often constrained by small samples and difficulties in measurement of nondurable consumption. Second, the severance payment is generous - equivalent to two months of pre-tax salary, or 2,300 Euros at the sample mean. This overcomes Browning and Crossley's (2001) criticism that the welfare cost of failing to smooth small amounts (e.g. the $\$ 300-\$ 600$ tax rebates in Johnson, Parker, and Souleles 2006 ) is negligible. Third, the panel structure of our data set allows us to measure the long-term effects of cash grants on subsequent job quality. The size of match quality effects is an important issue of independent interest in the job search literature, and estimating their magnitude enables us to further distinguish between alternative models of search behavior.

We exploit the quasi-experiment created by the discontinuous Austrian severance pay law using a regression discontinuity (RD) design, essentially comparing the search behavior of individuals who were laid off just before and just after the 36 month cutoff for eligibility. The key threat to a causal interpretation of our estimates is that firms may alter their firing decisions to avoid paying severance, leading to non-random selection around the discontinuity and invaliding the "experiment." We evaluate this possibility by comparing the number of layoffs at each level of job tenure, and by examining the characteristics of job losers with just under and just over 3 years of tenure. We find no systematic evidence of selection on observables around the discontinuity - a result that is consistent with relatively restrictive firing regulations in Austria and laws against the strategic timing of layoffs. ${ }^{2}$ We further evaluate the key identification assumption by analyzing subsamples in which selective firing is less plausible (people laid off from small firms, or as part of a larger group) and by conducting a "placebo test" of the effect of tenure in earlier jobs. None of these specification tests points to any evidence of selective firing, suggesting that discontinuities in search outcomes around the 36 month cutoff can be attributed to the causal effect of severance pay.

Our empirical analysis leads to three main findings. First, lump sum severance pay has a clearly discernible and economically significant effect on the duration of joblessness. The hazard rate of finding a new job during the first 20 weeks of the unemployment spell (the period of eligibility for regular unemployment benefits in Austria) is 8-12\% percent lower for those who are just barely eligible for severance pay than for those who are just barely ineligible. This sensitivity to cash-

\footnotetext{
${ }^{2}$ Firms with 5 or more workers must also obtain the approval of their Works Council to lay off workers, reducing the flexibility to strategically fire workers just before the 36 month cutoff.
} 
on-hand is inconsistent with a full insurance model where agents are perfectly insured against all income shocks. Second, using a parallel analysis of a discontinuity in the unemployment insurance (UI) benefit system, we find that job seekers who are eligible for 30 weeks of benefits exhibit 5-9\% lower rates of job finding during the first 20 weeks of search than job seekers eligible for 20 weeks of UI benefits. This result shows that individuals anticipate the longer duration of benefits and reduce their search effort before the benefit extension takes effect. Such forward-looking behavior is inconsistent with a naive "rule of thumb" model where agents are completely myopic.

Third, we find that neither lump sum severance payments nor extended benefits have any effect on the "quality" of subsequent jobs. Mean wages, the duration of subsequent jobs, and other measures of job quality are unaffected by eligibility for severance pay or extended benefits. An advantage of our approach relative to earlier studies is that we have enough precision to rule out fairly small job quality gains. For example, the additional search induced by the severance payment or benefit extension is estimated to raise the mean subsequent wage by less than $1 \%$ at the upper bound of the $95 \%$ confidence interval. Thus, severance pay and extended benefits appear to increase the duration of jobless spells primarily via a reduction in search intensity, rather than through an increase in the reservation wages of job seekers.

We interpret our reduced-form findings through the framework of a job search model that nests several commonly used models of household behavior. In particular, we construct a sample moment based on the relative effects of severance pay and benefit extensions that can be used to calibrate and test between these models. We then simulate the values of this moment from a simple version of the PIH model with unrestricted borrowing and a fully credit-constrained model. Comparing the predicted moments with our empirical estimates, we find that the PIH model is rejected by the data with $p<0.01$, even with high discount rates or risk aversion. Our estimates suggest that deviations from the PIH benchmark are substantial: typical job searchers behave as if they are located $70 \%$ of the way between the PIH with unrestricted borrowing and the fully credit-constrained case (see Figure 1). We conclude that models with forward-looking behavior but limited consumption smoothing - such as Deaton's (1991) buffer-stock model - are most likely to fit the data. This characterization implies that temporary income support and tax policies can have substantial effects on economic welfare.

The paper proceeds as follows. Section II discusses related literature. Section III presents a theoretical search model and derives the moment for calibration. Section IV describes the institutional background and data. Section V outlines our estimation strategy and identification assumptions. 
Section VI presents the empirical results on unemployment durations, and Section VII presents results on search outcomes. Section VIII uses the empirical estimates to test between models. Section IX concludes.

\section{Related Literature}

Our analysis builds on insights and methods from several literatures in macroeconomics, public finance, and labor economics. First, several studies have estimated the effects of transitory income shocks on consumption. ${ }^{3}$ Bodkin (1959) and Bird and Bodkin (1965) estimated that World War II veterans spent $40-70 \%$ of a one-time unexpected payment issued in 1950 on current nondurable consumption. Subsequent studies of tax rebates using aggregate data (e.g., Blinder, 1981; Blinder and Deaton, 1985; Poterba 1988) also found relatively large impacts on nondurable consumption in the quarter of receipt.

More recent microdata-based studies of pre-announced tax cuts and rebates have obtained somewhat mixed results. Shapiro and Slemrod (1995), Parker (1999), and Souleles (1999) present evidence that current nondurable spending absorbs 30-65 percent of the change in after-tax current income using variation in tax refunds and social security tax withholding. In contrast, Paxson (1992) finds that farmers in Thailand successfully smooth income fluctuations due to rainfall shocks. Browning and Collado (2001) find that the extra wages paid to Spanish workers in June and December have no effect on consumption patterns. Similarly, Hsieh (2003) finds no relation between spending and the timing of payments from the Alaska State fund. Most recently, Johnson, Parker, and Souleles (2006) analyze the 2001 federal tax rebates, and find increases in non-durable consumption in the quarter the check was mailed of 20-30 cents per dollar. As in other consumptionbased studies, however, the confidence intervals for these estimates are relatively wide, covering a range from 5 to 65 cents per dollar.

Browning and Crossley (2001) argue that many of the studies that find a high marginal propensity to consume out of current income are identified from small income fluctuations. Since the welfare losses from failing to smooth over small amounts are modest, they argue that the findings can be viewed as evidence of bounded rationality, rather than as a failure of the standard lifecycle

\footnotetext{
${ }^{3}$ Many other strands of the consumption literature are also related, including the tests for excess sensitivity in Flavin (1981), Hall and Mishkin (1982), and Altonji and Siow (1987), tests for the effect of current information on future changes in in consumption (Hall 1978), tests for liquidity constraints and precautionary-savings behavior (e.g. Zeldes 1989, Gourinchas and Parker 2001, Fuchs-Schundeln and Schundeln 2005), and tests for rule of thumb behavior (Campbell and Mankiw 1989). See Deaton (1992) for a summary and thoughtful interpretation of much of the literature up the early 1990s, and Browning and Crossley (2001) for a more recent survey.
} 
model. Our study involves a substantial cash grant (two months of wages) and yields relatively precise estimates of the effects of this grant, so we believe it is less subject to this criticism.

A second and related literature uses variation in UI benefits to estimate the effect of current income on the consumption of job losers. Gruber (1997) relates the change in food consumption for families with a recently unemployed head to the generosity of the UI benefits potentially available to the head. He estimates that a $10 \%$ increase in the UI benefit level leads to approximately a 3 percent increase in food consumption by the unemployed. Subsequent studies by Browning and Crossley (1999) and Bloemen and Stancanelli (2005) on samples of longer-term job losers in Canada and the U.K. find smaller effects of UI benefits on total expenditures for all job losers, but larger effects among job losers with low assets prior to job loss. Interestingly, Bloemen and Stancanelli report that job losers who received severance benefits have higher consumption while unemployed, a result consistent with our findings below.

Outside the consumption literature, our analysis is also related to studies of the effects of unemployment benefits and assets on the duration of unemployment. On the theoretical side, conventional job search models imply that higher unemployment benefits and longer potential eligibility for benefits will raise the average duration of unemployment (e.g., Mortensen 1977, Mortensen 1986). Most search models assume risk neutrality and ignore savings, and thus do not study wealth effects (i.e., the effects of cash-on-hand). A few studies have incorporated an intertemporal consumption decision, and derived conditions under which increases in wealth lower search intensity (Danforth, 1979; Lentz and Tranaes, 2005). On the empirical side, a number of well-known studies have shown that the duration of unemployment is affected by the generosity and potential duration of UI benefits (e.g., Meyer 1990, Katz and Meyer 1990, Lalive and Zweimuller 2004, Lalive et. al. 2006). These studies have generally assumed that the entire response of search behavior to UI benefits is due to moral hazard (a substitution effect) rather than wealth effects. Chetty (2006b) points out that the wealth effects of UI benefits may be non-trivial when agents have limited liquidity. He decomposes the UI benefit elasticity into a wealth effect and substitution effect by examining the heterogeneity of duration-benefit elasticities across liquidity constrained and unconstrained groups in the U.S. His results imply that a substantial portion of the UI benefit effect is a wealth effect, consistent with our findings here. Relative to existing studies in this literature, the key advantages of our approach are the use of an exogenous source of variation in wealth to estimate wealth effects, and the use of these estimates to distinguish between dynamic models of household behavior.

Our work also contributes to the literature on the job quality gains from prolonged search. 
Ehrenberg and Oaxaca (1976) estimate a positive effect of UI benefit levels on average wages at the next job using cross-sectional variation in replacement rates. In contrast, Classen (1977) found that increases in UI benefits legislated by certain states in the U.S. had little or no effect on wages at the next job. Subsequent studies have also found mixed and often fragile results: see Burtless (1990) and Cox and Oaxaca (1990) for reviews and Addison and Blackburn (2000) and Centeno (2004) for more recent analysis. This literature remains unsettled largely because of the absence of compelling variation in benefit policies. Our analysis yields more credible and precise estimates of match quality gains than earlier studies, reflecting our RD research design and the large panel used for the analysis.

Finally, our study is related to the extensive literature on optimal social insurance (e.g. Baily 1978, Flemming 1978, Hansen and Imrohoroglu 1992, Wang and Williamson 1996, Acemoglu and Shimer 1999, Chetty 2006a, Shimer and Werning 2006). While we do not analyze an optimal social insurance problem here, we provide a new estimate of the extent to which households can smooth consumption, a central parameter in such analyses.

\section{A Job Search Model}

We begin by presenting a simple job search model that provides an organizing framework for our empirical analysis. We use the model to characterize the comparative statics of search behavior, and to construct a moment that can be used to test between competing intertemporal models.

Model Setup. Our model is closely based on Lentz and Tranaes (2005), who incorporate savings decisions in a job search model with variable search intensity. We make a few assumptions to simplify the presentation. First, we assume that all jobs last indefinitely once found (i.e. there is no subsequent job destruction). Second, anticipating our empirical findings, we assume that wages are exogenously fixed, eliminating reservation-wage choices. We discuss the implications of relaxing these assumptions at the end of this section.

Consider a discrete-time setting where individuals have a finite planning horizon and a subjective time discount rate of $\delta$. Let $r$ denote the fixed interest rate in the economy. Flow utility in period $t$ is given by $u\left(c_{t}\right)-\psi\left(s_{t}\right)$, where $c_{t}$ represents consumption in the period, $s_{t}$ denotes search effort, and the functions $u$ and $\psi$ are strictly concave and convex, respectively. ${ }^{4}$ Normalize $s_{t}$ to equal

\footnotetext{
${ }^{4}$ This formulation assumes within-period separability between consumption and search effort. Aguiar and Hurst (2005) present evidence that separable utility is consistent with expenditure patterns during unemployment spells (but not retirement). See Lentz and Tranaes (2005) for a discussion of the effects of non-separability in search models.
} 
the probability of finding a job in the current period. Abstracting from on-the-job search, assume $s_{t}=0$ if the individual is employed in period $t$.

Assume that the agent becomes unemployed at $t=0$. An agent who enters a period $t$ without a job first chooses search intensity $s_{t}$, and immediately learns if he or she has obtained a job. If search is successful, the agent begins working in that period at a fixed real wage $w$ that persists indefinitely. Let $c_{t}^{e}$ denote the agent's optimal consumption choice in period $t$ if a job is found in that period. ${ }^{5}$ If the agent fails to find a job in period $t$, he receives an unemployment benefit $b_{t}$ and sets consumption to $c_{t}^{u}$. The agent then enters period $t+1$ unemployed and the problem repeats.

Optimal Search Intensity. The value function for an individual who finds a job at the beginning of period $t$, conditional on beginning the period with assets $A_{t}$ is

$$
V_{t}\left(A_{t}\right)=\max _{A_{t+1} \geq L} u\left(A_{t}-A_{t+1} /(1+r)+w\right)+\frac{1}{1+\delta} V_{t+1}\left(A_{t+1}\right)
$$

where $L$ is a lower bound on assets that may or may not be binding. The value function for an individual who fails to find a job at the beginning of period $t$ and remains unemployed is:

$$
U_{t}\left(A_{t}\right)=\max _{A_{t+1} \geq L} u\left(A_{t}-A_{t+1} /(1+r)+b_{t}\right)+\frac{1}{1+\delta} J_{t+1}\left(A_{t+1}\right)
$$

where $J_{t+1}\left(A_{t+1}\right)$ is the value of entering the next period unemployed. It is easy to show that $V_{t}$ is concave because the agent faces a deterministic pie-eating problem once re-employed. The function $U_{t}$, however, can be convex. Lentz and Tranaes (2005) address this problem by introducing a wealth lottery that can be played prior to the choice of search intensity whenever $U$ is non-concave, although they note that in simulations of the model, non-concavity never arises. We shall simply assume that $U$ is concave.

The agent chooses $s_{t}$ to maximize expected utility at the beginning of period $t$, taking into account the cost of search:

$$
J_{t}\left(A_{t}\right)=\max _{s_{t}} s_{t} V_{t}\left(A_{t}\right)+\left(1-s_{t}\right) U_{t}\left(A_{t}\right)-\psi\left(s_{t}\right)
$$

\footnotetext{
${ }^{5}$ Note that if the agent found a job in an earlier period, consumption in period $t$ may not equal $c_{t}^{e}$.
} 
The first order condition for optimal search intensity is

$$
\psi^{\prime}\left(s_{t}^{*}\right)=V_{t}\left(A_{t}\right)-U_{t}\left(A_{t}\right)
$$

reflecting the fact that the agent chooses $s_{t}$ to equate the marginal cost of search effort with the marginal value of search effort, which is given by the difference between the optimized values of employment and unemployment.

Our testable predictions and empirical analysis follow from the comparative statics of equation (4). First consider the effect of the UI benefit level on search effort. Differentiating equation (4) and using the envelope theorem, we obtain:

$$
\partial s_{t}^{*} / \partial b_{t}=-u^{\prime}\left(c_{t}^{u}\right) / \psi^{\prime \prime}\left(s_{t}^{*}\right)<0
$$

Equation (5) is the standard result that higher unemployment benefits reduce search effort, thereby increasing unemployment durations. Consistent with this prediction, many well-known studies have found that increases in UI benefits raise the duration of joblessness. This prediction does not distinguish between alternative models of household behavior, however, because higher benefits increase durations regardless of the degree of intertemporal consumption smoothing. To distinguish between the models of interest, we therefore turn to other comparative static implications of (4) that we can examine in our empirical setting.

Prediction 1: Severance Pay. The effect of an exogenous cash grant, such as a severance payment, on search effort is given by:

$$
\partial s_{t}^{*} / \partial A_{t}=\left\{u^{\prime}\left(c_{t}^{e}\right)-u^{\prime}\left(c_{t}^{u}\right)\right\} / \psi^{\prime \prime}\left(s_{t}^{*}\right) \leq 0
$$

Equation (6) shows that the effect of a cash grant on search intensity is determined by the gap in marginal utilities between employed and unemployed states, which is proportional to the size of consumption drop $c_{t}^{e}-c_{t}^{u}$. Intuitively, when consumption is smooth across states, a cash grant increases the value of being employed and unemployed by a similar amount, and thus does not affect search behavior much. In contrast, if consumption is substantially lower when unemployed, the cash grant raises the value of being unemployed relative to the value of being employed, leading to a reduction in search effort.

It is well known that if an agent has access to complete state-contingent insurance markets, and 
insurers can specify the agent's actions in each state, then $c_{t}^{u}=c_{t}^{e} \cdot{ }^{6}$ In such a setting $\partial s_{t}^{*} / \partial A_{t}=0$. Thus, testing whether lump-sum severance pay has an effect on unemployment durations constitutes a test of the full insurance model. More generally, if $c_{t}^{u}$ is close to $c_{t}^{e}$, as in a permanent income model with unrestricted borrowing, the asset effect is small. In contrast, if individuals face asset constraints or voluntarily reduce $c_{t}^{u}$ to maintain a buffer stock of savings, the asset effect will be relatively large. Thus, there is a direct connection between the responsiveness of search intensity to an increase in wealth and the amount of consumption smoothing implied by an intertemporal model.

An estimate of $\partial s_{t}^{*} / \partial A_{t}$ is also useful in assessing the degree of moral hazard caused by temporary income support programs, as shown by Chetty (2006b). To see this in our model, note that

$$
\partial s_{t}^{*} / \partial w=u^{\prime}\left(c_{t}^{e}\right) / \psi^{\prime \prime}\left(s_{t}^{*}\right)>0
$$

and hence

$$
\partial s_{t}^{*} / \partial b_{t}=\partial s_{t}^{*} / \partial A_{t}-\partial s_{t}^{*} / \partial w
$$

Equation (7) shows that the response of search intensity to an increase in unemployment benefits can be written as the sum of a pure wealth effect and a price (or substitution) effect The former has no direct efficiency costs, whereas the latter represents a "moral hazard" response to the price distortion induced by subsidizing unemployment. Many empirical studies of unemployment insurance ignore the asset effect by assuming that unemployment durations depend on the ratio of benefits to wages. These studies implicitly assume that the PIH with complete markets model applies. To the extent that job seekers have lower consumption when unemployed, however, one should expect benefits to have a larger impact (in absolute value) than wages. ${ }^{7}$

Prediction 2: Extended Benefits. Next, we examine how search intensity in period $t$ is affected by the level of future benefits, $b_{t+j}$. Using equations (2) and (3) we obtain:

$$
\partial s_{t}^{*} / \partial b_{t+j}=-p_{j, t}^{*} E_{t}\left[u^{\prime}\left(c_{t+j}^{u}\right)\right] /\left[(1+\delta)^{j} \psi^{\prime \prime}\left(s_{t}^{*}\right)\right] \leq 0
$$

where $p_{j, t}^{*}=\left(1-s_{t+1}^{*}\right)\left(1-s_{t+2}^{*}\right) \ldots\left(1-s_{t+j}^{*}\right)$ is the probability that an individual is still unemployed in

\footnotetext{
${ }^{6}$ The ability to specify the agent's actions in all states is important because a fully insured agent has no incentive to search.

${ }^{7}$ Interestingly, this pattern is present in the well-known study by Meyer (1990), whose estimates imply that the effect of UI benefits on the hazard rate of leaving unemployment is about 1.8 times larger than the effect of weekly earnings.
} 
period $t+j$ (conditional on being unemployed at $t$ ). This equation implies that a rise in the future benefit rate lowers search intensity in the current period, with a magnitude that varies inversely with the discount factor $(1+\delta)^{j}$. For a completely myopic agent, $\delta=\infty$, and hence equation (8) implies that $\partial s_{t}^{*} / \partial b_{t+j}=0$. Thus, testing whether increasing benefit levels in the future has an effect on the current search behavior constitutes a test of the "rule of thumb" (complete myopia) model.

Prediction 3: Future Job Quality. A final set of predictions that are useful in distinguishing between alternative models concern the effects of assets and unemployment benefits on the expected quality of the next job. The model presented here makes no predictions about job match quality because we have assumed that wages are fixed and agents only control search intensity. In a more general model with a non-degenerate distribution of wages or job qualities, however, an increase in assets or future benefits can potentially lead to a rise in the optimal reservation wage (Danforth 1979) and an increase in the average quality of the next job.

A Moment for Calibration. We now combine equations (6) and (8) to form a predicted moment that can be used to calibrate and test a broad set of intertemporal decision-making models. In particular, consider the ratio of the effects of assets and future unemployment benefits on search intensity at the beginning of a spell (period 0 ). To simplify notation, let $p_{j}^{*}=p_{j, 0}^{*}$ denote the probability that an individual is still unemployed $j$ periods after job loss. Since the present expected value of UI benefits $j$ periods in the future is proportional to the probability that an individual actually receives those benefits $\left(p_{j}^{*}\right)$, it is convenient to re-scale the effect of an increase in future benefits by this probability - that is, consider $\frac{1}{p_{j}^{*}} \partial s_{0}^{*} / \partial b_{j}$ instead of $\partial s_{0}^{*} / \partial b_{j}$. Define the moment

$$
m_{j} \equiv \frac{\partial s_{0}^{*} / \partial A_{0}}{\frac{1}{p_{j}^{*}} \partial s_{0}^{*} / \partial b_{j}}=D \times Z_{j} \times(1+\delta)^{j}
$$

where

$$
\begin{aligned}
D & =\frac{u^{\prime}\left(c_{0}^{u}\right)-u^{\prime}\left(c_{0}^{e}\right)}{u^{\prime}\left(c_{0}^{u}\right)} \\
Z_{j} & =\frac{u^{\prime}\left(c_{0}^{u}\right)}{E_{t}\left[u^{\prime}\left(c_{j}^{u}\right)\right]} .
\end{aligned}
$$

The moment $m_{j}$ can be easily simulated in models of household behavior because it requires knowledge only of the utility function $(u$ and $\delta)$, the initial consumption drop $\left(\frac{c_{0}^{u}-c_{0}^{e}}{c_{0}^{u}}\right)$ caused by unemployment, and the rate of decline in consumption over the spell $\left(\frac{c_{j}^{u}}{c_{0}^{u}}\right)$. If the path of 
consumption is flat during unemployment - as is approximately true for the $\mathrm{PIH}-$ then $Z_{j}=1$, and only the initial consumption drop has to be calculated. Importantly, the value of $m_{j}$ does not depend on the $\psi$ function. ${ }^{8}$ This feature of $m_{j}$ significantly expands the scope of models that can be calibrated using this moment, as we discuss below. The value of $m_{j}$ is also of direct interest because the ratio $D$ is a sufficient statistic for determining the marginal benefits of unemployment insurance in a wide class of dynamic models (Chetty 2006a).

Figure 1 shows predicted values of $m_{j}$ for a set of models that differ in assumptions about preferences and financial technologies. The models on the left side of the continuum assume a higher degree of intertemporal smoothing by households, and thus predict a lower sensitivity of search behavior to cash-on-hand. At the left extreme of the continuum is the full insurance model, where temporary income shocks have no effect on behavior (i.e., $m_{j}=0$ ). At the right extreme is a "complete myopia" model where households do not smooth intertemporally at all, and simply set current consumption equal to current income. In this model, severance pay affects search effort substantially but benefit extensions have no effect, implying $m_{j}=\infty$. The interior of the continuum includes models that have intermediate values of $m_{j} \in(0, \infty)$ : the PIH with unrestricted borrowing but no insurance, buffer stock models (Deaton 1991; Carroll 1997), and a credit-constraint model where agents are forward looking but face a binding asset constraint.

In section VIII, we calculate predicted values of $m_{2}$ shown in Figure 1 for the PIH and creditconstrained cases. We then compare these values with an empirical estimate of $m_{2}$, constructed from estimates of the effect of severance pay and extended benefits on job-finding hazards. This exercise can be loosely interpreted as a means of identifying the "location" of the representative household in the data on the continuum in Figure 1. More precisely, the moment $m_{j}$ defines a plane within the space of parameters defined by preferences and financial technologies (e.g. the asset limit, insurance market completeness, discount rate, risk aversion, prudence). Of course, a single moment is insufficient to pin down all of these parameters, but it does turn out to be sufficient to distinguish between certain benchmark cases.

Extensions. The formula for $m_{j}$ in (9) holds in a more general class of search models than the one we have presented. Consider for example a model with wage uncertainty, where agents choose a reservation wage in addition to search intensity and consumption. In such a model, the expression for the value function for an unemployed agent $U_{t}\left(A_{t}\right)$ will be more complex, and

\footnotetext{
${ }^{8}$ The function $\psi$ can be left unspecified because we have assumed separability between consumption and job search effort. Extending the analysis to models with non-separability is an interesting direction for further work.
} 
will depend on the reservation wage and the distribution of wage offers. However, the first order condition (4) for search intensity will continue to hold. The envelope conditions $\frac{\partial V_{t}\left(A_{t}\right)}{\partial A_{t}}=u^{\prime}\left(c_{t}^{e}\right)$ and $\frac{\partial U_{t}\left(A_{t}\right)}{\partial A_{t}}=u^{\prime}\left(c_{t}^{u}\right)$ also remain valid, since the reservation wage is chosen optimally. Thus, equation (9) holds in a model with endogenous reservation wages. ${ }^{9}$

Similarly, consider a model where jobs do not last indefinitely. This modification changes the functional form of $V_{t}\left(A_{t}\right)$, but the key first order condition (4) and envelope conditions still apply. Thus, equation (9) holds in this model as well. A third extension allows the productivity of job search to decrease as the spell elapses. At the start of a spell of unemployment, searchers can sample from the stock of existing vacancies; once they have exhausted their most promising leads, they are left with the flow of vacancies and thus search becomes less productive (as in McCall's (1990) sequential search model). This extension would have no effect on our predictions for the relative effects of assets and future benefits on search intensity at the beginning of the spell. ${ }^{10}$

The explanation for the generality of (9) is straightforward. Since a job searcher is optimally allocating consumption over time, marginal welfare changes from severance pay or extended benefits can always be evaluated by assuming that increases in assets or benefits are allocated to increased consumption in the period of receipt (i.e., by using the envelope conditions for the value functions associated with employment and unemployment). Since the ratio $m_{j}$ is fully determined by the marginal utilities of consumption in different states and periods, equation (9) does not depend on the specific structure of the model. Of course, the predicted values of $m_{j}$ will depend on the structure of the model: for example, the $m_{j}$ implied by a reservation-wage model may differ from a pure search intensity model because the implied values of $c_{0}^{e}$ and $c_{0}^{u}$ will generally differ in the two models. However, the predictions we test and the calibration methodology are robust to model specification.

\section{Institutional Background and Data}

The Austrian labor market is characterized by an unusual combination of institutional regulation and flexibility. Virtually all private sector jobs are covered by collective bargaining agreements,

\footnotetext{
${ }^{9} \mathrm{~A}$ caveat in calibrating the reservation wage model using (9) is that the observed effects of severance pay or UI benefits on the duration of joblessness include the combined effects on search intensity and the job acceptance rate.

${ }^{10}$ In the baseline model with constant productivity of search, job-finding rates rise over time because assets and consumption fall as the spell elapses (Lentz and Tranaes 2005). This counterfactual prediction can be resolved by allowing for decreasing productivity of search. Specifically, let $p_{t}(s)$ represent the probabability of finding a job in period $t$ with search effort $s$. Assuming that $p_{t}(s)$ is concave, the first order condition for optimal search effort becomes $\psi^{\prime}\left(s_{t}^{*}\right) / p_{t}\left(s_{t}^{*}\right)=V_{t}\left(A_{t}\right)-U_{t}\left(A_{t}\right)$. In this case, the observed job finding rate $p_{t}\left(s_{t}^{*}\right)$ can fall over time even though assets are falling as well.
} 
negotiated by unions and employer associations at the region and industry level (EIRO 2001). Firms with more than 5 employees are also required to consult with their works councils in the event of a layoff and to give at least 6 weeks notice of a pending layoff (Stiglbauer et al. 2003). Despite these features, rates of job turnover are relatively high and the unemployment rate is relatively low. Stiglbauer et al. (2003), for example, show that rates of "job creation" and "job destruction" for most sectors and the overall economy are comparable to those in the U.S. The average unemployment rate over the 1993-2004 period was among the lowest in Europe at 4.1\%.

A key aspect of the firing regulations in Austria is severance pay, which was introduced for white collar workers in 1921 and expanded to all other workers in 1979. Severance payments are made by firms according to a fixed rule legislated by the government. In particular, workers outside of the construction industry who are laid off after 3 years of service must be given a lump sum severance payment equal to 2 months of their previous salary. ${ }^{11}$ Payments are generally made within one month of the job termination, and are exempt from social security taxes.

Job losers with sufficient work history are also eligible for unemployment benefits. Specifically, individuals who have worked for 12 months or more in the two years preceding job loss are eligible for UI benefits that replace approximately $55 \%$ of their prior net wage, subject to a minimum and maximum (though only a small fraction of individuals are at maximum). Workers who are laid off by their employer are immediately eligible for benefits, while those who quit or are fired for cause have a four week waiting period. The maximum duration of regular unemployment benefits is a discontinuous function of the total number of months that the individual worked (at any firm) within the past five years. Individuals with less than 36 months of employment in the past 5 years receive 20 weeks of benefits, while those who have worked for 36 months or more receive 30 weeks of benefits (which we term "extended benefits"). ${ }^{12}$ Job losers who exhaust their regular unemployment benefits can move to a means-tested secondary benefit, known as "unemployment assistance," (UA) which pays a lower level of benefits indefinitely. UA benefits are reduced eurofor-euro by the amount of any other family income. As a result, the average UA replacement rate is $38 \%$ of the UI benefit level in the population (see the appendix for details of this calculation).

\footnotetext{
${ }^{11}$ The severance amount rises to 3 months of pay for workers with 5 years of service, 4 months after 10 years, and up to 12 months after 25 years of service. Employees who quit or are fired for cause are not eligible for severance pay. Workers in the construction industry are covered by a different law. The law governing severance pay was changed in January 2003 (outside our sample).

${ }^{12}$ Starting in 1989, job losers over the age of 40 who worked at least 312 weeks (6 years) in the past 10 years were eligible for 39 weeks of benefits. Additional benefits are available for people over 50, who are excluded from our analysis. Apart from the change in the benefits for those age 40-49, there were no other changes in the UI eligibility or benefit formulas over our sample period.
} 
The UI and UA systems are financed through payroll taxes, and are not experience-rated. Receipt of severance pay does not affect the unemployment benefit amount.

Our empirical analysis exploits the discontinuities in the severance pay and benefit duration laws to identify the causal effects of these two entitlements on search behavior. The effects of the two policies can be independently identified because they are discontinuous functions of different running variables: job tenure in the case of severance pay, and months worked in the past 5 years in the case of extended benefits. Nevertheless, there is a subset of individuals - those who did not work in the two years prior to their current job - for whom the severance pay and extended UI benefit discontinuities overlap. This creates a "double discontinuity" that complicates the empirical analysis relative to the standard regression discontinuity design proposed by Thistlewaite and Campbell (1960), where there is only one discontinuous policy change.

Figure 2a illustrates the double discontinuity issue by plotting the fraction of individuals in our data who receive an extended unemployment benefit (EB) as a function of months of job tenure. Individuals who have 36 or more months of job tenure necessarily have worked for more than 3 of the last 5 years; hence the fraction receiving EB is $100 \%$ on the right side of the severance pay discontinuity. Individuals who have 35 months of job tenure receive EB if they worked for one month or more at another firm within the past five years. Since only $80 \%$ of individuals laid off with 35 months of job tenure satisfy this condition, there is a 20 percentage point jump the fraction receiving EB at 36 months of job tenure. Consequently, any discontinuous change in behavior at 36 months of job tenure is mainly due to severance pay, but includes a small (20 percentage point) effect of extended benefits. A similar double discontinuity arises at the threshold for EB, as shown in Figure 2b. The fraction of individuals receiving severance pay jumps discontinuously by approximately $20 \%$ at 36 months worked. Hence changes in behavior around 36 months worked are likely to be caused primarily by EB, but could also be partly attributed to severance pay. We account for the double discontinuity in our empirical analysis using two independent methods described below.

\section{IV.A Data and Sample Definition}

We use data from the Austrian social security registry, which covers all workers except for the self-employed and civil servants. Approximately 85\% of the Austrian workforce is covered by the dataset. We consider all layoff events between 1981 and 2001. The dataset includes daily information on employment and registered unemployment status, total wages received from each 
employer in a calendar year, and information on workers' and firms' characteristics (e.g. age, education, gender, marital status, industry, and firm size). Further details on the database are given in the appendix.

The dataset does not have any information on actual severance payments or the amount of UI benefits paid. Hence, we cannot construct "first stage" estimates of the effect of the discontinuous policies on actual payments received. Compliance with the severance pay law is believed to be nearly universal, in part because of the monitoring effort of works councils and legal penalties for violations (CESifo 2004; Baker Tilly International, 2005). Given our data source, we also believe we have accurately captured the eligibility rules for extended benefits. Consequently, the eligibility rules for both severance pay and EB's create so-called "sharp" regression discontinuity designs, where the fraction eligible jumps from 0 to 1 at the discontinuity (Hahn, Todd, and van der Klaauw 2001).

We make four restrictions on the original dataset to arrive at our primary analysis sample. First, we include only non-construction workers between the ages of 20 and 50 at the time of the job termination, to avoid complications with the retirement system, special UI regulations for older workers (Winter-Ebmer 2003), and the differential treatment of construction workers. Second, we include only individuals who take up UI benefits within 28 days of job loss, thereby eliminating voluntary quitters (who are ineligible for severance pay and have a 28 day waiting period for UI eligibility). Third, we focus on individuals around the discontinuities of interest by only including individuals who worked at their previous firm for between 1 and 5 years, and who worked between 1 and 5 years of the past 5 years. Consequently, everyone in the sample is eligible for UI benefits (though not all are eligible for extended benefits), and everyone in the sample is eligible for either 2 months of severance pay or none. Finally, we drop individuals who were recalled to their prior firm in order to eliminate temporary layoffs who may not be searching for a job. These restrictions leave us with a sample of 650,922 unemployment spells.

Table 1 shows summary statistics for the full sample. Sixty percent of the sample has additional schooling beyond the compulsory level, mainly apprenticeship training. Only 44 percent of the sample are married, reflecting relatively the relatively young age of the sample and the prevalence of non-marital cohabitation in Austria. Owing to our sample requirement that people have worked between 1 and 5 years at their last job, average tenure is relatively short (26.5 months). However, most people have worked at other jobs in the past 5 years: the mean numbers of months worked is 41.2. Roughly one-fifth of the sample is eligible for severance pay, while $66 \%$ are eligible for 
extended UI benefits. The mean wage is 17,034 Euros per year in year 2000 Euros. $^{13}$ Wages are top-coded at the social security tax cap in the dataset. However, this cap binds for only a small fraction of individuals in our sample (less than $2 \%$ ).

There are two measures of unemployment durations that can be constructed in the data. The first is the total number of days that an individual is registered with the unemployment agency. Individuals are required to register while they are receiving benefits, and can remain registered even when their benefits are exhausted in order to take advantage of job training and job search assistance services offered by the agency. This measure corresponds to the official definition of "unemployment" in government statistics, and we therefore refer to it below simply as the individual's "unemployment duration." Spells of registered unemployment are relatively short: the median spell length is less than 3 months, $64 \%$ of spells end within 20 weeks, and $94 \%$ end within a year. Note that $0.5 \%$ of the unemployment durations are censored; the statistics in Table 1 do not adjust for censoring.

The second measure of the duration of job search, which we label "nonemployment duration," is the amount of time that elapses from the end of the previous job to the start of the next job. Although $92 \%$ of the sample is observed in a next job, some people lose a job and never return to the data set, leading to a tail of extremely long censored durations. ${ }^{14}$ As a result, the median nonemployment duration is 4.3 months while the mean is nearly 17 months (again, not adjusting for censoring). $51 \%$ of individuals find a new job within 20 weeks, and $77 \%$ find a new job within one year.

We use the nonemployment duration measure as our primary measure of duration of joblessness in our analysis for two reasons. First, the nonemployment measure captures actual transitions from a lost job to a new job, which corresponds most directly to the notion of "labor supply" in our job search model. Second, the unemployment measure can be mechanically affected by the program's parameters. For example, the extension of benefits from 20 weeks to 30 weeks can mechanically raise unemployment durations even if it has no impact on job finding rates. A drawback of the nonemployment duration measure is that it assumes that all nonemployed individuals are still searching for a job, whereas some may have exited the sample (to take a job outside the country, or in the government sector) or left the labor force temporarily (e.g. to receive training). ${ }^{15}$ To evaluate

\footnotetext{
${ }^{13}$ This is the gross wage: wages are subject to a payroll tax of approximately 30 percent.

${ }^{14}$ These individuals may take a job as a civil servant or become self-employed (occupations not covered by our dataset), leave the country (to work in Germany or Switzerland), or simply drop out of the labor force.

${ }^{15}$ Since we restrict our sample to those who take up UI, permanent labor force leavers should in principle be excluded. This facilitates the use of nonemployment duration as a measure of search duration.
} 
the robustness of our findings, we replicate our analysis using the unemployment duration measure, coding the duration as censored if there is a gap between the end of the registered unemployment spell and the start of the next job. As shown below, the two alternative measures of joblessness lead to very similar results, indicating that the findings are robust to the way in which the duration of "search" is measured.

The final row of the table summarizes the change in log (real) wage between the old and new jobs. The median wage growth rate is $-0.7 \%$, while the mean is $-3.4 \%$. However, there is substantial dispersion in the wage growth distribution (standard deviation $=51 \%$ ). ${ }^{16}$ This suggests that there is considerable scope for a given worker to earn higher or lower wages within the Austrian economy, a point relevant in evaluating the search outcome results in section VII.

\section{Estimation Strategy and Identification Assumptions}

Our identification strategy is to exploit the quasi-experiment created by the Austrian severance pay and extended benefit laws using a regression discontinuity $(\mathrm{RD})$ approach. We begin by describing the approach for identifying the causal effect of severance pay on durations, ignoring extended benefits. Consider the following model of the relationship between the duration of unemployment (y) and a dummy variable $S$ which is equal to 1 if he or she receives severance pay and 0 otherwise:

$$
y=\alpha+S \beta_{s p}+\varepsilon
$$

The parameter of interest is the coefficient $\beta_{s p}$, which measures the causal effect of severance pay on $y$. The problem for inference is that eligibility for severance pay is non-random. In particular, workers who are more likely to have a long enough job tenure $(J T)$ to be eligible for severance pay may have other unobserved characteristics that also affect their unemployment duration:

$$
E[\varepsilon \mid J T] \neq 0 .
$$

\footnotetext{
${ }^{16}$ The wage at a given employer is defined as total earnings from that employer over the calendar year divided by days worked at that employer during the calendar year, multiplied by 365 . The earnings growth measure thus adjusts for differences in days worked across jobs, but does not adjust for differences in hours worked per day. Therefore, part of the dispersion in earnings growth may be due to variation in hours worked per day.
} 
Since $S$ is a function of $J T$, this can lead to a bias in the direct estimation of $\beta_{s p}$ in equation (10) using OLS. This bias can be overcome if

$$
\lim _{\Delta \rightarrow 0^{+}} E[\varepsilon \mid J T=36+\Delta]=\lim _{\Delta \rightarrow 0^{+}} E[\varepsilon \mid J T=36-\Delta]
$$

i.e., if the distribution of unobserved characteristics of people with job tenure just slightly under 36 months is the same as the distribution among those with tenure just slightly over 36 months. In this case, the control function $f(J T)$ defined by

$$
E[\varepsilon \mid J T]=f(J T)
$$

is continuous at $J T=36$. Thus, one can augment equation (10) with the control function, leading to:

$$
y=\alpha+S \beta_{s p}+f(J T)+\nu
$$

where $\nu \equiv \varepsilon-E[\varepsilon \mid J T]$ is mean independent of $S$. Moreover, since $S$ is a discontinuous function of job tenure, whereas the control function is by assumption continuous at 36 months, the coefficient $\beta_{s p}$ is identified. Intuitively, any discontinuous relation between job tenure and duration at 36 months can be attributed to the causal impact of a severance payment under the identification assumption in (11).

In practice, the control function $f(J T)$ is unknown and has to be approximated by some smooth flexible function, such as a low-order polynomial (e.g., Angrist and Lavy 1999, Dinardo and Lee 2005). We follow this approach and use a third or fourth order polynomial, allowing the linear and higher order terms to be interacted with a dummy for tenure over 36 months.

Selection Around the Discontinuity. One may be concerned about the validity of the identification assumption in (11) because firms have an incentive to fire workers prior to the 36 month cutoff to avoid the costs of severance payments. Such selective firing could invalidate the RD research design by creating discontinuous differences in workers' characteristics to the left and right of the cutoff.

Although the continuity assumption cannot be fully tested, its validity can be evaluated by checking whether the frequency of layoffs and the means of observable characteristics trend smoothly with job tenure through the 36 month threshold (Lee 2006). As a first check, Figure 3 shows 
the number of job losers entering unemployment, by months of job tenure. ${ }^{17}$ There is no evidence of a spike in layoffs at 35 months, nor of a relative shortfall in the number of people who are laid off just after the threshold, suggesting that employers do not in fact selectively time their firing decisions to avoid the costs of severance pay. ${ }^{18}$ Given that such strategic behavior is illegal, and the fact that each layoff must be approved by the firm's works council, this is perhaps unsurprising. Moreover, firms that continually fire workers just before the eligibility threshold would presumably pay a price through reputation effects. Cases in which firms are perceived to have deliberately fired employees to avoid paying severance have led to lawsuits and coverage in the media.

Next, we check for potential differences in sample composition around the 36 month threshold by examining how observable characteristics vary with job tenure. Figure 4a plots average age in each tenure-month cell by job tenure, and shows that there is no evidence of selection on age. Figure $4 \mathrm{~b}$ conducts a similar analysis on the mean wages of those laid off at different tenures. In this case there is a small but statistically significant jump in mean wages at the discontinuity, indicating that higher-wage employees are relatively more likely to be laid off just after 36 months than just before. While this is potentially worrisome for our research design, it is important to distinguish between economic and statistical significance in a dataset of this size. The jump in the best-fit lines shown in Figure 4b is approximately 300 Euros/year, or about $1.6 \%$ of the mean wage for people with 35 months of tenure. ${ }^{19}$ This small discontinuity is only statistically detectable because of the sample size and the relatively precise wage measures available in our data. We find similar results - either statistically insignificant effects or small but significant discontinuities - for other observables such as education, industry, occupation, previous firm size, duration of last job, last nonemployment duration, and month/year of job loss.

The degree of potential bias from the small amount of selection on wages and other characteristics can be assessed by estimating the effect of these covariates on unemployment durations. Intuitively, unless the correlation between wages and unemployment durations is very large, a

\footnotetext{
${ }^{17}$ In this and all other figures, we define a "month" as a period of 31 days. We define the months starting from the discontinuity ( 3 years $=1096$ days), counting 31 day intervals on the left and the right. Because of this counting convention and our sample restriction of having between 1 and 5 years of job tenure and months worked, the month groups 12 and 59 contain less than 10 days. Therefore, we exclude these points from the figures and only plot values for months 13 to 58. In the regression analysis, all time variables are analyzed at a daily level, and the small number of observations that fall into months 12 and 59 are included as well.

${ }^{18}$ Some people who are laid off move directly to another job without an intervening spell of unemployment. We examined the frequency distribution of the total number of layoffs at each value of previous job tenure, and found no evidence of a spike at 36 months. We also examined the probability that a laid off person filed for UI (and thus appears in our data set). This probability also evolves smoothly through the 36 month threshold.

${ }^{19}$ Note that higher wage workers have shorter unemployment durations in our data. This small amount of selection should therefore, if anything, work against finding a positive effect of severance pay on durations.
} 
small discontinuity in wages (or any unobserved characteristic correlated with wages) cannot lead to much bias in the estimated effect of severance pay on search durations. To quantify the potential bias, we estimate the effect of wages and other covariates on re-employment hazards using a Cox proportional-hazards specification for nonemployment durations:

$$
h_{d}=\alpha_{d} \exp (X \phi)
$$

where $h_{d}$ denotes the re-employment hazard on day $d$ of the spell for a given individual, $\alpha_{d}$ is an unrestricted "day effect" (i.e., the "baseline" hazard), and $X$ denotes a rich set of observed characteristics, including demographics, previous work history and wages, and region and time effects. $^{20}$ We then predict the relative hazard for each observation $i, \widehat{r_{i}}=\exp (X \widehat{\phi})$, using the estimated $\widehat{\phi}$ vector. Finally, we compute the means of the predicted relative hazards by month of job tenure, $\mathrm{E}\left[\widehat{r}_{i} \mid J T\right]$ and plot this function, looking for any indication that the average predicted hazard is different for those laid off before or after the eligibility threshold.

Figure $4 \mathrm{c}$ shows the results of this exercise. The predicted relative hazards trend downward across the chart, indicating that individuals with higher job tenure have observable characteristics associated with longer durations. However, the predicted hazards are smooth through the 36 month threshold, showing that the small discontinuities in the observable covariates have little net impact on nonemployment durations. Importantly, the $X^{\prime} s$ included in the construction of Figure 4c include endogenous variables such as wages and the durations of prior spells of work and unemployment. These variables are likely to pick up any unobserved characteristics that are correlated with search behavior. Hence, if people laid off just before the 36 month threshold are systematically different on unobservables than those laid off just after 36 months, we would expect a jump in the hazard predicted by the endogenous observables. Since there is no such jump in Figure 4c, we conclude that individuals are "nearly randomized" around $J T=36$, implying that any discontinuity in search behavior at this point can be attributed to the causal effect of severance pay. $^{21}$

\footnotetext{
${ }^{20}$ The complete list of regressors is: age, age-squared, gender, education, marital status, Austrian nationality, "blue collar" status, log of the previous wage and its square, number of employees at the previous firm, years of work experience and its square, an indicator for having a job before the one just lost, the duration of the job before the one just lost, "blue collar" status at job prior to the one lost, a dummy for being recalled to the job before the one just lost, indicator for having a prior spell of nonemployment, the last nonemployment duration before the current spell, total number of spells of nonemployment (since the start of the data set), and dummies for industry, region of residence, month of job loss, and year of job loss.

${ }^{21}$ We further evaluate the identification assumption after our main analysis in section VI, by examining subsamples of the data and implementing a placebo test.
} 
Our identification strategy for estimating the effect of the UI benefit extension on durations is conceptually similar to the strategy for severance pay. Formally, we replace the indicator for severance pay $S$ in equation (12) with an indicator $E$ for extended benefit status, and replace job tenure with a measure of months worked $(M W)$ in the five years before the job termination. Again, the potential problem with a simple regression of unemployment duration on EB status is that people with a longer work history may be more (or less) likely to find a job quickly. As in equation (10), the key assumption that facilitates an $\mathrm{RD}$ approach is that the expected value of unobserved characteristics is the same for people with $M W$ just under 36 months and just over 36 months. We evaluate this assumption by plotting the frequency of layoffs, the average values of various observable covariates, and the predicted unemployment exit hazards against $M W$. In the interest of space, we do not report these results here. We find that there are no discontinuities in the relative number of layoffs, nor in the predicted relative hazard at $M W=36$. Moreover, in contrast to the situation in Figure $4 \mathrm{~b}$, there is no significant jump in mean wages or any other covariate around $M W=36$. Overall, we conclude that the patterns in the data are consistent with the assumption that EB status is "as good as randomly assigned" among people with values of $M W$ on either side of the 36 month threshold.

Identification with Double Discontinuity. As noted above, although severance pay and EB status depend on different running variables, there is a group of people in our sample - those with only one job in the past 5 years - who reach the 36 month eligibility thresholds for the two programs at the same point. There are two ways to handle the resulting "double discontinuity" problem. The first is to analyze a subsample in which the two discontinuities are not overlapping. To implement this approach, we consider a "restricted sample" of individuals who worked for one month or more within the past five years at a firm different from the one from which they were just laid off. Everyone in the restricted sample who has $J T \geq 35$ months has $M W \geq 36$ and thus qualifies for EB. Thus, only severance pay eligibility shifts at $J T=36$ in the restricted sample (the fraction eligible for EB remains constant at $100 \%$ around $J T=36$ ). Conversely, as months worked approaches 36 months, no one in the subsample has yet worked 36 months at the same employer. Thus, only EB status shifts at $M W=36$ in the restricted sample. The separation of the two discontinuities permits the use of conventional single-variable RD methods to identify the severance and EB effects in the restricted sample.

An alternative approach to separating the two effects, which can be applied in the full sample, is to explicitly model the joint effects of severance pay and extended benefits. Consider the extended 
model

$$
y=\alpha+S \beta_{s p}+E \beta_{e b}+\varepsilon
$$

where $S$ and $E$ are indicators for severance pay and EB eligibility, respectively. ${ }^{22}$ As in the single discontinuity case, the problem for inference is that the unobserved determinants of $y$ may be correlated with $J T$ and/or $M W$. Define the control function $g(J T, M W)$ as

$$
E[\varepsilon \mid J T, M W]=g(J T, M W) .
$$

The key assumption needed is that $g(J T, M W)$ is continuous at $J T=36$ for all values of $M W$, and continuous at $M W=36$ for all values of $J T$. Under this identifying assumption, we can augment equation (13) with the control function

$$
y=\alpha+S \beta_{s p}+E \beta_{e b}+g(J T, M W)+\nu
$$

where $\nu \equiv \varepsilon-E[\varepsilon \mid J T, M W]$ is mean independent of $E$ and $S$. Since $S$ and $E$ jump discontinuously at $J T=36$ and $M W=36$, respectively, and $J T$ and $M W$ are imperfectly correlated, the coefficients $\beta_{s p}$ and $\beta_{e b}$ are identified controlling for $g$. We implement this model by assuming as above that $g$ can be approximated by a low order polynomial of $J T$ and $M W$.

\section{Effects of Cash-on-Hand and Benefit Extensions on Durations}

This section presents results on the effect of severance pay and UI benefit extensions on durations. We begin with a graphical overview and then estimate a set of hazard models to obtain numerical measures of the elasticities of interest.

\section{VI.A Graphical Results}

Severance Pay. We begin our analysis in Figure 5a by plotting mean nonemployment durations vs. months of job tenure. For simplicity, in this figure we ignore censoring (effectively treating all measured durations as complete), and exclude all observations with a nonemployment duration of more than two years to eliminate the long right tail of the distribution. For visual reference, we superimpose a quadratic regression model fit separately to points on the right and left of the

\footnotetext{
${ }^{22}$ Note that (13) does not include an interaction effect between $S$ and $E B$. While in principle we would like to allow for an interaction between the two policies, in practice everyone with $S=1$ has $E B=1$. Hence the interaction cannot be identified.
} 
eligibility threshold. The figure shows a clearly discernible jump of about 10 days in the average nonemployment duration at the threshold.

We cannot attribute the entire gap in Figure 5a to the effects of severance pay because the fraction of individuals receiving EB also jumps at the cutoff. To isolate the pure effect of severance pay, we focus on the "restricted sample" - individuals who worked for at least one month at another firm within the past five years - where the two discontinuities are not overlapping. Figure 5b replicates Figure 5a for this sample. This figure shows a jump in the mean nonemployment duration of approximately 8 days at the 36 month cutoff, confirming that most of the 10 day gap in Figure $5 \mathrm{a}$ is indeed caused by the severance payment.

Given the censoring of nonemployment spells, a more precise way to measure the effect of severance pay on search behavior is to examine how the job finding (re-employment) hazard rate changes at the severance pay eligibility threshold. Figure 6 presents such an analysis. In constructing this figure, we include all nonemployment spells and adjust the hazards for censoring. We focus on the re-employment hazard in the first 20 weeks - the period of interest from the perspective of testing between models since it includes only the time before the benefit extension - by censoring all observations at 140 days. To obtain an estimate of the average re-employment hazard for people with different months of previous job tenure, we fit a Cox proportional-hazards model with dummies for each tenure group. We adjust for the double discontinuity problem by including cubic polynomials in months worked, a dummy for extended benefit eligibility, and their interaction:

$$
\begin{aligned}
h_{d}=\alpha_{d} \exp \{ & \theta_{13} I(J=13)+\ldots+\theta_{34} I(J=34)+\theta_{36} I(J=36)+\ldots+\theta_{58} I(J=58) \\
& +\beta \times E+\beta_{1} M W+\beta_{2} M W^{2}+\beta_{3} M W^{3} \\
& \left.+\beta_{1}^{E} E \times(M W-36)+\beta_{2}^{E} E \times(M W-36)^{2}+\beta_{3}^{E} E \times(M W-36)^{3}\right\} .
\end{aligned}
$$

The key coefficients of interest in this specification are the $\theta_{J} \mathrm{~s}$, which measure the percentage difference between average daily hazard for people with $J$ months of previous job tenure and those with 35 months of tenure (the omitted group). Figure 6 a plots the estimated $\theta_{J}$ s from equation (14). Consistent with the results in Figure 5, there is a discontinuous drop of approximately $10 \%$ in the average hazard rate at the severance pay discontinuity. Since the estimated relative hazards in this figure are adjusted for the EB effect, the entire jump in this figure can be attributed to the 
effect of severance pay in the full sample. ${ }^{23}$

One of the appealing features of a regression discontinuity approach is that estimates of the discontinuity should be invariant to the presence or absence of control variables (Lee and Card 2006). ${ }^{24}$ As in a classical experimental design, however, the addition of controls may lead to some gain in precision. Moreover, a comparison of the estimated discontinuities with and without controls provides an informal specification test that the underlying smoothness assumptions required for the $\mathrm{RD}$ design are valid. Figure $6 \mathrm{~b}$ replicates Figure 6a adjusting for observables, by adding the following covariates to (14): gender, "blue collar" status, marital status, Austrian nationality, age and its square, the previous log wage and its square, and dummies for month and year of job loss. As in Figure 6a, the job finding hazard shows about a 10\% drop at the 36 month threshold for receiving severance pay.

A potential concern in Figures $6 \mathrm{a}$ and $6 \mathrm{~b}$ is that there is some seasonality in the hazard rates associated with job tenure. Close examination of the graphs suggests that the hazard rates in the last few months of each tenure-year (e.g. months 21-23, 33-35, etc.) are approximately $2.5 \%$ higher than the hazards in the remainder of the tenure-year. One explanation for this pattern is that individuals who leave a firm shortly before completion of a full year of service are different from those who leave just after. Such differences may arise because planned terminations are more likely to take place after a full year of service is complete, or because of features such as employer-provided pensions that vest after integer numbers of years of service. Since the severance pay cutoff falls at an integer threshold (three years of tenure), one may be concerned that the seasonality in hazards biases the RD estimate of the severance pay effect. To gauge the size of the potential bias, we estimated a parametric RD model with an "end of tenure year" indicator which equals 1 in the three months before the end of each tenure year (21-23, 33-35, 45-47, and 57-59). We then adjusted the average hazards in Figure 6a for seasonality by subtracting the estimated end of tenure year effect from the hazard rates at the end of each tenure year. ${ }^{25}$ Figure $6 \mathrm{c}$ plots the resulting seasonality-adjusted hazards. This figure shows that the seasonality adjustment fully

\footnotetext{
${ }^{23}$ We have also implemented a more flexible model by including unrestricted baseline parameters for each tenure group (permitting $\alpha_{J d}$ to vary freely across tenure-month categories $J$ ), and then examining how the average estimated daily hazard $\alpha_{J d}$ varies with $J$. This approach yields very similar results to the more restrictive proportional-hazards approach of equation (14).

${ }^{24}$ Note that our presentation of the RD method excluded controls. One can think of the $\varepsilon$ term as including the effect of all the characteristics that vary across the sample, including potentially observable as well as unobserved characteristics.

${ }^{25}$ More precisely, we estimated specification 3 in Table 2, adding the "end of tenure year" indicator. We then subtracted the coefficient estimate on the indicator from the hazard rates shown in Figure 6a for the last three months of each tenure-year category (i.e., 21-23, 33-35, etc).
} 
eliminates the potentially worrisome patterns in Figures $6 \mathrm{a}$ and $6 \mathrm{~b}$. With this adjustment, the average hazard rate falls by approximately $8 \%$ at the severance pay cutoff, indicating that the results are only slightly affected by the seasonality pattern.

As noted above, the causal interpretation of our results relies on the identifying assumption that in the absence of severance pay there would be no systematic differences in nonemployment durations between individuals laid off on either side of the 36 month eligibility threshold. The rich panel structure of our dataset allows a simple "placebo" test of this assumption, using the $16 \%$ of our sample who we observe with more than one job termination. In particular, if people who are laid off after 35 months of tenure are systematically different than those laid off after 36 months, one would expect a discontinuous effect of job tenure at the job before the one just lost on the current duration of nonemployment. Figure 7 examines this relationship, and shows that current nonemployment durations evolve smoothly through the 36 month cutoff for lagged job tenure, supporting our identification assumption. Any omitted-variables explanation of our findings would therefore require that people's unobserved characteristics change over time such that a discontinuity in nonemployment durations at 36 months emerges only in the current job.

Thus far we have summarized the effect of severance pay on search behavior in a single statistic, either mean durations or the average job finding hazard over the first twenty weeks of the spell. We now explore how severance pay affects search behavior as the spell elapses. Figure 8a plots average weekly job finding hazards for individuals laid off in tenure-months 33-35 (no severance) and those laid off in months 36-38 (who receive severance). This figure is drawn using the restricted sample; hence, the differences between the job finding hazards in this figure can be attributed entirely to severance pay (and not EB). The figure shows that severance pay lowers job finding hazards throughout the spell. The gap between the hazard rates in the two groups expands after week 5 of the spell, and gradually narrows starting around week 25 . This pattern is consistent with a model where agents become increasingly sensitive to cash-on-hand as the spell elapses, but eventually deplete the initial cash grant.

We interpret Figures 5-8 as showing that a shock to cash-on-hand has substantial effects on labor market behavior, rejecting the full insurance model (PIH with complete markets).

Extended Benefits. We now replicate the preceding analysis for the extended benefit policy. Figure 9a plots the relationship between average nonemployment durations and months worked $(M W)$ in the past five years in the full sample. As in Figure 5a, this figure ignores censoring and excludes observations with a nonemployment duration of more than 2 years. Figure 9 a shows 
that there is a clearly discernible jump in the average duration of joblessness of approximately 7 days around the EB discontinuity. Figure $9 \mathrm{~b}$ replicates Figure 9a in the restricted sample, where the entire discontinuity at $M W=36$ can be attributed to EB. This figure confirms that the discontinuity in EB eligibility is in fact responsible for the most of the jump in nonemployment durations in Figure 9a.

In Figure 9c, we examine how the average hazard rates over the first twenty weeks of the spell vary around the EB discontinuity. We estimate a proportional hazard model analogous to that in (14) on the full sample, with dummies for months of work in the previous 5 years instead of job tenure. To eliminate the problem of a double discontinuity, we include a cubic polynomial in job tenure and a dummy for severance pay eligibility (plus their interactions). Consistent with the results in Figures 9a-b, this figure shows that there is a discontinuous drop of approximately $7 \%$ in the average hazard rate at the EB discontinuity.

In Figure 8b, we examine how extending UI benefits affects search behavior as the spell elapses, comparing the weekly job finding hazards for individuals in the three months to the left and right of the $M W=36$ discontinuity in the restricted sample. This figure shows that the benefit extension has a large effect on behavior after week 20, when the additional income is received. However, people eligible for extended benefits also have substantially lower job finding hazards than those ineligible for EB prior to week 20, i.e. before they actually receive any additional income. This result provides clear evidence that at least some individuals are forward-looking, and take into account their future expected income stream when choosing search behavior in the early weeks of the spell. ${ }^{26}$ This finding rejects a model of completely myopic behavior.

\section{VI.B Hazard Model Estimates}

To quantify the effects of severance pay and extended benefits on the duration of job search more precisely, we estimate a series of proportional hazards models for the risk of finding a new job. These models include unrestricted daily baseline hazards, a set of covariates $(X)$, indicators for eligibility for severance pay and extended benefits ( $S$ and $E$, respectively), and third-order polynomials in job tenure $(J T)$ and months of work in the previous 5 years $(M W)$ that allow the derivative of the control function to change discontinuously at the eligibility cutoffs:

\footnotetext{
${ }^{26}$ This behavioral response is consistent with but conceptually distinct from the well-known finding of Katz and Meyer (1990). Katz and Meyer show that unemployment exit hazards rise in the weeks immediately before the date of benefit exhaustion. We show that the benefit exhaustion date affects search behavior early in the spell as well by comparing job finding hazards under two different potential duration policies.
} 


$$
\begin{aligned}
h_{d}=\alpha_{d} \exp \{ & \beta_{s p} S+\beta_{e b} E+\phi X \\
& +\mu_{1} J T+\mu_{2} J T+\mu_{3} J T^{3} \\
& +\mu_{1}^{S} S \times(J T-36)+\mu_{2}^{S} S \times(J T-36)^{2}+\mu_{3}^{S} S \times(J T-36)^{3} \\
& +\beta_{1} M W+\beta_{2} M W^{2}+\beta_{3} M W^{3} \\
& \left.+\beta_{1}^{E} E \times(M W-36)+\beta_{2}^{E} E \times(M W-36)^{2}+\beta_{3}^{E} E \times(M W-36)^{3}\right\} .
\end{aligned}
$$

In all cases, we censor the spells at 140 days in order to isolate the effects of the policy variables in the first 20 weeks of job search, prior to the point at which extended benefits become available. Thus, the estimated effect of extended benefits can be interpreted as the effect of future benefits on current search activity.

Table 2 presents estimates of $\beta_{s p}$ and $\beta_{e b}$ from a set of alternative samples and specifications. In column 1, we estimate the effect of severance pay on the job finding hazard in the restricted sample. Since the severance and EB discontinuities do not overlap in the restricted sample, this specification includes the cubic control function for $J T$ only (i.e., the $\beta_{e b}$ and $\beta_{j}$ coefficients in (15) are restricted to equal 0). Receipt of severance pay is estimated to reduce the job-finding hazard by $12.7 \%$ on average in the first twenty weeks of the spell. In column 2 , we implement an analogous specification to estimate the effect of extended benefits, including the cubic control function for $M W$ instead of $J T$ along with the $E$ indicator variable instead of $S$. Eligibility for extended benefits is estimated to reduce the job-finding hazard by $8.4 \%$.

In column 3, we estimate the severance pay and EB effects jointly in the full sample using the "double RD" control function in (15). These estimates corroborate that the results in the full sample are similar to those in the restricted sample, namely that eligibility for severance pay reduces job finding hazards somewhat more than eligibility for EB. Both coefficient estimates are highly statistically significant, with a t-statistic of 7.4 for severance pay and 5.8 for EB.

Column 4 reports estimates of the double RD model controlling for the following observables: the worker's gender, marital status, Austrian nationality, "blue collar" occupation indicator, age and its square, log of the previous wage and its square, as well as dummies for the month and year of the job termination. The EB point estimate falls slightly to $-6.4 \%$ when these controls are included, while the severance pay effect remains roughly constant at $-11.5 \%$. Both estimates remain highly statistically significant, indicating the results are robust to these changes in the covariate set. 
Robustness Checks. In Table 3, we investigate the robustness of these baseline results by extending the final specification from Table 2 (the double RD specification with controls) in various ways. In the model in column 1 of Table 3a, we add an indicator for months at the end of the tenure year (i.e., months 21-23, 33-35,...) to adjust for seasonal patterns associated with integer years of tenure. In specification 2, we take an alternative approach to dealing with the tenure seasonality problem by excluding all observations in the last three months of each tenure year. Both of these approaches to adjusting for seasonality yield similar results, confirming that the estimated severance pay and EB effects are not spuriously generated by seasonal patterns.

In specification 3, we expand the set of covariates to include the "saturated" control set used to estimate the predicted hazards in Figure 4c. Many of these covariates - such as the duration of the previous job and the duration of the previous spell of nonemployment - are correlated with the unobserved skills and tastes of job seekers, and could not be included in a conventional causal model for the effects of severance pay and extended benefits. In a regression discontinuity design, however, adding such "endogenous" control variables does not affect the consistency of the RD estimates. As would be expected given the results in Figure 4c, inclusion of this rich set of endogenous covariates has little effect on the estimated discontinuities, helping to mitigate any concern that our results are driven by selection around the discontinuity.

In column 4 of Table 3a we examine the robustness of our results to way in which search duration is measured. Specifically, we measure duration as the time registered as unemployed rather than the time to the next job. We code observations where the end of registered unemployment does not coincide with the start of a new job as censored, and replicate the baseline model (specification 4 of Table 2) with this alternative duration measure. The estimates show that our results are robust to the way in which durations are measured.

In the next group of specifications, we assess the importance of selection around the severance pay discontinuity by restricting the analysis to subgroups for which selective firing is less likely to occur. In each case, we replicate the baseline specification 4 of Table 2 . In the model reported in column 1 of Table 3b, we restrict the sample to individuals laid off by small firms - those with less than 100 employees. Since workers in smaller firms typically perform more specialized job functions and have fewer close substitutes, we conjecture that these firms will find it harder to lay off one worker instead of another simply to save a severance payment. Hence, there should be less scope for selective firing in small firms. Consistent with this intuition, we find no evidence of a discontinuity in wages in this subsample of small firms (unlike the situation for the full sample 
shown in Figure 4b). The estimates in column 1 of Table $3 \mathrm{~b}$ show that severance pay and EB effects remain similar in the small firm subsample, suggesting that our main results are not driven by selection effects.

In the models in columns 2-4 of Table $3 \mathrm{~b}$, we take a different approach to identifying subsamples with less selection. An ideal method of constructing a sample purged of selection around the discontinuity would be to focus on firm or plant closures, where firms cannot selectively choose which workers to fire. Unfortunately, most firms in Austria are so small that even though we have the full universe of layoffs over two decades, the sample of individuals laid off in mass events around the discontinuities of interest is small. Given this constraint, we implement a second-best strategy of focusing on cases where multiple individuals were laid off together from the same company in the same month. Such layoffs are more likely to be caused by an "exogenous" shock such as financial distress, and thus less likely to involve selective firing. In column 2 we estimate the baseline model (specification 4 of Table 2) on the subsample of workers who were laid off along with one or more workers from their firm in the same month. In column 3 we restrict the sample to layoffs involving four or more individuals, while in column 4 we restrict the sample to layoffs involving 5 or more individuals. The point estimates of the severance pay and EB coefficients remain quite stable as we restrict the sample to larger layoff events, though the standard errors rise substantially, reflecting the loss of sample size as we focus on bigger layoff events. ${ }^{27}$ We view these results as providing further support for the causal interpretation of our estimates.

Placebo Tests. The last three columns of Table 3b report estimates of the "placebo test" corresponding to Figure 7 by examining how tenure at the previous job and months worked prior to the relevant period for EB eligibility affect job finding hazards. To implement these placebo tests, we focus on the subsample of individuals who have two or more unemployment spells in the data. Let "job 1" denote the job prior to the one most recently lost, and "job 2" denote the job most recently lost. We obtain a sample consistent with the one we use for our main analysis by restricting attention to individuals who (a) had job tenure of between 1 and 5 years at both jobs and (b) worked for between 1 and 5 years of the five years preceding each of the job losses. We then estimate the effect of the severance pay and EB "placebos" - indicators for having more than 36 months of job tenure on job 1, and more than 36 months of work in the 5 years before the end of job 1, respectively. Columns 5 and 6 report estimates for models analogous to the specifications in

\footnotetext{
${ }^{27}$ The sample of layoffs involving 5 or more individuals from the same company includes only 35,579 observations ( $5.5 \%$ of our full sample), showing why closures or "mass layoffs" alone constitute too small a sample for the analysis.
} 
columns 3 and 4 of Table 2 (i.e., with and without controls) using the placebo variables and control functions based on job 1. Note that the placebo variables do not predict receipt of severance pay or EB in the current spell conditional on the control functions because eligibility for these policies is a smooth function of the job tenure and months worked variables for job 1. Both sets of estimates confirm that there is no placebo effect, consistent with Figure 7.

Finally, the model in column 7 of Table $3 \mathrm{~b}$ includes the true severance pay and EB eligibility indicators along with the placebo indicators and cubic polynomials for all four running variables. The true severance pay and EB variables are still estimated to reduce job finding hazards substantially (though the standard errors rise because the sample is one-fifth the original size), while the placebo effects are statistically indistinguishable from zero. The hypothesis that the placebo and true severance pay effects are equal is rejected with $p<0.01$.

We have fit a wide variety of other specifications to further probe the robustness of the results in Tables 2, 3a, and 3b. The estimated severance pay and EB effects are always on the order of -6 to -12 percent, with a ratio of $\beta_{s p} / \beta_{e b}$ between 1.2 and 1.8 in most cases. For example, replacing the third-order polynomials with fourth-order polynomials leads to estimated severance pay and EB effects that are a little bigger in magnitude than those reported in Table 2. Trimming very high or very low wage workers, dropping those recalled to the job prior to the one just lost, and estimating the effects of the two policies on average hazards over a shorter period (e.g. the first 10 weeks) or a longer period (e.g. the first six months or year of the spell) also yield similar results.

Heterogeneity Analysis. Starting with Zeldes (1989), several studies have tested whether liquidity constraints affect consumption by comparing the effects of cash-on-hand in liquidity constrained vs. unconstrained groups. One could in principle implement similar tests using data from the labor market. Unfortunately, we cannot cut our sample by measures of liquidity because the Austrian Social Security database does not have information on the assets or family circumstances of job losers. Cutting the data on variables that are likely to be correlated with liquidity - such as age or wage - is also problematic because our treatment effects are likely to vary across these groups for other reasons. For example, higher wage or older workers may have more assets on average, but also receive larger severance pay amounts on average and are less likely to receive unemployment assistance. Thus, we cannot make sharp predictions about heterogeneity across demographic groups. In practice, we find no systematic differences in the estimated effects of severance pay and EB across demographic groups (gender, age, wage, blue collar status, education, and region). ${ }^{28}$

\footnotetext{
${ }^{28}$ Another potentially interesting comparison, given the unusual length of our sample period, is between job losers
} 
While we cannot obtain clear evidence on heterogeneity in the Austrian data, such evidence is available in U.S. data. Chetty (2006b) studies the heterogeneity in the effect of UI benefits on unemployment durations. He finds that the effect of UI benefits on durations is largest among groups that are likely to have limited ability to smooth consumption - e.g. those with low assets prior to job loss or a single earner in the household. This finding is consistent with models such as buffer-stock behavior, which also match the results we obtain here.

\section{Search Outcomes}

Having found that severance pay and extended benefits increase the duration of job search, it is interesting to ask whether there are any differences in the nature of the jobs obtained through a longer search process. In addition to providing further evidence on search models, this analysis is useful in assessing whether improvements in future job outcomes provide a rationale for temporary income support programs. As above, we begin with a graphical overview of the main findings and then present regression estimates.

\section{VII.A Graphical Results}

The first measure of job quality we examine is the wage on the next job. Define $g_{i}=\log \left(w_{i}^{n}\right)-$ $\log \left(w_{i}^{p}\right)$ where $w_{i}^{n}$ is individual $i^{\prime}$ s wage in the first year at the next job and $w_{i}^{p}$ is his wage in the final year at the previous job. Note that $g_{i}$ is missing for $15 \%$ of the sample, most of which is accounted for by individuals who do not find a new job before the end of the sampling period. Figure 10a plots the average value of $g_{i}$ in each tenure-month cell. The smoothness of wage growth rates through the 36 month discontinuity indicates that the increased duration of search induced by severance payments does not yield any improvements in ex-post wages.

Even if there are no benefits in terms of wages, individuals could potentially find jobs with higher quality in other dimensions. One convenient summary statistic for the match quality of subsequent jobs is their duration: better matches should presumably last longer (see e.g., Jovanovic 1979). We examine the effect of severance pay on the duration of the next job in Figure 10b. This figure plots the average monthly hazard of leaving the next job (over the first 5 years on that job) by tenure at the job that just ended. We construct this figure by fitting a Cox model for the duration

in the 1980s and 1990s. Despite some changes in the macroeconomic environment and in various policies (e.g., the growing availability of training programs for job seekers), the estimated effects of the severance pay and EB programs are similar in the two decades. 
of the next job, with dummies for the tenure-month categories (omitting month 35), as in Figure 6a. We then plot the coefficients on the tenure-month categories, which can be interpreted as the percentage difference in the average job-leaving hazard in a given tenure-month group relative to tenure-month 35. The job-leaving hazards are smooth through the discontinuity, indicating that severance pay eligibility has no effect on the duration of the subsequent job.

We replicate the same analysis for extended benefits in Figure 11 by changing the running variable on the $\mathrm{x}$-axis to months worked in the past five years. Again, we find that both wages and subsequent job-leaving hazards are smooth through the EB discontinuity. Hence, extending unemployment durations by increasing the maximum potential duration of UI benefits does not appear to yield any match quality gains as measured by wages or subsequent job duration. We have also constructed similar graphs for other measures of job match quality, which we discuss below in the context of regression estimates.

\section{VII.B Regression Estimates}

To formally identify the match quality impacts of severance pay and extended benefits, we estimate double RD specifications analogous to (15), changing the dependent variable to a measure of job quality. The results of this analysis are reported in Tables $4 \mathrm{a}$ and $4 \mathrm{~b}$.

Specification 1 of Table 4a examines the effect of severance pay and EB on wage growth $\left(g_{i}\right)$ using an OLS regression without any controls. Specification 2 adds the "saturated" control set used in specification 3 of Table $3 \mathrm{a}$ to this regression. Specification 3 reports coefficient estimates from a hazard model for the duration of the new job without controls, censoring next job durations at five years to examine how the policies affect average job-leaving hazards in the first five years. Finally, specification 4 replicates specification 3 with the saturated control set. The regression estimates

in Table 4a are consistent with the figures: there is no evidence of match quality gains in any of the specifications. For example, in the specifications with controls, severance pay is estimated to change wage growth by a statistically insignificant $-0.2 \%$ and change the hazard rate of leaving the next job by $0.0 \%$.

An important distinction between the present analysis and some earlier studies that have failed to detect evidence of quality gains is the relative precision of our estimates. The standard errors in specifications 1 and 2 of Table 4a show that even a 1\% improvement in wages caused by either severance pay or EB would be detectable in our analysis. Hence, our evidence suggests that the job quality gains from extending unemployment durations are not merely statistically insignificant, 
but quite small in magnitude. ${ }^{29}$

In Table 4b, we consider some additional measures of match quality. All of the specifications in this table are OLS regressions using the double RD specification with the saturated control set. The model in column 1 considers the possibility that severance pay or EB's have an effect on job quality that is only realized with a lag. The dependent variable in this model is the growth in wages from the previous job to the second calendar year of the next job (including only individuals who stayed at their next job for more than one year). The model in column 2 considers the change in the size of the firm at which the individual is employed (measured as the change in $\log$ number of employees). The idea underlying this specification is that larger firms may offer better jobs to workers on certain dimensions such as stability (Oi and Idson 1999); thus, one way a worker can obtain a better match through more search is by finding a job at a larger firm. Finally, the models in columns 3 and 4 examine the effects of severance pay and extended benefits on two measures of sectoral mobility: the probability of switching industries (column 3) and the probability of taking a job in a different geographical area (column 4). We code industries into six categories (agriculture/mining, manufacturing, sales, hotel, transport, and service). The mean rate of industry switching in the sample is $57 \%$. We define geographical areas using the 108 districts in Austria. The mean probability of switching to a firm in a different district is $47 \%$.

There is no evidence of economically significant gains in any of the four additional measures of job match quality in Table $4 \mathrm{~b}$. We also checked for match quality effects using analogous regression models and graphical methods for several other measures (not reported): the probability of switching from a "blue collar" to a "white collar" occupation, the mean growth in wages and total earned wage income (at any employer) in each of the five years following the unemployment spell, and the total number of days employed (at any firm) in each of the five years following the unemployment spell. In addition, we examined percentiles of the wage distribution to check if there are gains in the tails of the distribution. None of these outcomes shows evidence of discontinuities at the eligibility thresholds for extended benefits or severance pay. We also split the data into subgroups (e.g. by age, gender, wage, education) and found no evidence of match effects in any of the subgroups.

In view of these results, we conclude that the extension of search duration through increases in cash-on-hand or provision of extended UI benefits has little or no effect on subsequent job quality

\footnotetext{
${ }^{29}$ Shimer and Werning (2005) simulate a reservation wage model with a standard deviation of wage opportunities of approximately $1 \%$. We cannot detect the match quality effects generated by such a model.
} 
in the short and intermediate run (up to 5 years). There are several potential explanations for the absence of match quality effects. One possibility is that there is limited variation in the quality of jobs available to a given worker because of the high rate of union coverage in Austria. As noted in section IV, however, the variation in wage changes experienced by job losers is fairly large $(\sigma(\Delta \log w)=0.51)$, suggesting that there is significant ex-ante uncertainty about job qualities. A second explanation is that because employed workers can continue to search, people do not raise their reservation job qualities significantly in response to the availability of severance pay or extended benefits. Indeed, if search is equally productive on and off the job, the reservation wage only depends on current UI benefits (Lise 2006), and we would expect no effect of severance or EB on the quality of the next job. A third explanation is that the arrival rate of job offers is relatively low, so the option value of waiting for a better offer is small and most workers take the first offer they receive. Unfortunately, given the available evidence, we cannot distinguish between these alternative explanations.

\section{Calibration Results for Competing Models of Behavior}

In this section, we use the theoretical framework developed in Section III to interpret the implications of our empirical findings for models of intertemporal behavior. In relating our empirical estimates to the search model, we define each "period" as an interval of 10 weeks. Under this timing convention, the benefit extension from 20 to 30 weeks raises the value of UI benefits 2 periods after the period of job loss. Ignoring discounting over only 20 weeks, the key equation (9) predicting the relative effects of severance pay and increased future UI benefits on search intensity in period 0 states that:

$$
m_{2} \equiv \frac{\partial s_{0}^{*} / \partial A_{0}}{\frac{1}{p_{2}^{*}} \partial s_{0}^{*} / \partial b_{2}}=D \times Z_{2}
$$

where

$$
\begin{aligned}
D & =\frac{u^{\prime}\left(c_{0}^{u}\right)-u^{\prime}\left(c_{0}^{e}\right)}{u^{\prime}\left(c_{0}^{u}\right)} \\
Z_{2} & =\frac{u^{\prime}\left(c_{0}^{u}\right)}{E_{0}\left[u^{\prime}\left(c_{2}^{u}\right)\right]} .
\end{aligned}
$$

We first calculate the empirical value of $m_{2}$ defined in equation (9) using the hazard model estimates. We then illustrate how this sample moment can be used to test and calibrate models 
by simulating $m_{2}$ for two benchmark cases: a simple PIH model and a credit-constrained case.

Empirical Estimate of Sample Moment. The hazard model estimates give the effects of eligibility for 2 months of severance pay or 10 weeks of additional UI benefits on the re-employment hazard rate. To calculate the value of $m_{2}$ implied by these estimates, we first re-scale the coefficients into the effects of a $\$ 1$ increase in cash-on-hand and a $\$ 1$ increase in $b_{2}$. Since we use a proportional hazards specification, and $s_{0}^{*}$ represents the probability of finding a job in the first 10 weeks of search, the estimated effect of eligibility for severance pay on the hazard rate is $\beta_{s p} \approx \partial \log s_{0}^{*} / \partial A_{0} \times v_{s p}$, where $v_{s p}$ denotes the total cash value of the severance payment. ${ }^{30}$ Likewise, $\beta_{e b} \approx \partial \log s_{0}^{*} / \partial b_{2} \times v_{e b}$, where $v_{e b}$ represents the cash value of extended benefits. Hence

$$
m_{2}=\frac{\partial s_{0}^{*} / \partial A_{0}}{\frac{1}{p_{2}^{*}} \partial s_{0}^{*} / \partial b_{2}}=\frac{\partial \log s_{0}^{*} / \partial A_{0}}{\frac{1}{p_{2}^{*}} \partial \log s_{0}^{*} / \partial b_{2}}=\frac{\beta_{s p}}{\beta_{e b}} \times \frac{v_{e b}}{v_{s p}} \times p_{2}^{*} .
$$

In the appendix, we show that $v_{s p} \approx 2.69 w$, where $w$ is the net (after-tax) monthly wage, because of the favorable tax treatment of severance pay. We also show that $v_{e b} \approx 0.85 w$, because of the availability of UA after exhaustion of regular UI benefits. Therefore, we estimate that $v_{e b} / v_{s p} \approx$ 0.32 on average.

Next, we calculate $p_{2}^{*}$, the probability that extended benefits are actually received. $50 \%$ of the job losers in our sample remain out of work after 20 weeks. However, $15 \%$ of job losers are still not observed with a job even 2 years later. Since our dataset covers roughly $85 \%$ of employment in Austria, we believe that most of this group represents people who have found a job outside the sectors covered in the data (self-employment or as a civil servant). Assuming that the individuals who are not observed in a job within two years have the same job finding rates on average as other job seekers, but are simply not observed returning to work, the actual probability of remaining out of work for 20 weeks or more is $41 \%$. We therefore set $p_{2}^{*}=0.41$.

Combining all these elements, it follows that $m_{2}=0.13 \beta_{s p} / \beta_{e b}$. Using the estimates of $\beta_{s p}$ and $\beta_{e b}$ reported in column 3 of Table 2 (the baseline no-controls specification), we obtain a point estimate of $m_{2}=0.174$ with a standard error (constructed by the delta method) of 0.041 . Using the estimates from column 3 of Table $3 a$ (which includes our richest set of controls) yields $m_{2}=0.19$ with a standard error of 0.071 . These estimates of $m_{2}$ are broadly representative of the 11 alternatives reported in Tables 2 and 3, which have a mean ratio of $m_{2}=0.19$.

\footnotetext{
${ }^{30}$ Our models actually measure the effect of severance pay and EB's on hazard rates on the first 20 weeks of joblessness. Models based on only the first 10 weeks, however, give very similar results. To maximize precision we use the estimates that average over the longer period.
} 
Predicted Moment for Credit-Constraint Model. Consider a model where individuals are forward looking but cannot borrow and set consumption equal to income in each period. We now calculate the value of $m_{2}$ predicted by this "fully credit constrained" model.

Let $\rho_{t}=\frac{b_{t}}{w}$ denote the benefit-replacement rate in period $t$ of the unemployment spell. Let $F$ represent other family income, which we shall assume is exogenously fixed, and let $\sigma=w /(w+F)$ denote the share of the job-seeker's earnings in total family income. As discussed in the appendix, we estimate from available survey data that a typical Austrian wage earner in our age range contributes about $1 / 2$ of his or her family income $(\sigma=0.50)$.

In the credit-constrained case, $c_{0}^{e}=w+F$, and $c_{0}^{u}=\rho_{0} w+F$. Assuming that $u(c)$ is in the constant relative risk aversion class,

$$
\begin{aligned}
D & =\frac{u \prime\left(\rho_{0} w+F\right)-u \prime(w+F)}{u \prime\left(\rho_{0} w+F\right)} \\
& =\frac{u \prime\left(\left(\sigma \rho_{0}+(1-\sigma)\right)-u \prime(1)\right.}{u \prime\left(\left(\sigma \rho_{0}+(1-\sigma)\right)\right.}
\end{aligned}
$$

Setting $\rho_{0}=0.55$, the implied value of $D$ represents the percentage change in the marginal utility of consumption associated with a $22.5 \%$ reduction in consumption. For example, if the coefficient of relative risk aversion $(\gamma)$ is $2, D=0.4$.

To complete the calibration of $m_{2}$, note that $c_{2}^{u}=\rho_{2} w+F$, where $\rho_{2}$ represents the replacement rate for income support in the absence of extended benefits, which we estimate to be approximately 0.21. Thus

$$
\begin{aligned}
Z_{2} & =\frac{u^{\prime}\left(\rho_{0} w+F\right)}{u^{\prime}\left(\rho_{2} w+F\right)} \\
& \approx\left[\frac{1.55}{1.21}\right]^{-\gamma}
\end{aligned}
$$

assuming that $u$ is in the CRRA class with elasticity $\gamma$. For example, with $\gamma=2, Z_{2}=0.61$. Using (16), it follows that $m_{2}=0.4 \times 0.61=0.24$ if $\gamma=2$. Predicted values of $m_{2}$ for other values of $\gamma$ are presented in the Panel A of Table 5 .

Predicted Moment for PIH Model. Now consider a model where individuals have unrestricted access to credit at a fixed interest rate - the permanent income hypothesis (PIH) benchmark. The calculation of $m_{2}$ in this case is more complicated, and in general requires an iterative solution procedure with a complete specification of $\psi$ and other parameters of the model. We instead derive an upper bound for $m_{2}$ under three simplifying assumptions. First, we assume that the 
rate of time discount equals the interest rate. This implies that once employed, people choose a constant consumption profile. Second, we assume that people have a relatively long work life, so that the annuity income from an asset amount $A$ is approximately $r /(1+r) A{ }^{31}$ Together with our assumption that jobs persist indefinitely, these assumptions imply $c_{t}^{e}=w+F+r /(1+r) A_{t}$.

Our third assumption is that individuals can find a job with certainty within $T$ periods. As noted above, $85 \%$ of the job losers in our sample are observed in a new job within 2 years, and the remaining $15 \%$ are likely to have taken jobs outside the sectors covered by our data. Therefore, we set $T=100$ weeks (i.e., 10 periods of 10 weeks). ${ }^{32}$

To derive an upper bound for $m_{2}$, observe that consumption falls over the spell in the PIH model: $c_{2}^{u} \leqslant c_{0}^{u}$. Thus $m_{2} \leqslant D$. We derive an upper bound on $D$ in a series of steps. The first step is to calculate a lower bound on the optimal path of $c_{t}^{e}$. Since consumption is always lower when unemployed than employed $\left(c_{t}^{u} \leq c_{t}^{e}\right)$, the rate of decline in assets over a spell of unemployment can be bounded. ${ }^{33}$ This restriction on the rate of decline in assets yields a lower bound on consumption if the agent finds a job in period $t$ :

$$
c_{t}^{e} \geqslant c_{0}^{e}-r \sum_{k=1}^{t}\left(w-b_{k}\right)
$$

where $c_{0}^{e}=w+F+r /(1+r) A_{0}$. Next, we use this bound on $c_{t}^{e}$ to derive an upper bound on $u^{\prime}\left(c_{0}^{u}\right)$, the marginal utility of consumption in the first period of the unemployment spell. Consider the Euler equation for an individual who does not find a job at the beginning of period 0:

$$
u^{\prime}\left(c_{0}^{u}\right)=E_{0}\left[s_{1}^{*} u^{\prime}\left(c_{1}^{e}\right)+\left(1-s_{1}^{*}\right) u^{\prime}\left(c_{1}^{u}\right)\right]
$$

where $s_{1}^{*}$ is the optimal level of search intensity in period $1 .^{34}$ If the job seeker can always find a job within $T$ periods, (17) implies that

$$
u^{\prime}\left(c_{0}^{u}\right)=\sum_{t=1}^{T} q_{t}^{*} u^{\prime}\left(c_{t}^{e}\right)
$$

\footnotetext{
${ }^{31}$ This is a reasonable approximation for our case, since we focus on people under age 50, and the Austrian pension system is quite generous (replacing about $75 \%$ of wages).

${ }^{32}$ Increasing $\mathrm{T}$ to 3 or 4 years has little effect on our calibration results, provided that we continue to assume that those who are not observed on a job at that point are actually censored, rather than still looking for work.

${ }^{33}$ Specifically, if a person is still unemployed in period $t-1, A_{t}=(1+r)\left(A_{t-1}+F+b_{t-1}-c_{t-1}^{u}\right)$. Using the fact that $c_{t-1}^{u} \leqslant c_{t-1}^{e}$ and the equation for $c_{t-1}^{e}$, this implies that $A_{t} \geqslant A_{t-1}-(1+r)\left(w-b_{t-1}\right)$, and thus $A_{t} \geqslant A_{0}-(1+r) \sum_{k=0}^{t-1}\left(w-b_{k}\right)$.

${ }^{34}$ This is derived by using the first order condition for $A_{t+1}$ in equation (2) with $r=\delta$, and the results: $J_{t+1}^{\prime}\left(A_{t+1}\right)=$ $s_{t+1}^{*} V_{t+1}^{\prime}\left(A_{t+1}\right)+\left(1-s_{t+1}^{*}\right) U^{\prime}\left(A_{t+1}\right), V_{t+1}^{\prime}\left(A_{t+1}\right)=u^{\prime}\left(c_{t+1}^{e}\right)$, and $U_{t+1}^{\prime}\left(A_{t+1}\right)=u^{\prime}\left(c_{t+1}^{u}\right)$.
} 
where $q_{t}^{*}=\left(1-s_{1}^{*}\right)\left(1-s_{2}^{*}\right) \ldots\left(1-s_{t-1}^{*}\right) s_{t}^{*}$ represents the probability of obtaining a job in period $t$, conditional on unsuccessful search in period 0 . We use the empirical distribution of waiting times to a new job in our sample to estimate $q_{t}^{*} \cdot{ }^{35}$ Finally, plugging in the lower bound on $c_{t}^{e}$ and the empirical values of $q_{t}^{*}$ into equation (18), we obtain an upper bound on $u^{\prime}\left(c_{0}^{u}\right)$. This translates directly into a bound on $D$ since $c_{0}^{e}$ is fixed.

Obtaining a numerical value for $D$ through this procedure requires specification of several parameters related to the income path and preferences. We assume that $\rho_{t}=0.55$ for the first 30 weeks (3 periods) of joblessness, and that $\rho_{t}=0.21$ thereafter, reflecting the safety net of unemployment assistance. We also assume that a typical job loser contributes $\sigma=50 \%$ of his or her family income, and that assets at the time of job loss $A_{0}=0$.

The free parameters in calibrating the PIH model are the interest rate $(r)$ and coefficient of relative risk aversion $(\gamma)$. We present the predicted upper bounds on $D=m_{2}$ for various combinations of these two parameters in Panel B of Table 5. Note that alternative parameter combinations can lead to approximately the same prediction for $m_{2}$. For example, a model with $\gamma=1, r=10 \%$ yields a bound of $D=m_{2}=0.013$, the same value implied by a model with $\gamma=2, r=5 \%$.

Comparing the Empirical Estimate to the Benchmarks. How does the empirical value of the sample moment compare with the values predicted by the two benchmark models? Panel C of Table 5 shows the empirical values of $m_{2}$ implied by the no-controls and saturated-controls hazard model estimates for comparison to the values predicted by the two models.

The data appear to be clearly inconsistent with the PIH model, using values for the interest rate and the coefficient of relative risk aversion in a conventional range. For example, the lower bound of the $95 \%$ confidence interval for the estimate of $m_{2}$ based on the baseline hazard model without controls is 0.115. Comparing this lower bound to the predictions in Panel B of Table 5, one could reject any parameter combination with $r<30 \%$ or $\gamma<3$. Hence, unlike consumption-based studies which also find evidence of "excess sensitivity" (e.g. Gruber 1997), the estimates here are sufficiently precise to rule out the benchmark PIH even with fairly extreme assumptions about risk aversion and the interest rate.

The estimates of $m_{2}$ are closer to the fully credit-constrained model, which predicts $m_{2}=0.24$ if $\gamma=2$. This prediction is above our point estimates of $m_{2}$, but lies within the $95 \%$ confidence

\footnotetext{
${ }^{35}$ In calculating $q_{t}^{*}$, we ignore those who are not observed in a new job within $T=10$ periods (100 weeks), again assuming that this group finds jobs in sectors not covered by our dataset at the same rate as the rest of the sample.
} 
interval of the estimates.

Summary and Interpretation. Figure 1 summarizes our calibration results by showing where the representative agent in the data lies on the continuum of dynamic models ordered by sensitivity to cash-on-hand. The predicted values of $m_{2}$ for the PIH and credit-constraint models in this figure assume $r=5 \%$ and $\gamma=2$, which are typical parameter choices for the interest rate and risk aversion in the literature (see e.g., Carroll 2004, Chetty 2006b). Our empirical estimate of $m_{2} \simeq 0.17$ is about $70 \%$ of the way between the values predicted by the PIH and credit-constraint models. A model with heterogeneous agents, some of whom behave as the PIH predicts and some of whom set consumption equal to income (as in Campbell and Mankiw 1989), could therefore fit the data.

We considered the two benchmark models above primarily for illustrative purposes. One could conduct similar calibration exercises for many other models of household behavior. With an appropriate choice of preferences and financial technologies, several models could potentially generate a value of $m_{2}$ consistent with the data. One well-known model that is likely to be consistent with our estimates is Deaton's (1991) buffer-stock model, which assumes forward-looking behavior but minimum asset limits that eventually constrain borrowing. In such a model, the optimal level of consumption while unemployed can be substantially lower than in the PIH, leading to a larger predicted value for $m_{2}$ than a simple PIH model. A similar profile of consumption is predicted by the buffer-stock model proposed by Carroll $(1997,2004)$, which does not have an exogenous asset limit. However, a key assumption of the Carroll model - that income can fall to 0 - is less attractive for Austria, where permanent unemployment assistance constitutes a lower bound on income. ${ }^{36}$

\section{Conclusion}

The general objective of this paper has been to bring methods and data from the labor economics literature to bear on an issue of longstanding interest in macroeconomics and public finance. Specifically, we used data on job search behavior coupled with discontinuities in the eligibility rules for severance pay and UI benefits in Austria to distinguish between models of intertemporal behavior.

We reached three main empirical findings: (1) A cash grant equivalent to two months of wages induces substantial changes in search behavior well beyond what is predicted by a benchmark lifecy-

\footnotetext{
${ }^{36}$ See Michaelides (2003) for a more detailed discussion of how the availability of social insurance can be used to distinguish between the Deaton and Carroll models.
} 
cle model with unrestricted borrowing; (2) extending UI benefits also affects search behavior early in the spell, providing evidence that households are forward-looking; and (3) lengthening durations through EB and severance pay policies has little or no effect on subsequent job match quality. Interpreting our reduced-form empirical results through the framework of a job search model, we conclude that the behavior of job searchers is best described by a model such as buffer-stock behavior, where agents have limited capacity to smooth income fluctuations. We also construct a sample moment based on the ratio of the severance pay and EB effects that can be used to calibrate intertemporal models to our empirical findings.

This characterization of household behavior has several normative implications. At a broad level, it implies that temporary changes in income have more important economic consequences than traditional models suggest. For example, temporary fiscal policy changes such as tax cuts could have significant effects on the economy. The evidence of imperfect smoothing suggests that there may be a significant role for temporary income support programs such as unemployment insurance, temporary welfare, and workers compensation. In addition, the finding that cash grants change search behavior in a manner similar to UI benefit extensions implies that much of the behavioral response to temporary benefit social insurance programs is an "income" or liquidity effect rather than moral hazard caused by distortion in incentives. Analyzing these issues formally in dynamic models calibrated to match the evidence documented here is an interesting direction for further research.

More generally, the basic idea of using data on labor supply instead of consumption to distinguish between models can be applied in other settings. For example, examining whether work hours or retirement choices exhibit "excess sensitivity" to cash-on-hand may yield further insights into models of household behavior. 


\section{Appendix}

\section{A. Sample Definition.}

The Austrian Social Security Database contains employment records for private sector employees, public sector workers who are not classified as permanent civil servants, and the unemployed. The groups for whom information is missing are self employed and civil servants. Based on Austrian national statistics, about $10 \%$ of the labor force were self employed and $7 \%$ were civil servants in 1996. Therefore, we estimate that the Social Security Database covers roughly $85 \%$ of the total workforce.

For each covered job, the database reports the starting and ending date of the job, the identity of the employer, certain characteristics of the job (e.g., industry, occupation), and total earnings. No information is available on hours of work. Earnings are censored at the Social Security contribution limit, but this only affects a small fraction $(2 \%)$ of the observations in our sample. The database also includes starting and ending dates for unemployment insurance (UI) claims, and information on whether an individual is registered with the employment office as looking for work. No information is available on the amount of UI payments actually received. We code an individual as "unemployed" if he or she is receiving UI, or registered as looking for work.

From the database, we extract all job terminations between 1981 and 2001 that were followed by a UI claim and did not result in a retirement claim within the same calendar year $(1,817,221$ terminations). We exclude terminations from jobs in schools, hospitals, and other public sector service industries (4\% of the total) because some of these jobs are fixed term. We also exclude jobs in the construction sector ( $17 \%$ of the remaining sample) because of the different severance pay regulations. We then eliminate terminations from jobs that lasted for 5 or more years, and for individuals who worked all weeks in the past 5 years. These two restrictions reduce the remaining sample by a further $33 \%$. We eliminate terminations involving people whose age in years is under 20 or over 49 at the time of the job loss (a further $10 \%$ of the remaining sample), and individuals who return to the same employer (a further $19 \%$ of the remaining sample). Finally, we drop all terminations with a delay of over 28 days between the job termination date and the start of the UI claim. This restriction eliminates job quitters (who face a 4 week waiting period for UI) and eliminates another $10 \%$ of the remaining sample. The final sample includes 650,922 job losses. Note that individuals can appear in our sample of job losses multiple times. Among individuals included in the sample at least once, we observe a single job loss for $84 \%$, two job losses for $13 \%$, and 3 or more job losses for the remaining $3 \%$ of individuals.

For the job losses in our sample, we use all available information on employment, unemployment, and earnings in the Social Security database files for the years 1972 to 2003 . We merge in information on completed education and marital status from the Austrian unemployment registers, which are available from 1987 to 1998. Spell-specific demographic information is available in this file for each unemployment spell, and we use the information in the last recorded unemployment spell for each individual to assign education and marital status. For individuals whose only spell of unemployment occurred before 1987 or after 1998, however, these variables are missing. We can assign information for $66 \%$ of job losses occurring before 1987, and $75 \%$ of job losses after 1998 .

\section{B. Cash Value of Severance Pay and Extended Benefits.}

Severance pay is equal to 2 months of gross wages, but is taxed at roughly $6 \%$. The average tax rate on earnings in Austria is approximately 30 percent. Letting $w$ represent the net monthly wage, the value of severance pay is therefore $2 w(1-.06) /(1-0.3)=2.69 w$. 
Extended benefits provide 10 extra weeks (2.5 extra months) of eligibility for UI. In the absence of UI, however, people are eligible for unemployment assistance (UA). Thus the value of extended benefits is approximately $2.5 w \rho(1-U A / U I)$, where $\rho$ is the replacement rate of regular UI benefits and $U A / U I$ represents the ratio of UA benefits to UI benefits. The statutory replacement rate for UI benefits is $55 \%$. However, most workers receive supplementary UI benefits for their dependents: on average we estimate that this raises the replacement rate to $64 \%$. Offsetting this is the fact that workers in Austria receive 14 "monthly" salaries per year whereas UI benefits are monthly. Thus the average effective replacement rate is $\rho=0.64 \times 12 / 14=0.55$.

Benefits for UA are based on the formula $U A=0.92 U I-F+C$, where $F$ represents other family member's earnings and $C$ represents dependent allowances. Data from the 2004 Survey of Income and Living Conditions show that the average wage earner in Austria between the ages of 20 and 49 contributed just under one-half of his/her family income. Based on this, we assume that $F$ is approximately equal to $w$ for a typical worker in our sample. Dependent allowances were 423 Euros per month for a partner and 213 Euros per month for each dependent child in 2000. Assuming that a typical job loser has a partner and 2 children and a net wage of 1200 Euros per month, we therefore estimate that $U A / U I=0.38$. Thus, we estimate that the value of extended benefits is $2.5 w(0.55)(1-0.38)=0.85 w$. 


\section{References}

Acemoglu, Daron and Robert Shimer, "Efficient Unemployment Insurance," Journal of Political Economy CXIII (1999), 893-928

Addison, John T. and McKinley L. Blackburn, "The Effects of Unemployment Insurance on Postunemployment Earnings," Labour Economics, VII (January 2000), 21-53.

Aguiar, Mark and Erik Hurst, "Consumption vs. Expenditure," Journal of Political Economy CVII (2005), 919-48.

Altonji, Joseph G. and Aloysius Siow "Testing the Response of Consumption to Income Changes with (noisy) Panel Data," Quarterly Journal of Economics, CII (1987), 293-328.

Angrist, Joshua and Victor Lavy, "Using Maimonides' Rule To Estimate The Effect Of Class Size On Scholastic Achievement," Quarterly Journal of Economics, CXIV(2) (1999), 533-575.

Baily, Martin N., "Some aspects of optimal unemployment insurance," Journal of Public Economics, X (1978), 379-402.

Baker Tilly International, "Doing Business in Austria." Baker Tilly International (August 2005). Available at: http://www.bakertillyinternational.com/pdf/Doing_Business_in_AustriaOct05.pdf

Bird, Roger C. and Ronald G. Bodkin, "The National Service Life-Insurance Dividend of 1950 and Consumption: A Further Test of the 'Strict' Permanent-Income Hypothesis," The Journal of Political Economy, LXXIII (October 1965), 499-515.

Blinder, Alan S., "Temporary Income Taxes and Consumer Spending," Journal of Political Economy, University of Chicago Press, LXXXIX (February 1981), 26-53.

Blinder, Alan S. and Angus Deaton, "The Time Series Consumption Function Revisited," in William C. Brainard and George L. Perry, eds., Brookings Papers on Economic Activity 2 (Washington D.C., 1985), 465-521.

Bloemen, Hans and Elena Stancanelli, "Financial Wealth, Consumption Smoothing and Income Shocks Arising from Job Loss," Economica, LXXII (2005), 431-452.

Bodkin, Ronald, "Windfall Income and Consumption," The American Economic Review, XLIX (1959), 602-614.

Browning, Martin, and Dolores M. Collado, "The Response of Expenditures to Anticipated Income Changes: Panel Data Estimates," American Economic Review XCI (2001), 681-692.

Browning, Martin and Thomas Crossley, "Unemployment Insurance Levels and Consumption Changes," Journal of Public Economics, LXXX (1999), 1-23.

Browning, Martin and Thomas Crossley, "The Life-Cycle Model of Consumption and Saving," Journal of Economic Perspectives, XV (Summer 2001), 3-22.

Browning, Martin and Annamaria Lusardi, "Household Saving: Micro Theories and Micro Facts," Journal of Economic Literature, XXXIV (December 1996), 1797-1855.

Burtless, Gary S., "Unemployment insurance and labor supply: a review", in W. Lee Hansen and James F. Byers, eds., "Unemployment Insurance: The second half-century," (University of Wisconsin Press, Madison, WI 1990), 69-107.

Campbell, John Y. and N. Gregory Mankiw, "Consumption, Income and Interest Rates: Reinterpreting the Time Series Evidence," NBER Macroeconomics Annual (1989), 185-216.

Carroll, Christopher, "Buffer-Stock Saving and the Life Cycle/Permanent Income Hypothesis," Quarterly Journal of Economics CXII (1997), 1-56.

Carroll, Christopher, "Theoretical Foundations of Buffer Stock Saving," NBER Working Paper No. 10867 (2004).

Centeno, Mário, "The Match Quality Gains from Unemployment Insurance." Journal of Human Resources XXXIX(3) (2004), 839-863. 
CESifo, "Dismissal Protection in Europe." CESifo DICE Report 2/2004. Munich: CESifo, 2004.

Chetty, Raj, "A General Formula for the Optimal Level of Social Insurance," Journal of Public Economics XC (November 2006a), 1879-1901.

Chetty, Raj, "Why do Unemployment Benefits Raise Unemployment Durations? Moral Hazard vs. Liquidity," UC-Berkeley mimeo (2006b).

Chetty, Raj, "A New Method of Estimating Risk Aversion." American Economic Review (2006c).

Classen, K.P., "The effect of unemployment insurance on the duration of unemployment and subsequent earnings," Industrial and Labour Relations Review 30 (1977), 438-50.

Cox, James C. and Ronald L. Oaxaca, "Unemployment insurance and job search," in L. Bassi and D. Crawford, eds, "Research in labor economics," XI, JAI Press (1990), 223-240.

Danforth, J. P., "On the Role of Consumption and Decreasing Absolute Risk Aversion in the Theory of Job Search," in S. A. Lippman, and J. J. McCall, eds, "Studies in the Economics of Search," (North-Holland, New York 1979), 109-131.

Deaton, Angus S., "Savings and Liquidity Constraints," Econometrica LIX (1991), 1221-1248.

Deaton, Angus, (1992) "Understanding Consumption," (Oxford University Press, Oxford 1992).

DiNardo, John and David Lee, "Economic Impacts of New Unionization on U.S. Private Sector Employers: 1984-2001," Quarterly Journal of Economics CXIX(4) (2004), 1383-1442.

Ehrenberg, R. and Ronald Oaxaca, "Unemployment insurance, duration of unemployment, and subsequent wage gain," American Economic Review LXVI(5) (1976), 754-766.

EIRO (European Industrial Relations Observatory). "Austria: Collective Agreement Extension Mechanisms and Practices Examined," Dublin: European Foundation for the Improvement of Living and Working Conditions, EIRO Online (January 2001), Available at http://www.eiro.eurofound.eu.int/2001/12/feature/at0112250f.html

Flavin, Marjorie, "The adjustment of consumption to changing expectations about future income," Journal of Political Economy LXXXIX(5) (1981), 974-1009.

Flemming, J., "Aspects of optimal unemployment insurance," Journal of Public Economics X (1978), 403-425.

Fuchs-Schündeln, Nicola and Matthias Schündeln, "Precautionary Savings and Self-Selection: Evidence from the German Reunification 'Experiment'," Quarterly Journal of Economics CXX (2005), 1085-1120.

Gourinchas, Pierre-Olivier, and Jonathan A. Parker, "Consumption over the Life Cycle," Econometrica, LXX (2002), 47-89.

Gruber, Jonathan, "The Consumption Smoothing Benefits of Unemployment Insurance," American Economic Review LXXXVII (1997), 192-205.

Hahn, Jinyong, Petra Todd and Wilbert Van der Klaauw, "Identification and Estimation of Treatment Effects with a Regression-Discontinuity Design," Econometrica LXIX(1) (January 2001), 201-209.

Hall, Robert E., "Stochastic Implications of the Life Cycle-Permanent Income Hypothesis: Theory and Evidence," Journal of Political Economy LXXXVI(6) (December 1978), 971-987.

Hall, Robert and Frederic S. Mishkin, "The Sensitivity of Consumption to Transitory Income: Estimates from panel data on households," Econometrica L (1982), 461-481.

Hansen, Gary D., and Ayse Imrohoroglu, "The Role of Unemployment Insurance in an Economy with Liquidity Constraints and Moral Hazard," Journal of Political Economy C(1) (1992), 118-142.

Hsieh, Chang-Tai, "Do Consumers Respond to Anticipated Income Shocks? Evidence from the Alaska Permanent Fund," American Economic Review IC (March 2003), 397-405. 
Jovanovic, Boyan, "Job matching and the theory of turnover," Journal of Political Economy LXXXVII (1979), 972-990.

Katz, Lawrence and Bruce Meyer, "The Impact of the Potential Duration of Unemployment Benefits on the Duration of Unemployment," Journal of Public Economics XLI (1990), 45-72.

Lalive, Rafael, Jan C. Van Ours, and Josef Zweimuller, "How Changes in Financial Incentives Affect the Duration of Unemployment," Review of Economic Studies, forthcoming 2006.

Lalive, Rafael and Josef Zweimuller, "Benefit Entitlement and Unemployment Duration: The Role of Policy Endogeneity," Journal of Public Economics LXXXVIII (December 2004), 2587-2616.

Lee, David "Randomized Experiments from Non-random Selection in U.S. House Elections," Journal of Econometrics, forthcoming, 2006.

Lee, David and David Card, "Regression Discontinuity Inference with Specification Error," National Bureau of Economic Research Technical Working Paper \#322, 2006.

Lentz, Rasmus and and Torben Tranaes, "Job Search and Savings: Wealth Effects and Duration Dependence," Journal of Labor Economics XXIII (2005), 467-489.

Lise, Jeremy, "On the Job Search and Precautionary Savings: Theory and Empirics of Wealth and Inequality." Unpublished Manuscript, Queen's University Department of Economics (2006).

McCall, Brian P., "Occupational Matching: A Test of Sorts," Journal of Political Economy XCVIII (February 1990), 45-69.

Meyer, Bruce, "Unemployment insurance and unemployment spells," Econometrica LVIII(4) (1990), 757- 782 .

Michaelides, Alex, "A Reconciliation of Two Alternative Approaches towards Buffer Stock Saving," Economics Letters 79 (2003), 137-143.

Mortensen, Dale T., "Unemployment Insurance and Job Seach Decisions," Industrial and Labor Relations Review XXX(4) (July 1977), 505-517.

Mortensen, Dale T., "Job Search and Labor Market Analysis," In Ashenfelter, Orley and Richard Layard, eds. Handbook of Labor Economics II (Amsterdam: Elsevier Science, 1986), 849-920.

Oi, Walter and Todd Idson, "Firm Size and Wages." In Ashenfelter, Orley and David Card, eds, Handbook of Labor Economics IIIB (Amsterdam: North-Holland, 1999).

Parker, Jonathan, "The Reaction of Household Consumption to Predictable Changes in Social Security Taxes," American Economic Review, LXXXIX(4) (September 1999), 959-973.

Paxson, Christina, "Using Weather Variability to Estimate the Response of Savings to Transitory Income in Thailand." American Economic Review LXXXII(1) (1992), 15-33.

Pichelmann, Karl and Helmut Hofer, "Austria: Long Term Success Through Social Partnership." ILO Employment and Training Department Country Employment Policy Review (Geneva: International Labor Office 1999).

Poterba, James M., "Are Consumers Forward Looking? Evidence from Fiscal Experiments," American Economic Review (Papers and Proceedings), LXXVIII(2) (May 1988), 413-418.

Shapiro, Matthew D., and Joel Slemrod, "Consumer Response to the Timing of Income: Evidence from a Change in Tax Withholding," American Economic Review LXXXV (March 1995), 274-283.

Shimer, Robert and Ivan Werning, "Liquidity and Insurance for the Unemployed," Univ. of Chicago mimeo (2005).

Shimer, Robert and Ivan Werning, "Reservation Wages and Unemployment Insurance," forthcoming, Quarterly Journal of Economics (2006).

Souleles, Nicholas (1999), "The Response of Household Consumption to Income Tax Refunds," American Economic Review LXXXIX(4) (September 1999), 947-958. 
Stiglbauer, Alfred, Franz Stahl, Rudolf Winter-Ebmer and Josef Zweimüller, "Job Creation and Job Destruction in a Regulated Labor Market: The Case of Austria," Empirica XXX (2003), $127-148$.

Thistlewaite, D. and D. Campbell, "Regression-Discontinuity Analysis: An Alternative to the Ex Post Fact Experiment," Journal of Educational Psychology LI (1960), 309-317.

Winter-Ebmer, Rudolf, "Benefit Duration and Unemployment Entry: A Quasi-Experiment in Austria," European Economic Review XLII (2003), 259-273.

Wang, Cheng and Stephen Williamson, "Unemployment insurance with moral hazard in a dynamic economy," Carnegie-Rochester Conference Series on Public Policy XLIV (1996), 1-41.

Zeldes, Stephen P., "Consumption and Liquidity Constraints: An Empirical Investigation," Journal of Political Economy XCVII(2) (1989), 305-346. 
TABLE 1

Sample Characteristics: Austrian Job Losers, 1980-2001

\begin{tabular}{|c|c|c|c|}
\hline & Mean & Median & Std. Dev. \\
\hline \multicolumn{4}{|l|}{ Worker Characteristics: } \\
\hline Age in Years & 31.20 & 30.00 & 7.96 \\
\hline Female & 0.52 & 1.00 & 0.50 \\
\hline Post-compulsory Schooling & 0.60 & 1.00 & 0.49 \\
\hline Married & 0.43 & 0.00 & 0.50 \\
\hline Austrian Citizen & 0.88 & 1.00 & 0.33 \\
\hline Blue Collar Occupation & 0.58 & 1.00 & 0.49 \\
\hline \multicolumn{4}{|l|}{ Previous Job/Employment: } \\
\hline Months of Tenure & 25.61 & 21.90 & 11.93 \\
\hline Months Worked in Past 5 Years & 41.11 & 44.10 & 13.79 \\
\hline Eligible for Severance Pay & 0.21 & 0.00 & 0.41 \\
\hline Eligible for Extended UI & 0.66 & 1.00 & 0.47 \\
\hline Previous Wage (Euros/yr) & 17,034 & 15,950 & 7,588 \\
\hline Wage Top-Coded & 0.02 & 0.00 & 0.14 \\
\hline Number of Employees at Firm & 299.45 & 31.00 & 1271.82 \\
\hline \multicolumn{4}{|l|}{ Post-Layoff: } \\
\hline Duration of Unemployment (months) & 4.75 & 2.94 & 8.37 \\
\hline Unemployed $<20$ Weeks & 0.64 & 1.00 & 0.48 \\
\hline Unemployed < 52 Weeks & 0.94 & 1.00 & 0.24 \\
\hline Duration of Nonemployment (months) & 16.93 & 4.29 & 38.19 \\
\hline Nonemployed $<20$ Weeks & 0.51 & 1.00 & 0.50 \\
\hline Nonemployed $<52$ Weeks & 0.77 & 1.00 & 0.42 \\
\hline Observed in New Job & 0.92 & 1.00 & 0.27 \\
\hline \multicolumn{4}{|l|}{ Among those with New Job: } \\
\hline Months to Re-employment & 8.96 & 3.84 & 17.71 \\
\hline Change in Log Wage & -0.03 & -0.01 & 0.51 \\
\hline
\end{tabular}

Note: Based on sample of 650,922 job losers over the period 1980-2001. Sample includes universe of Austrians losing a job in the private sector who (1) are between the age 20-50, (2) worked at their previous firm between 1 and 5 years and worked a total of between 1 and 5 years out of the last 5 years, (3) took up UI benefits within 28 days of job loss (eliminating job quitters), (4) were not recalled to their prior firm. Individuals losing a job in construction are also excluded. Wages expressed in real (year 2000) Euros.

Unemployment duration is time registered as unemployed; nonemployment duration is time to next job. 
TABLE 2

Effects of Severance Pay and EB on Durations: Hazard Model Estimates

\begin{tabular}{lcccc}
\hline \hline & $\begin{array}{c}(1) \\
\text { Restricted } \\
\text { sample }\end{array}$ & $\begin{array}{c}(2) \\
\text { Restricted } \\
\text { sample }\end{array}$ & $\begin{array}{c}(3) \\
\text { Full } \\
\text { sample }\end{array}$ & $\begin{array}{c}\text { With } \\
\text { controls }\end{array}$ \\
Severance pay & -0.127 & & -0.125 & -0.115 \\
& $(0.019)$ & & $(0.017)$ & $(0.018)$ \\
Extended benefits & & -0.084 & -0.093 & -0.064 \\
& & $(0.018)$ & $(0.016)$ & $(0.017)$ \\
Sample size & 512,767 & 512,767 & 650,922 & 565,835 \\
\hline
\end{tabular}

NOTE--All specifications report estimates of Cox hazard models for nonemployment durations (time to next job) censored at twenty weeks; hence, coefficient estimates can be interpreted as percent change in average job finding hazard over first twenty weeks of the spell. Specifications 1 and 2 are estimated on the restricted sample of individuals who worked at another firm for at least one month within the past five years. Specification 1 includes an indicator for severance pay eligibility and a cubic polynomial for job tenure interacted with severance indicator. Specification 2 includes an indicator for extended-benefit eligibility and a cubic polynomial for months worked in past 5 years interacted with EB indicator. Specifications 3 and 4 report estimates of model specified in equation (15), with cubic polynomials for both job tenure and months worked interacted with severance pay and EB indicators. Specifications 3 and 4 are estimated on the full sample, defined in notes to Table 1. Specification 4 includes the following additional controls: gender, marital status, Austrian nationality, "blue collar" occupation indicator, age and its square, log previous wage and its square, and dummies for month and year of job termination. Standard errors shown in parentheses. 
TABLE 3a

Hazard Model Estimates: Robustness Checks

\begin{tabular}{lcccc}
\hline \hline & $(1)$ & $(2)$ & $(3)$ & $(4)$ \\
& $\begin{array}{c}\text { Add Control } \\
\text { for End of } \\
\text { Tenure-Year }\end{array}$ & $\begin{array}{c}\text { Exclude End of } \\
\text { Tenure-Year } \\
\text { Months }\end{array}$ & $\begin{array}{c}\text { Add } \\
\text { Saturated } \\
\text { Control Set }\end{array}$ & $\begin{array}{c}\text { Measure } \\
\text { Duration by } \\
\text { Unemployment }\end{array}$ \\
Severance pay & -0.076 & -0.095 & -0.094 & -0.109 \\
Extended benefits & $(0.019)$ & $(0.033)$ & $(0.019)$ & $(0.023)$ \\
& -0.065 & -0.059 & -0.064 & -0.053 \\
Sample size & $(0.017)$ & $(0.019)$ & $(0.018)$ & $(0.023)$ \\
\hline
\end{tabular}

NOTE--All columns report estimates of Cox hazard models as specified in equation (15), with cubic polynomials for job tenure and months worked interacted with severance pay and EB indicators. Columns 1-3 use nonemployment durations censored at twenty weeks as dependent variable; column 4 uses unemployment durations, censored if there is a gap between end of unemployment and start of new job or if spell exceeds twenty weeks. Coefficient estimates can be interpreted as percent change in average job finding or unemployment exit hazard over first twenty weeks of the spell. All specifications include the covariate set used in specification 4 of Table 2. Specification 1 includes in addition the "end of tenure year" dummy to correct for tenure seasonality. Specification 2 excludes observations in the last three months of each tenure year.

Specification 3 adds the following controls: total number of employees at firm from which the work was laid off, total years of work experience and its square, indicator for having a job before the one just lost, the duration of the job before the one just lost, "blue collar" status at job prior to the one lost, a dummy for being recalled to the job before the one just lost, indicator for having a prior spell of nonemployment, the last nonemployment duration before the current spell, total number of spells of nonemployment in career, and dummies for education, industry, and region of job loss. 
TABLE 3b

Additional Robustness Checks and Placebo Tests

\begin{tabular}{|c|c|c|c|c|c|c|c|}
\hline & (1) & $(2)$ & (3) & (4) & (5) & (6) & (7) \\
\hline & \multirow{2}{*}{$\begin{array}{l}\text { Small Firms } \\
(<100) \text { Only }\end{array}$} & \multirow{2}{*}{$\begin{array}{l}\geq 2 \text { Layoffs } \\
\text { by firm }\end{array}$} & \multirow{2}{*}{$\begin{array}{l}\geq 4 \text { Layoffs } \\
\text { by firm }\end{array}$} & \multirow{2}{*}{$\begin{array}{l}\geq 5 \text { Layoffs } \\
\text { by firm }\end{array}$} & \multicolumn{3}{|c|}{$\begin{array}{l}\text { Placebo Test: Severance Pay and } \\
\text { EB Eligibility Based on Previous Job }\end{array}$} \\
\hline & & & & & no controls & controls & no controls \\
\hline Severance pay & $\begin{array}{l}-0.087 \\
(0.022)\end{array}$ & $\begin{array}{l}-0.101 \\
(0.034)\end{array}$ & $\begin{array}{l}-0.132 \\
(0.058)\end{array}$ & $\begin{array}{l}-0.100 \\
(0.066)\end{array}$ & -- & -- & $\begin{array}{l}-0.199 \\
(0.048)\end{array}$ \\
\hline Extended benefits & $\begin{array}{l}-0.076 \\
(0.020)\end{array}$ & $\begin{array}{l}-0.070 \\
(0.033)\end{array}$ & $\begin{array}{l}-0.079 \\
(0.059)\end{array}$ & $\begin{array}{l}-0.114 \\
(0.069)\end{array}$ & -- & -- & $\begin{array}{l}-0.126 \\
(0.058)\end{array}$ \\
\hline $\begin{array}{l}\text { Severance pay } \\
\text { placebo (previous job) }\end{array}$ & -- & -- & -- & -- & $\begin{array}{c}0.000 \\
(0.048)\end{array}$ & $\begin{array}{c}0.015 \\
(0.049)\end{array}$ & $\begin{array}{c}0.008 \\
(0.048)\end{array}$ \\
\hline $\begin{array}{l}\text { Extended benefits } \\
\text { placebo (previous job) }\end{array}$ & -- & -- & -- & -- & $\begin{array}{c}0.028 \\
(0.029)\end{array}$ & $\begin{array}{c}0.029 \\
(0.030)\end{array}$ & $\begin{array}{c}0.024 \\
(0.029)\end{array}$ \\
\hline Sample size & 377,525 & 145,905 & 48,390 & 35,579 & 86,339 & 82,388 & 86,339 \\
\hline
\end{tabular}

NOTE--All columns report estimates of Cox hazard models for nonemployment duration (censored at twenty weeks) as specified in equation (15). Specifications 1-4 and 6 include the covariates used in specification 4 of Table 2. Specifications 1-4 include cubic polynomials for job tenure and months worked interacted with severance pay and EB indicators. Specification 1 is estimated on subsample of individuals laid off from a firm with under 100 employees. Specification 2 is estimated on subsample of individuals laid off from a firm that fired two or more workers in same month. Specification 3 restricts the sample to layoffs of four or more workers and specification 4 to layoffs of five or more workers. Specifications 5-7 are estimated on the subsample of individuals with 2+ terminations in the sample, and who have (a) job tenure of $1-5$ years in both jobs and (b) worked $1-5$ years in the 5 years preceding both job losses. These models include cubics in tenure at previous job and months worked prior to the previous job loss, interacted with "placebo" severance pay and EB indicators based on previous job (see text for details). Specification 7 includes actual severanc indicators as well as placebo indicators, along with cubic polynomials for the four running variables. 


\section{TABLE 4a}

Effects of Severance Pay and EB on Match Quality

\begin{tabular}{lcccc}
\hline \hline & $\begin{array}{c}(1) \\
\text { No controls }\end{array}$ & Saturated controls & No controls & Saturated controls \\
Dependent var: & log wage change & log wage change & job leaving haz. & job leaving haz. \\
\hline Severance pay & -0.009 & -0.002 & -0.017 & 0.000 \\
& $(0.007)$ & $(0.006)$ & $(0.014)$ & $(0.015)$ \\
Extended benefits & -0.005 & -0.008 & -0.005 & 0.007 \\
& $(0.006)$ & $(0.006)$ & $(0.013)$ & $(0.014)$ \\
Sample size & 553,607 & 445,926 & 601,152 & 476,307 \\
\hline
\end{tabular}

NOTE--All specifications include cubic polynomials for job tenure and months worked interacted with severance pay and EB indicators. All specifications are estimated on the full sample of workers who find a new job before the sample ends. Columns 1 and 2 report coefficients from OLS regressions of change in log wage from last year of lost job to first year of next job. Columns 3 and 4 report coefficient estimates from Cox hazard model for duration of next job, censored at five years. Coefficient estimates in columns 3 and 4 can be interpreted as average change in job leaving hazard over first five years of next job. Specifications 1 and 3 include no additional controls; specifications 2 and 4 include "saturated" control set used in specification 3 of Table $3 a$ (see notes to Table $3 a$ for details). 
TABLE 4b

Additional Measures of Match Quality

\begin{tabular}{|c|c|c|c|c|}
\hline Dependent var: & $\begin{array}{c}(1) \\
\text { Log wage change } \\
\text { over } 2 \text { years }\end{array}$ & $\begin{array}{c}(2) \\
\text { Change in } \\
\text { log firm size }\end{array}$ & $\begin{array}{c}\text { (3) } \\
\text { Switch } \\
\text { industries }\end{array}$ & $\begin{array}{c}\text { (4) } \\
\text { Move to firm in } \\
\text { different district }\end{array}$ \\
\hline Severance pay & $\begin{array}{c}0.006 \\
(0.008)\end{array}$ & $\begin{array}{c}-0.034 \\
(0.032)\end{array}$ & $\begin{array}{c}-0.002 \\
(0.007)\end{array}$ & $\begin{array}{c}0.015 \\
(0.007)\end{array}$ \\
\hline Extended benefits & $\begin{array}{l}-0.021 \\
(0.008)\end{array}$ & $\begin{array}{c}-0.011 \\
(0.030)\end{array}$ & $\begin{array}{c}0.001 \\
(0.007)\end{array}$ & $\begin{array}{c}0.003 \\
(0.006)\end{array}$ \\
\hline Sample size & 250,788 & 430,120 & 447,931 & 447,767 \\
\hline
\end{tabular}

NOTE--All specifications report estimates of OLS regressions that include cubic polynomials for job tenure and months worked interacted with severance pay and EB indicators, as well as the "saturated" control set used in specification 3 of Table $3 a$ (see notes to Table 3a for details). All specifications are estimated on the full sample of workers who find a new job before the sample ends and for whom the dependent variable is non-missing. Dependent variables of the models are as follows: specification 1 -- change in log wage from last year of lost job to second year of next job; specification 2 -- difference in log of number of employees at new firm and previous firm; specification 3 -- indicator for switching industries; specification 4 -- indicator for switching to a firm in a different geographical district. 


\section{TABLE 5}

Calibration Results vs. Empirical Estimates of Sample Moment $\mathrm{m}_{2}$

\section{A. Credit-Constraint Model}

\begin{tabular}{cccc}
\multicolumn{5}{c}{ Coefficient of Relative Risk Aversion $(\gamma):$} \\
1.0 & 2.0 & 3.0 & 4.0 \\
\hline 0.176 & $\mathbf{0 . 2 4 3}$ & 0.254 & 0.237
\end{tabular}

\section{B. PIH Model with Unrestricted Borrowing}

\begin{tabular}{rcccc} 
& \multicolumn{5}{c}{ Coefficient of Relative Risk Aversion $(\gamma)$ : } \\
\cline { 2 - 5 } Interest Rate $(r):$ & 1.0 & 2.0 & 3.0 & 4.0 \\
\cline { 2 - 5 } $3 \%$ & 0.004 & 0.008 & 0.012 & 0.016 \\
$5 \%$ & 0.007 & $\mathbf{0 . 0 1 3}$ & 0.020 & 0.026 \\
$10 \%$ & 0.013 & 0.026 & 0.039 & 0.052 \\
$15 \%$ & 0.020 & 0.039 & 0.059 & 0.078 \\
$30 \%$ & 0.040 & 0.079 & 0.117 & 0.155
\end{tabular}

\section{Empirical Estimates}

$\begin{array}{rcc} & \text { Point Estimate } & \text { Std. Error } \\ \text { No Controls: } & \mathbf{0 . 1 7 4} & 0.041 \\ \text { Saturated Controls: } & 0.192 & 0.071\end{array}$

NOTE--Panels $A$ and $B$ report predicted values of ratio $m_{2}$ from Credit Constraint and PIH models with parameter values as shown. Rate of time discount is set equal to the interest rate in $\mathrm{PIH}$ calibrations. See text for formulas used to calculate these numbers. Panel $\mathrm{C}$ shows empirical estimates of $\mathrm{m}_{2}$ using hazard model estimates from Column 3 of Table 2 (no controls) and Column 3 of Table $3 a$ (saturated controls). Standard errors are calculated using delta method. Values shown in bold correspond to those discussed in text and shown in Figure 1. 


\section{Figure 1}

Dynamic Models Ordered by Sensitivity to Cash-on-Hand

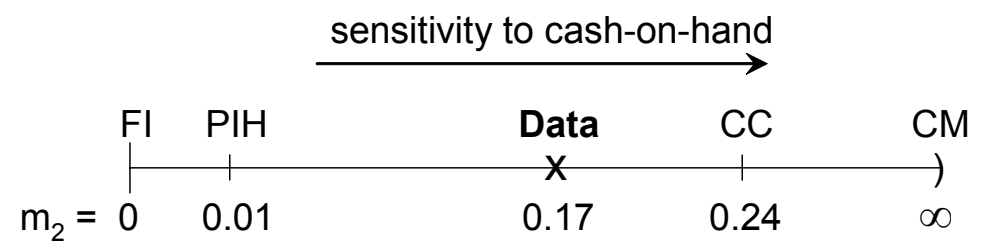

FI. $\quad$ Full insurance: PIH with complete markets

$\mathrm{PIH}$. Standard PIH with unrestricted borrowing and lending

Data. Empirical estimate of $\mathrm{m}_{2}$ using Austrian data

CC. Credit constrained: binding asset limit but forward looking

CM. Complete myopia "rule of thumb" with consumption = income

NOTE-This figure orders a set of intertemporal models by their predicted values of the moment $m_{2} \equiv \frac{\partial s_{0}^{*} / \partial A_{0}}{\frac{1}{p_{2}^{*} \partial s_{0}^{*} / \partial b_{2}}}$, a normalized measure of sensitivity to cash-on-hand (see section III for details). The values of $m_{2}$ shown for the PIH and CC models are calculated in section VIII, and assume a coefficient of relative risk aversion of 2 . See Table 5 for calibrated values of $m_{2}$ for the PIH and CC models under alternative assumptions. The empirical value of $m_{2}$ from the data is based on the hazard model estimates in column 3 of Table 2; see section VIII for details. 
Figure $2 a$

Eligibility for Extended Benefits by Job Tenure

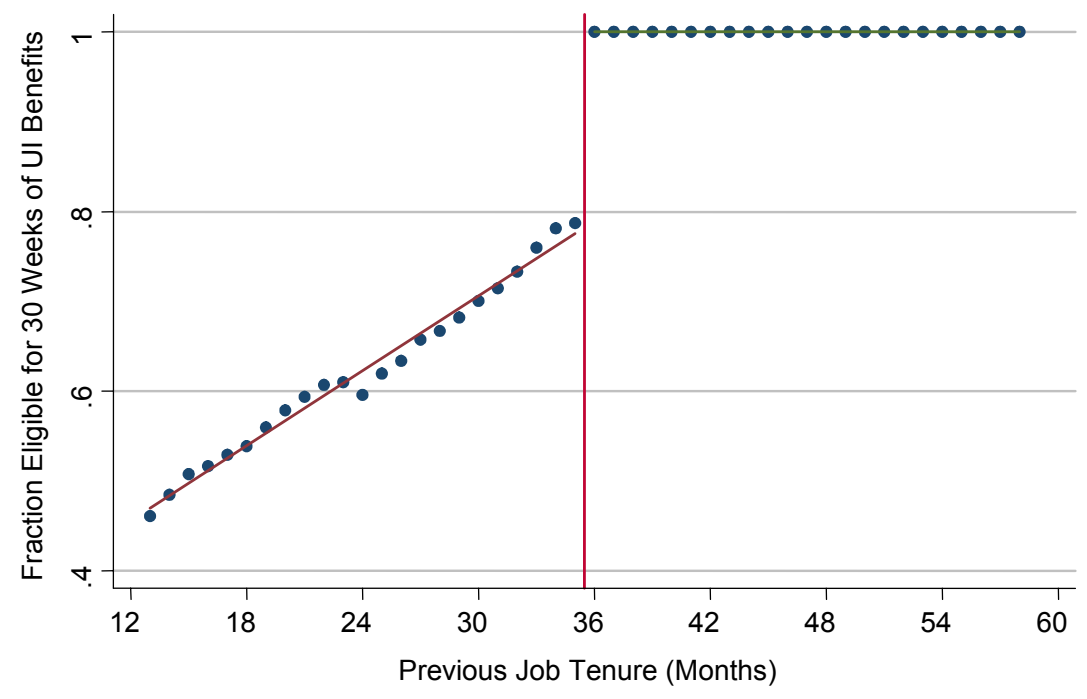

Figure 2b

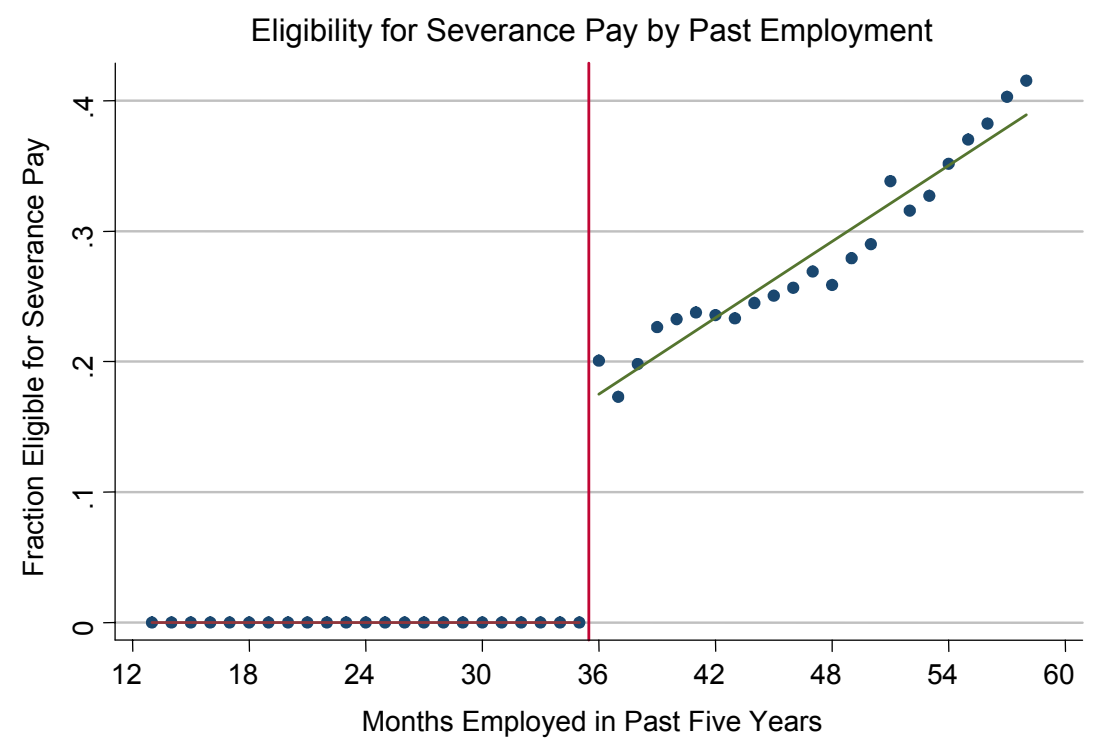

NOTE-These figures illustrate the "double discontinuity" problem. In Figure 2a, individuals in the sample are grouped into "tenure-month" categories based on the number of whole months they worked at the firm from which they were laid off. Figure 2a plots the fraction of individuals in each tenure-month category who are eligible for EB. The fraction eligible for severance pay jumps from 0 to 1 at 36 months of job tenure. In Figure $2 b$, individuals in the sample are grouped into "months-employed" categories based on the number of whole months they worked at any firm within the past five years. Figure $2 b$ plots the fraction of individuals in each months-worked category who are eligible for severance pay. The fraction eligible for EB jumps from 0 to 1 at 36 months worked. 
Figure 3

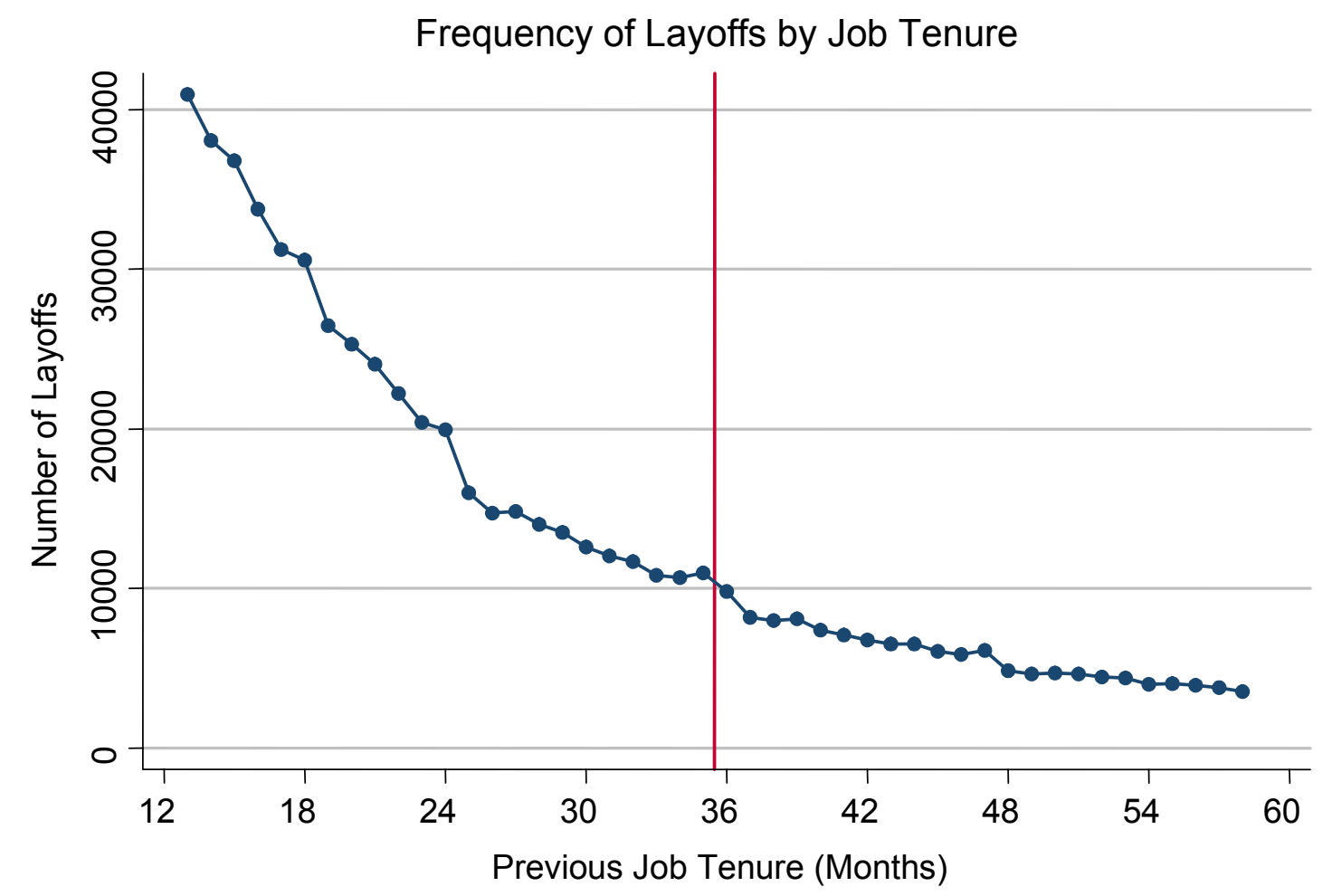

NOTE-In this figure, individuals in the sample are grouped into "tenure-month" categories based on the number of whole months they worked at the firm from which they were laid off. The figure plots the frequency of layoffs by tenure-month category, i.e. the total number of individuals in the sample within each tenure-month category. The vertical line denotes the cutoff for severance pay eligibility. 
Figure 4a

Age by Job Tenure

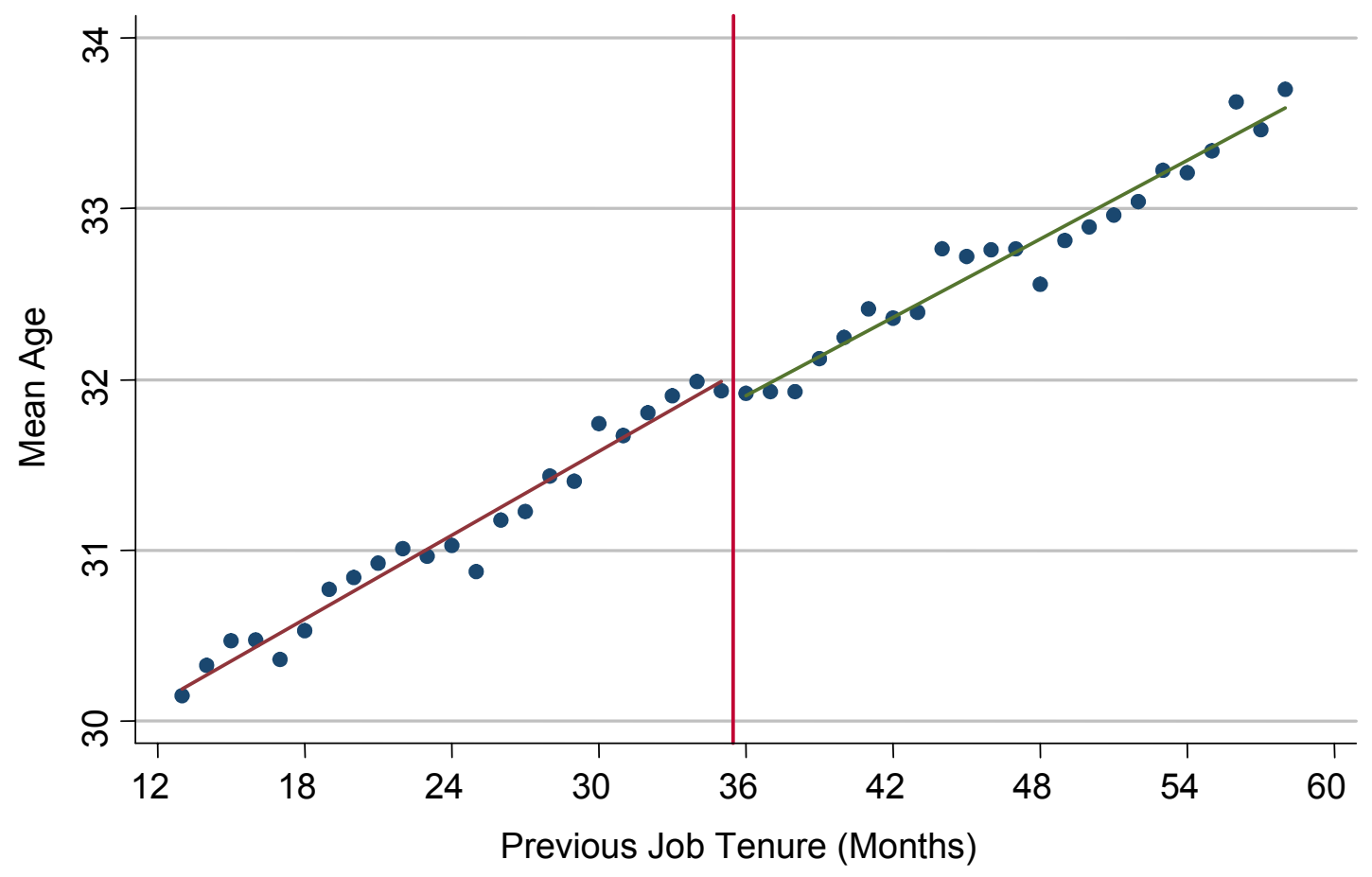

Figure $4 b$

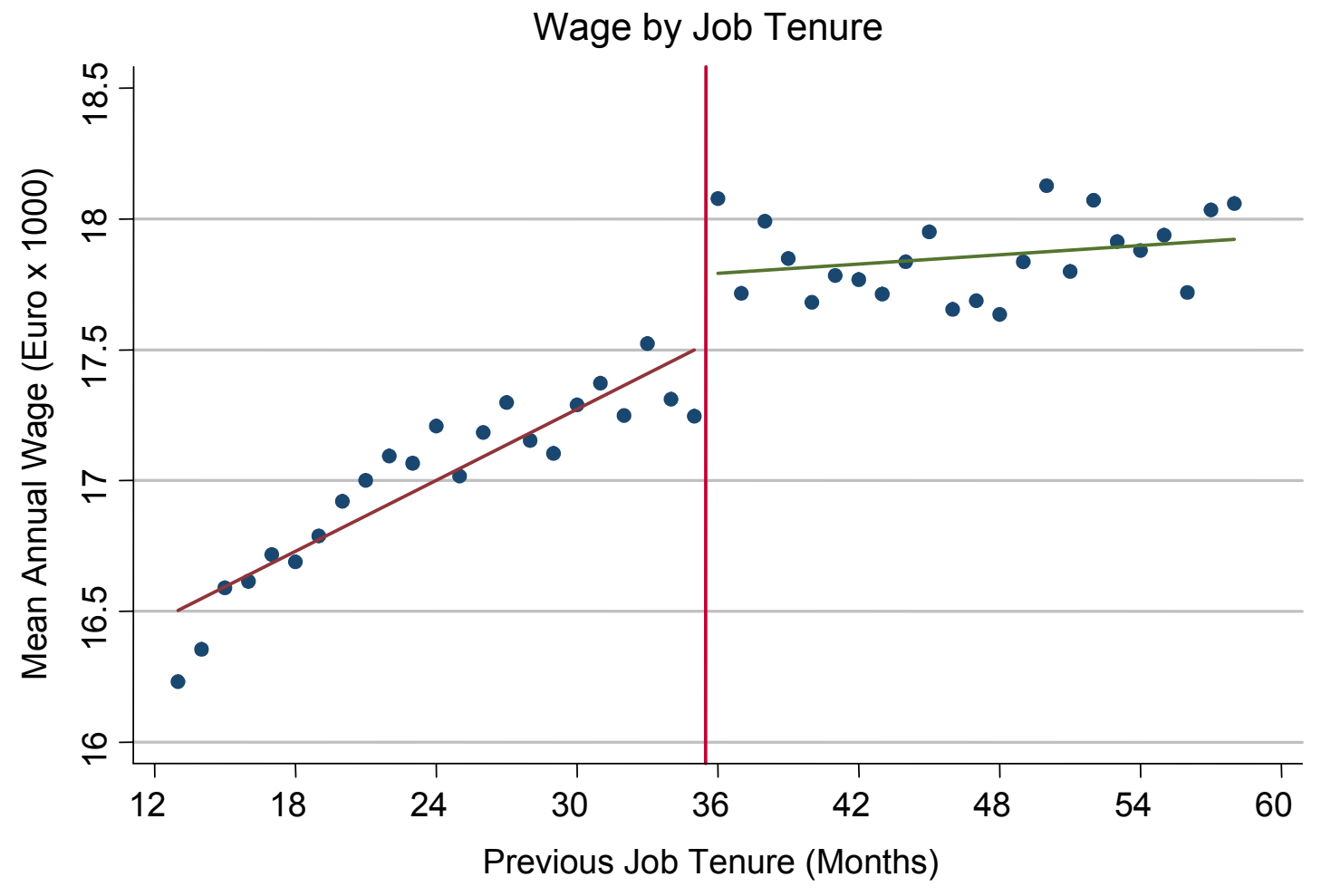


Figure 4c

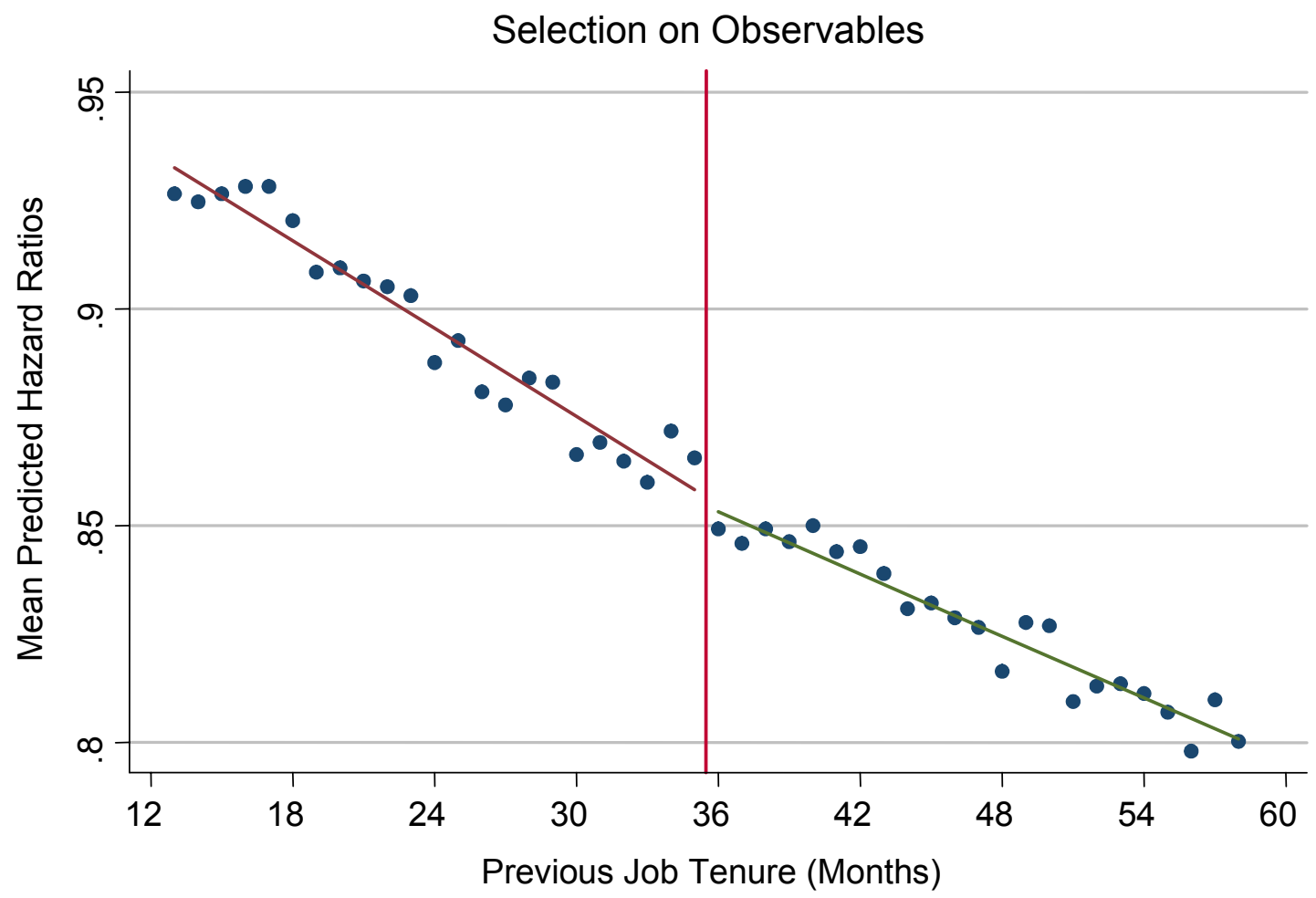

NOTE-Figures 4a-c show how observable characteristics vary around the cutoff for severance pay eligibility. Figure 4 a plots the average age of workers at the date of layoff in each tenure-month category. Figure $4 \mathrm{~b}$ plots the average annual wage in the final year of the job from which the individual was laid off. Figure 4c plots predicted hazard ratios from a Cox proportional-hazards model using the "saturated" set of covariates listed in the notes to Table 3a. 
Figure 5a

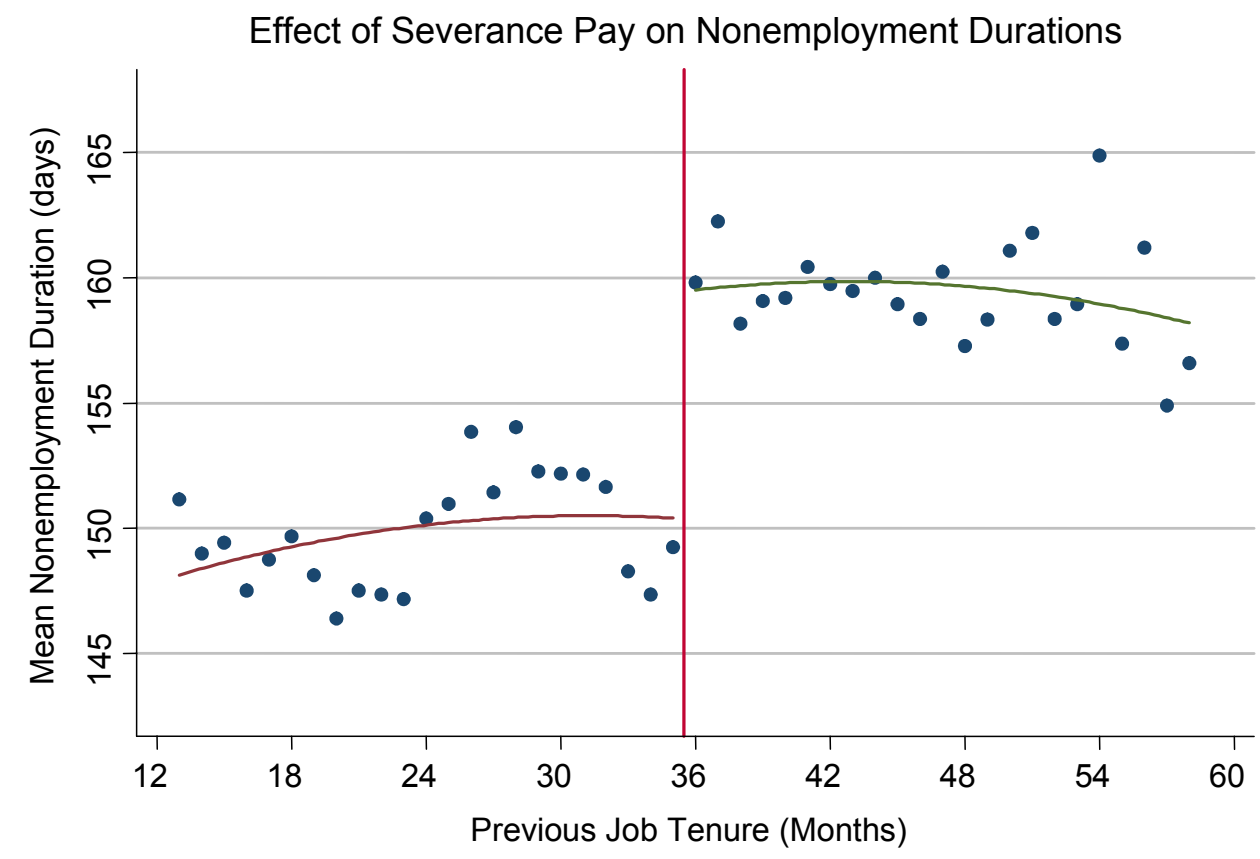

Figure $5 b$

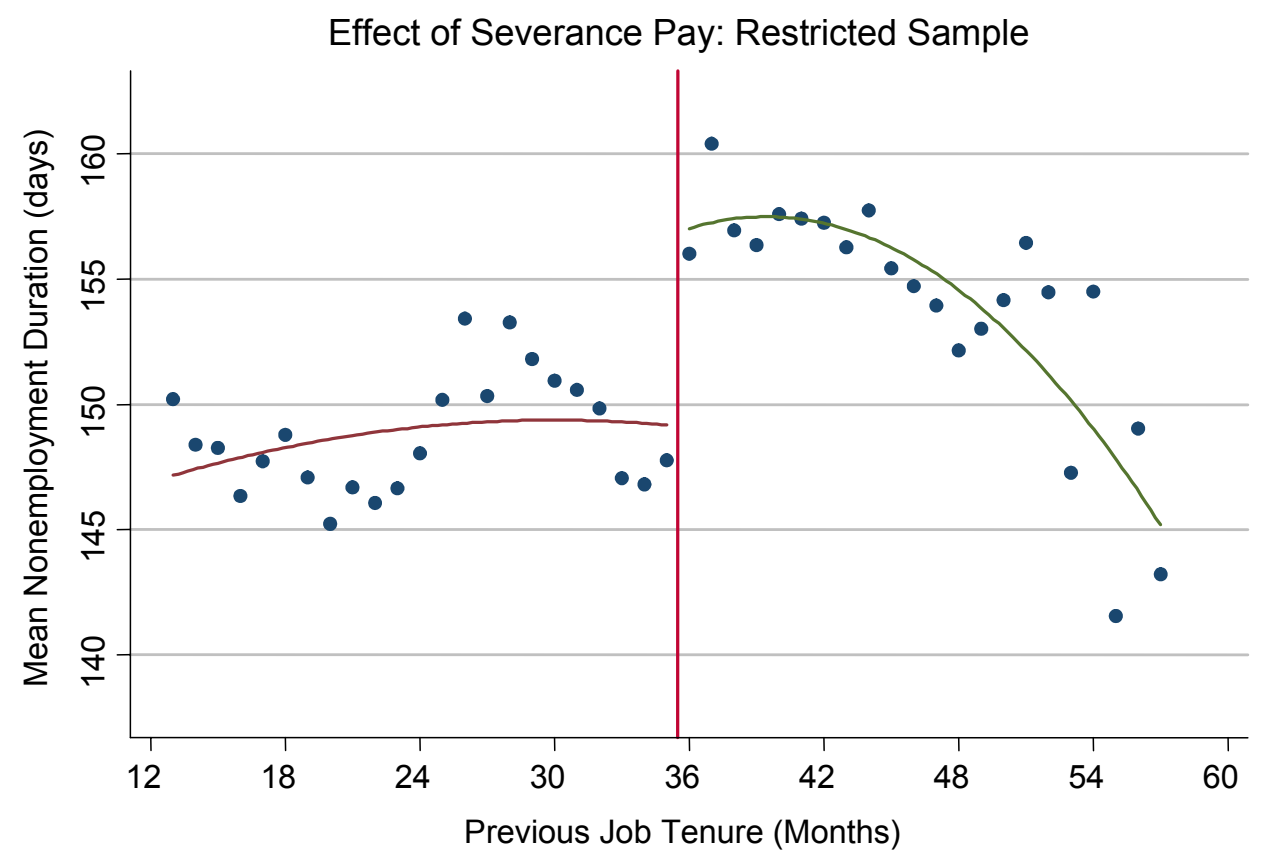

NOTE-These figures plot average nonemployment durations (time to next job) in each tenure-month category. They exclude observations with nonemployment durations of more than two years and ignore censoring. The vertical line denotes the cutoff for severance pay eligibility. Figure $5 a$ uses the full sample. Figure $5 \mathrm{~b}$ uses the "restricted sample" of individuals who have been employed at another firm (besides the one from which they were most recently laid off) for at least one month within the past five years. 
Figure 6a

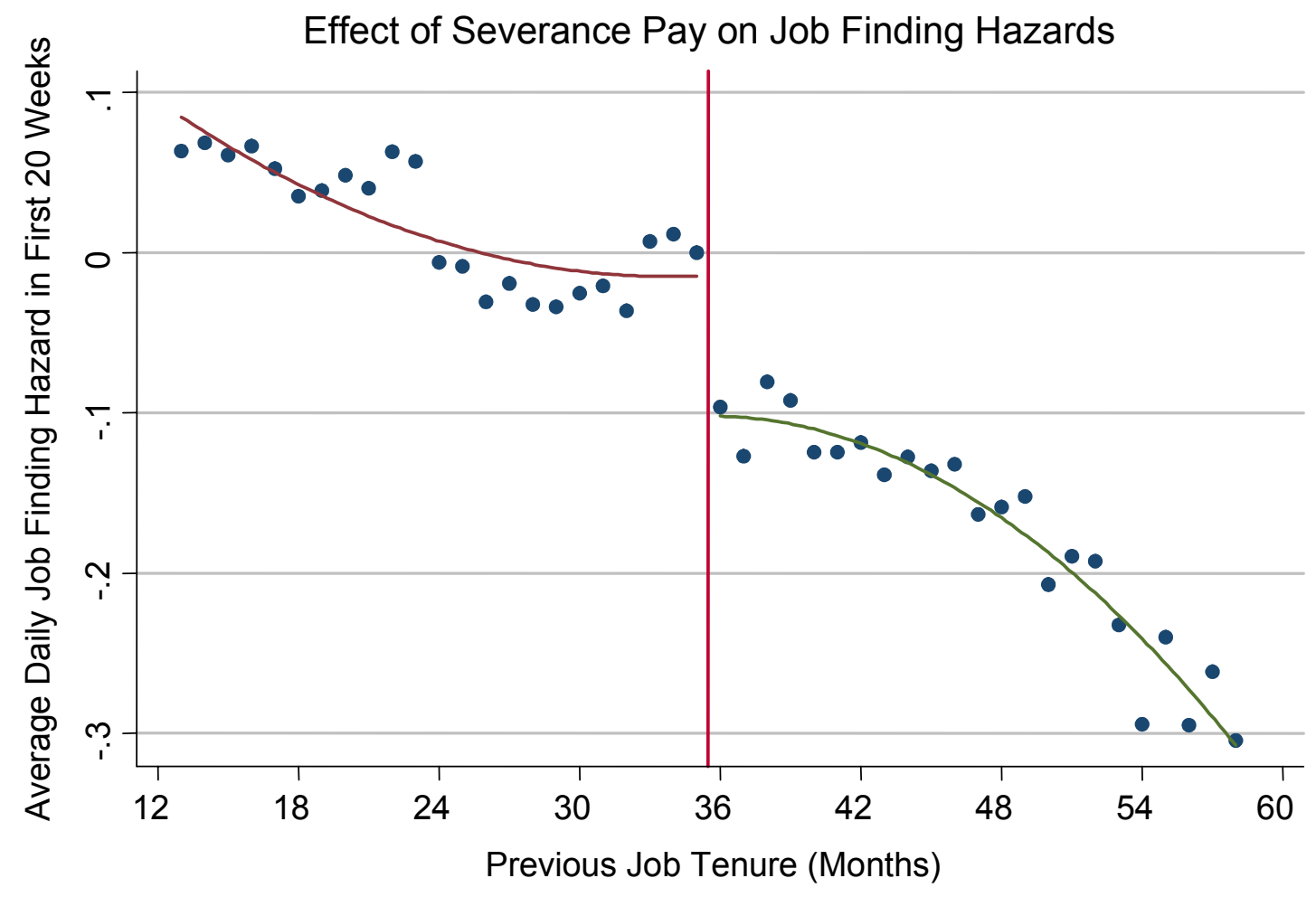

Figure $6 b$

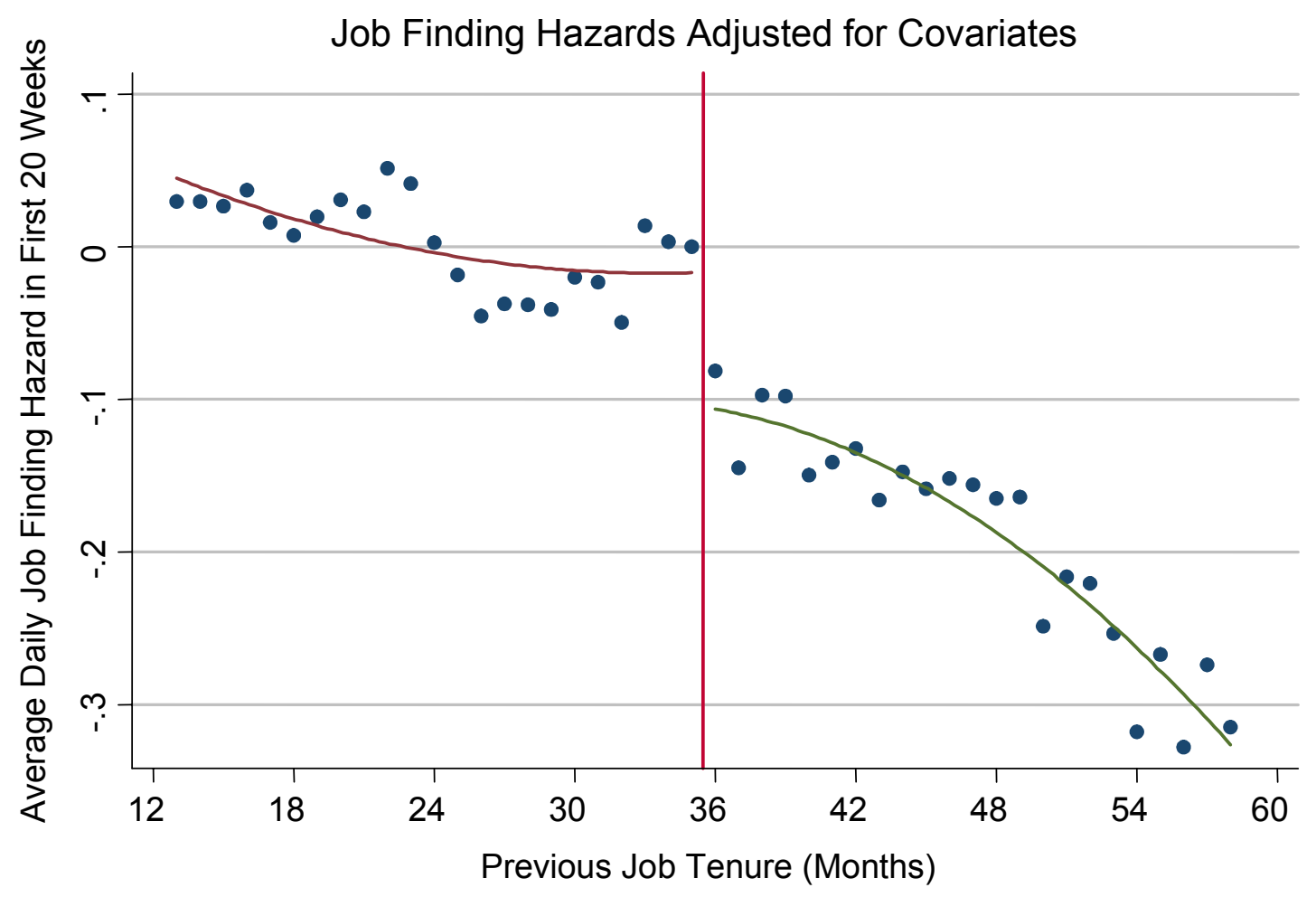




\section{Figure 6c}

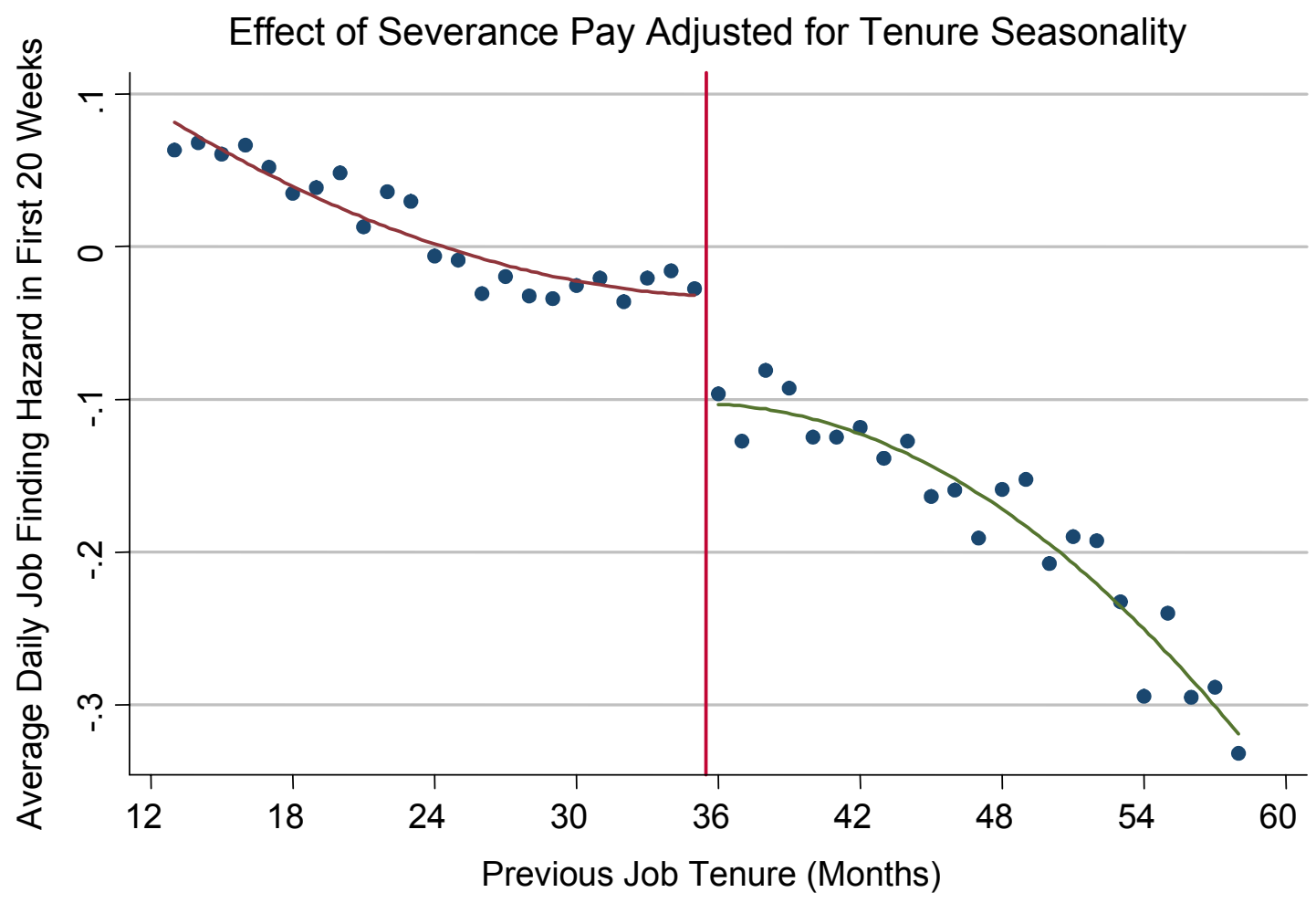

NOTE-Figures 6a-c plot the $\theta_{J}$ coefficients from the Cox proportional hazards regression specified in equation (14). The values can be interpreted as the percentage difference in the average job finding hazard during the first twenty weeks after job loss between each tenure-month group and tenure-month group 35. For example, Figure 6a shows that the average hazard among individuals laid off with 36 months of job tenure is $10 \%$ below that of individuals laid off with 35 months of job tenure. Figure $6 a$ plots the coefficients from a regression that controls only for the EB effect. Figure $6 \mathrm{~b}$ controls for the set of additional covariates used in column 4 of Table 2. Figure 6c corrects for the "tenure seasonality" pattern visible in the first two figures as described in the text. All three figures are drawn using the full sample described in the notes to Table 1. 


\section{Figure 7}

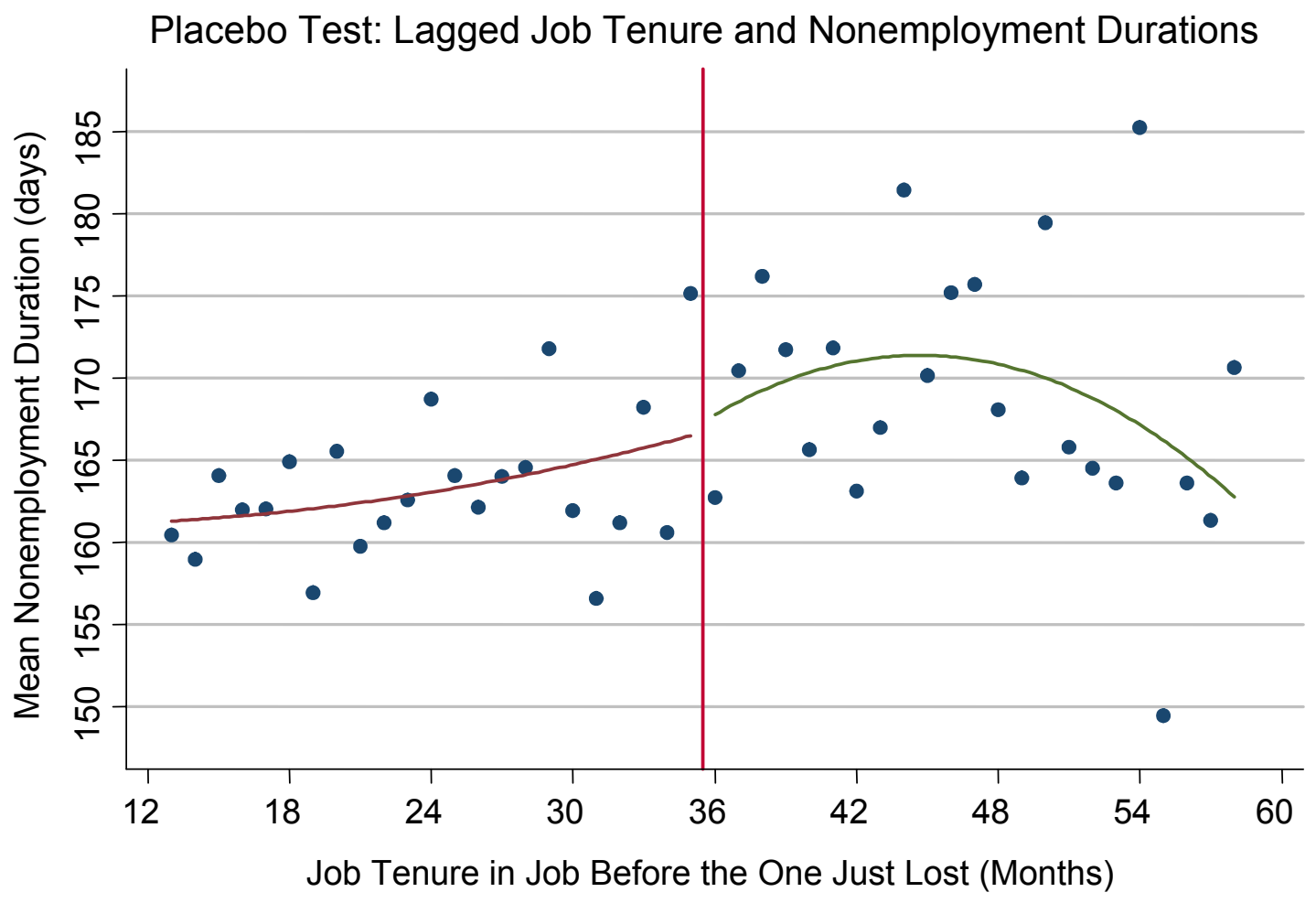

NOTE-The sample for this figure includes all individuals who have two or more unemployment spells in the data. Individuals are grouped into categories based on the number of whole months they worked at the firm prior to the one from which they were most recently laid off. The figures plots mean nonemployment durations (time to next job) in the current spell by tenure at the prior firm. The figure excludes observations with nonemployment durations of more than two years and ignores censoring. The vertical line denotes completion of three years of service at the prior firm; the fraction receiving severance pay in the current spell evolves smoothly through this cutoff. 
Figure 8a

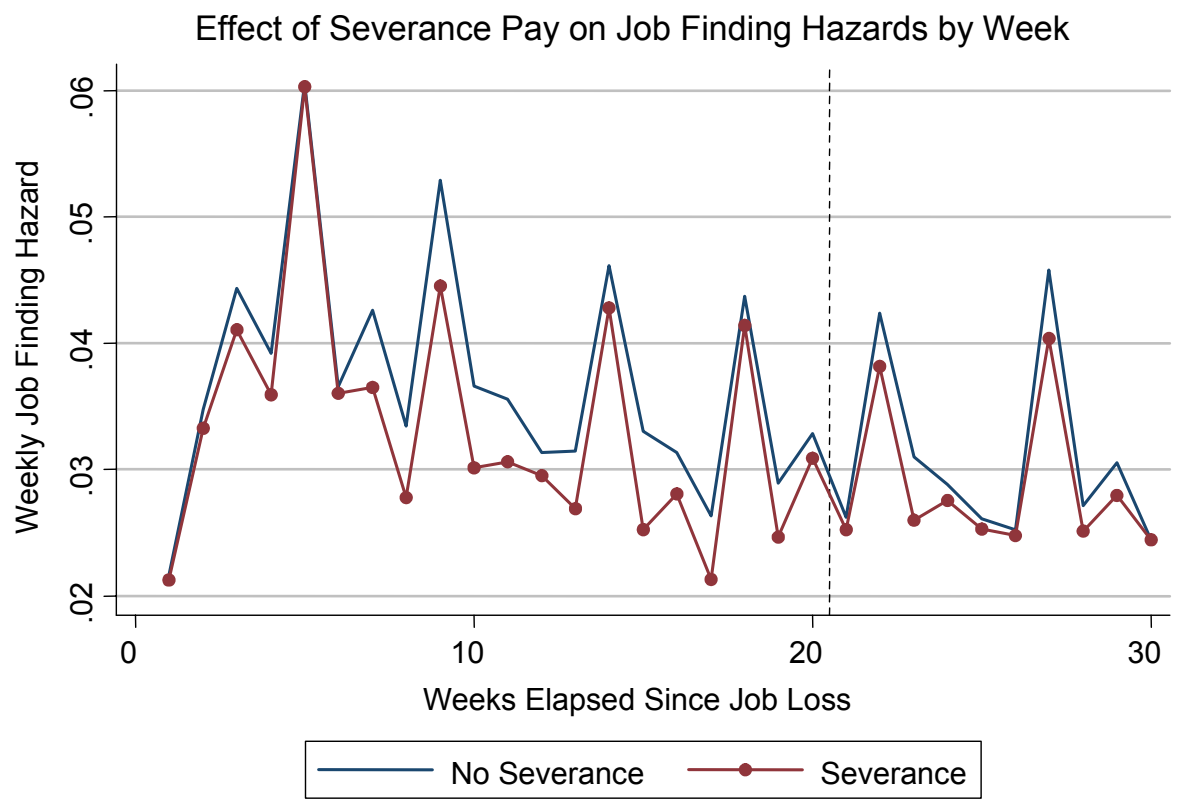

Figure $8 b$

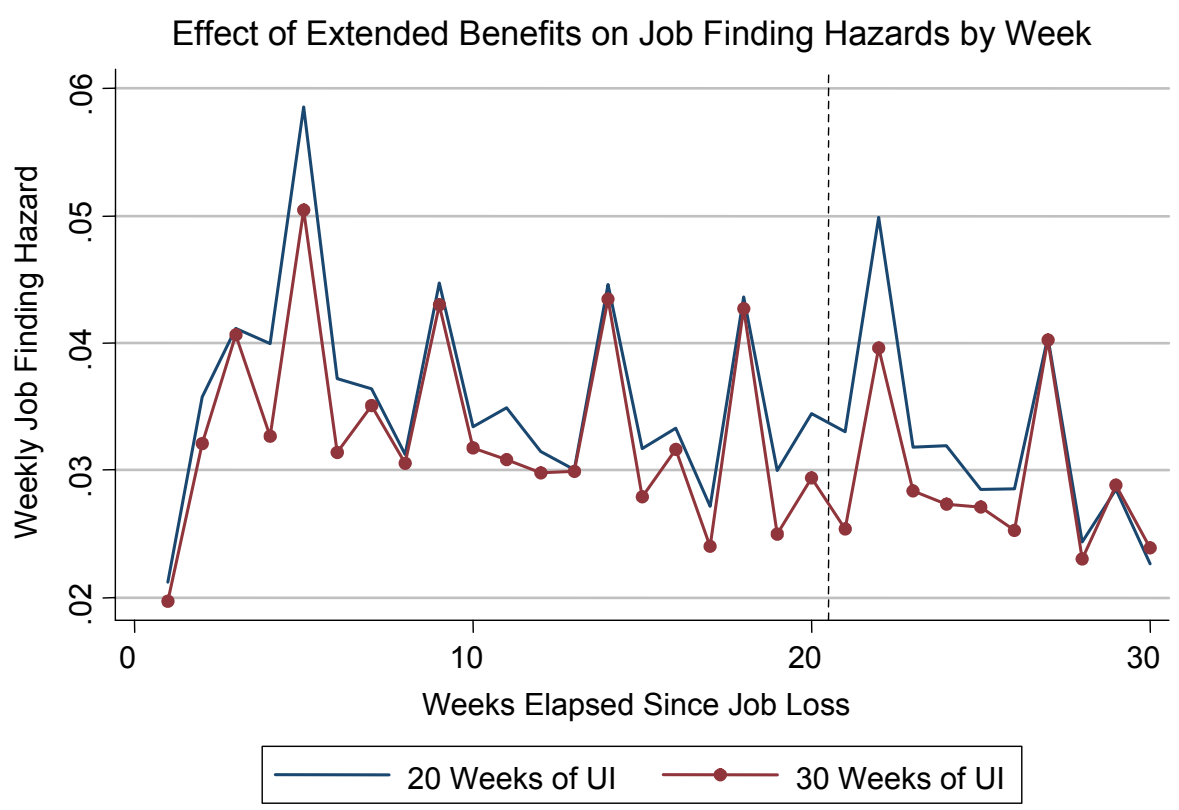

NOTE-These figures plot average weekly job finding hazards during the first thirty weeks after job loss in the restricted sample. In Figure 8a, individuals in the "no severance" group are those laid off with between 33 and 35 whole months of job tenure; individuals in the "severance" group have between 36 and 38 whole months of job tenure. In Figure 8b, individuals in the "20 weeks of Ul" group have worked for between 33 and 35 whole months in the past five years; individuals in the "30 weeks of UI" group have between 36 and 38 months worked. The dashed vertical line denotes the point at which the UI benefit extension applies (20 weeks). 
Figure 9a

Effect of Benefit Extension on Nonemployment Durations

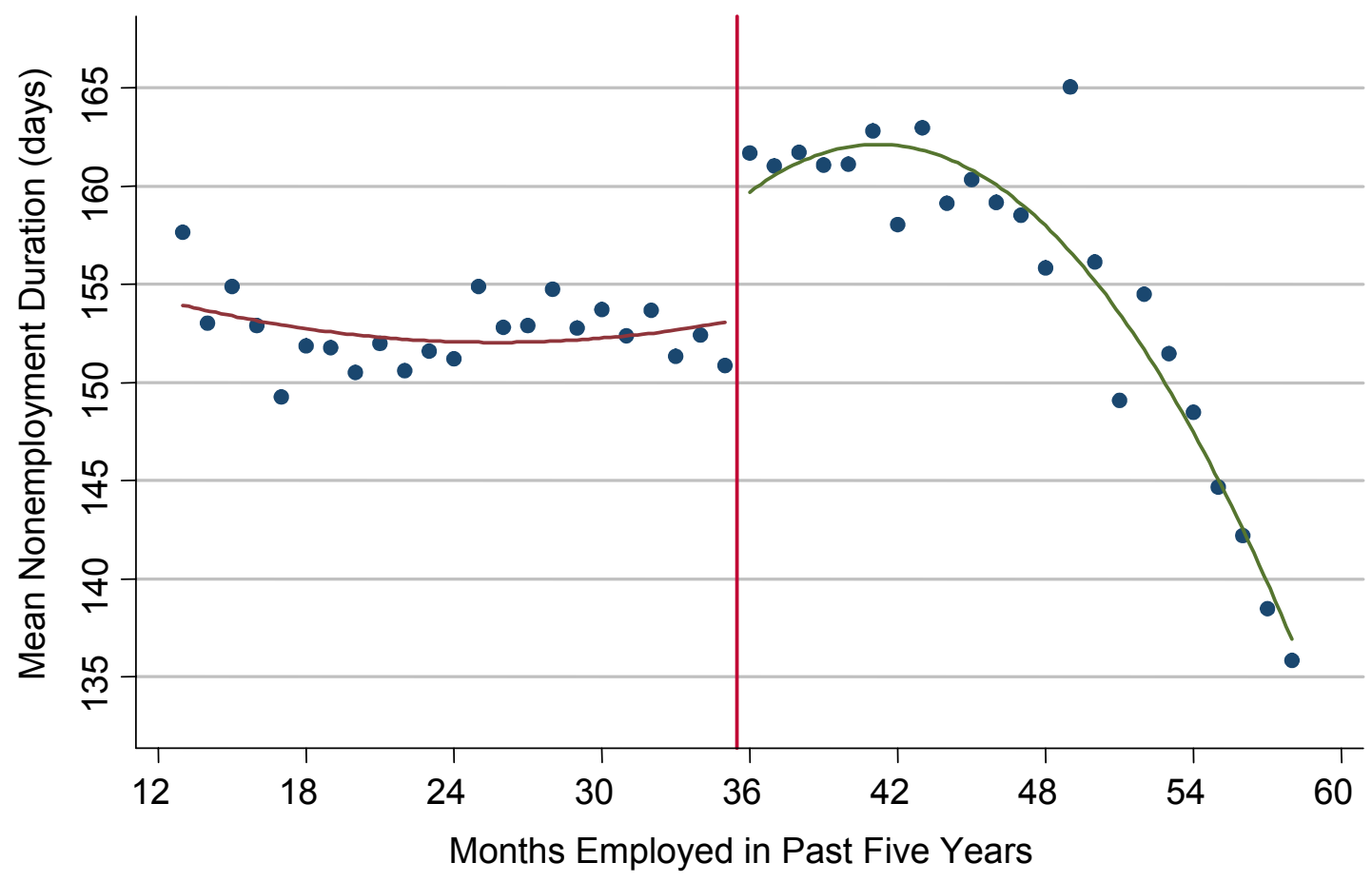

Figure 9b

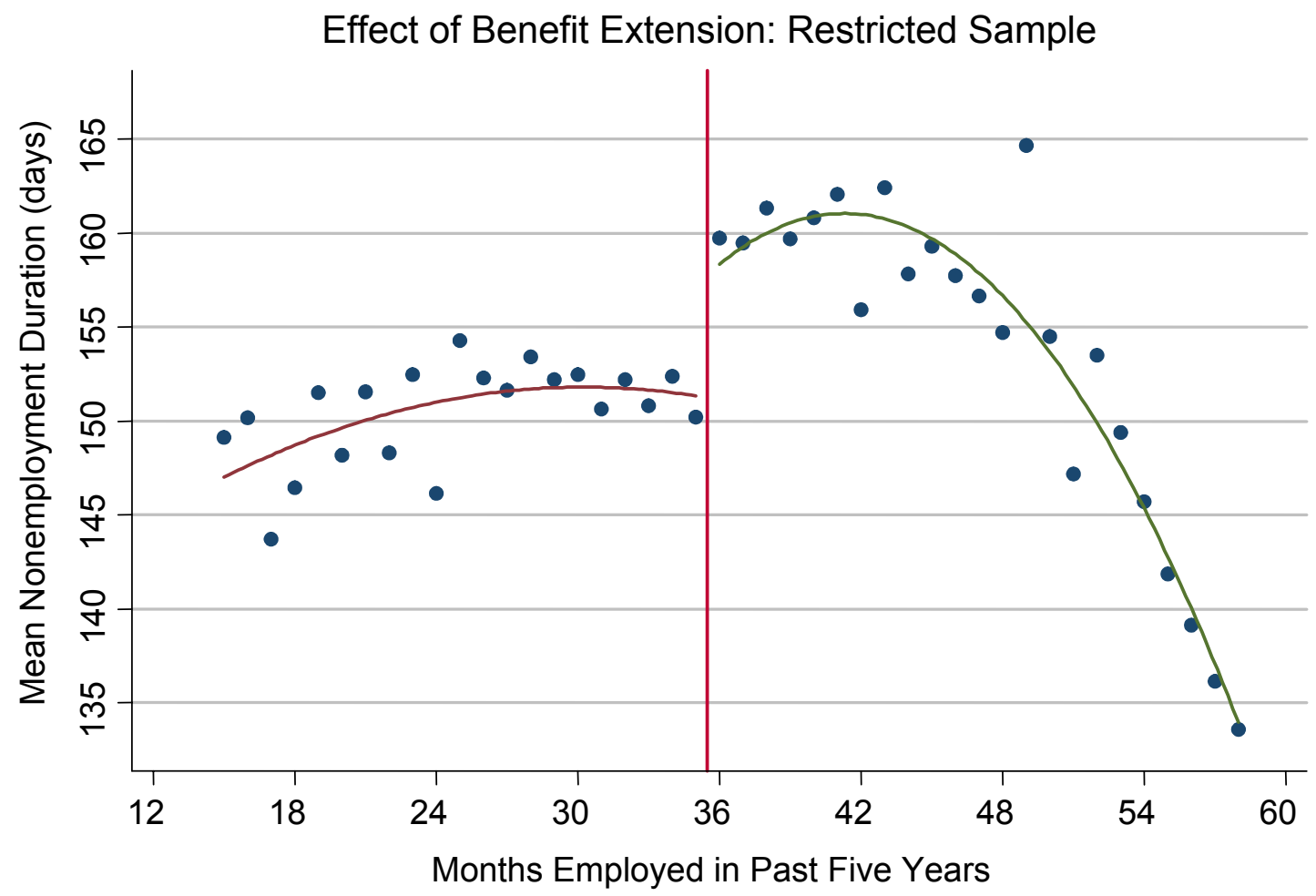




\section{Figure 9c}

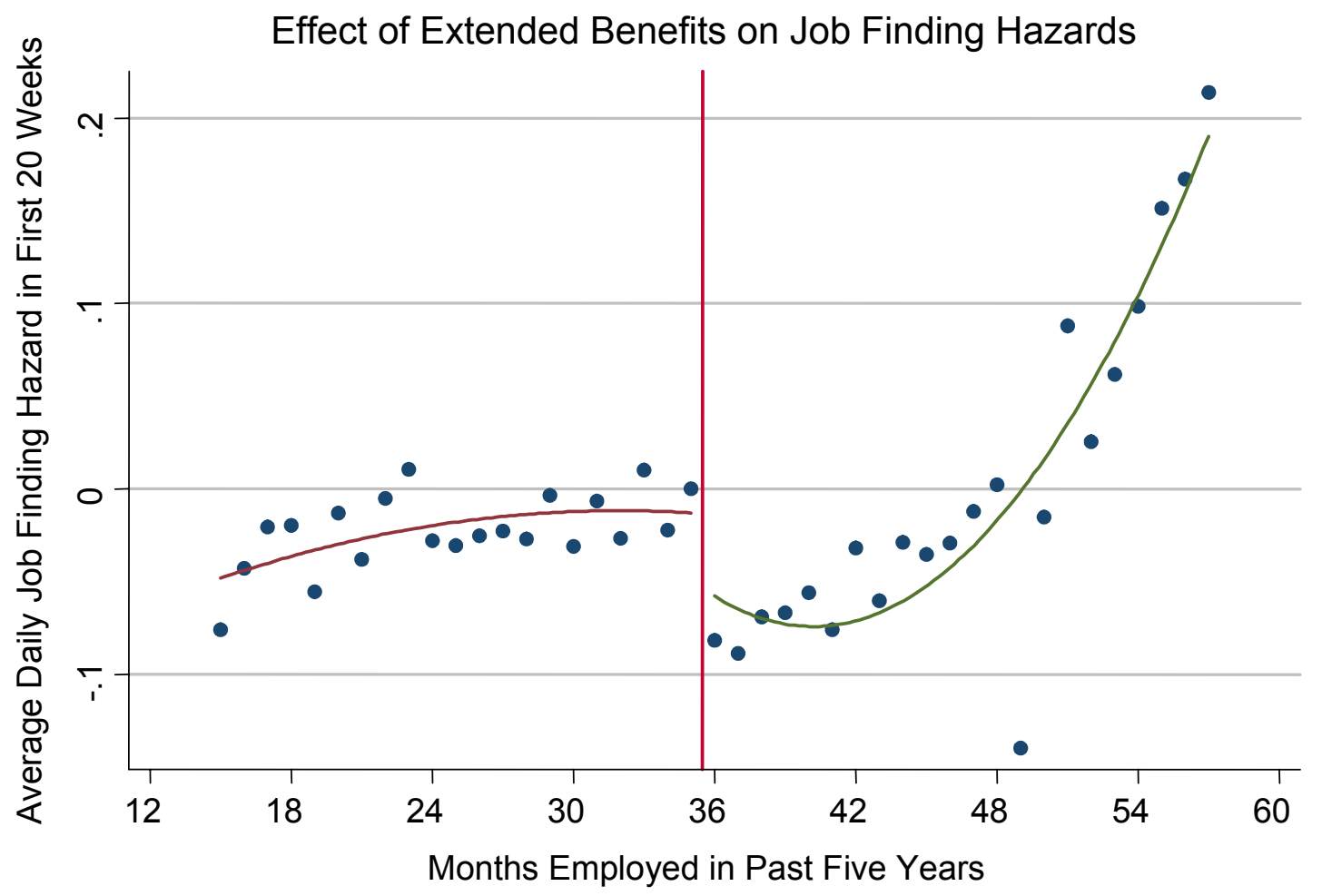

NOTE-In Figures 9a-c, individuals are grouped into "months-employed" categories based on the number of whole months they worked at any firm within the past five years. Figures $9 a$ and $9 \mathrm{~b}$ plot mean nonemployment durations in each months-employed category in the full and restricted samples, respectively. These two figures exclude observations with nonemployment durations of more than two years and ignore censoring. Figure $9 \mathrm{c}$ plots coefficients from a Cox proportional hazards regression analogous to that used in Figure 6a, controlling for the severance pay effect using a cubic polynomial, in the full sample. The values plotted can be interpreted as the percentage difference in the average job finding hazard during the first twenty weeks of the spell between each months-worked group and the group with months-worked equal to 35 . 
Figure 10a

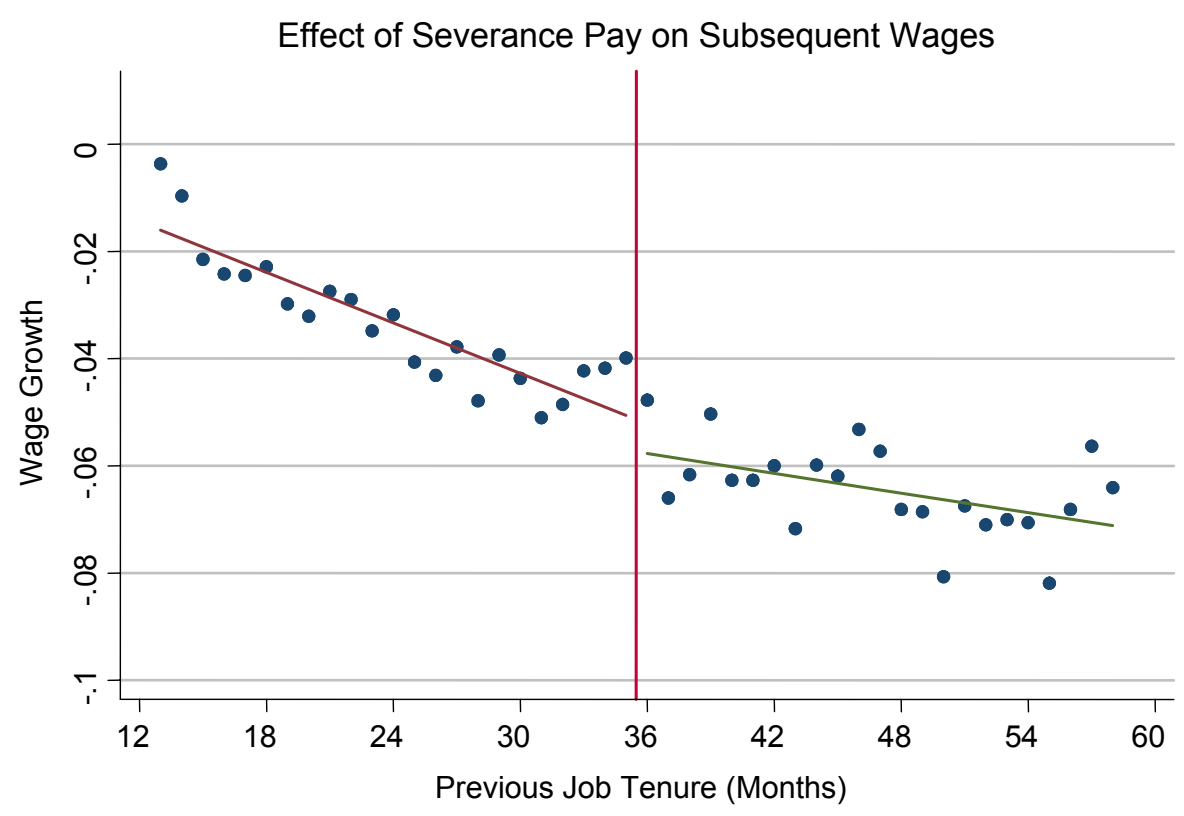

Figure $10 b$

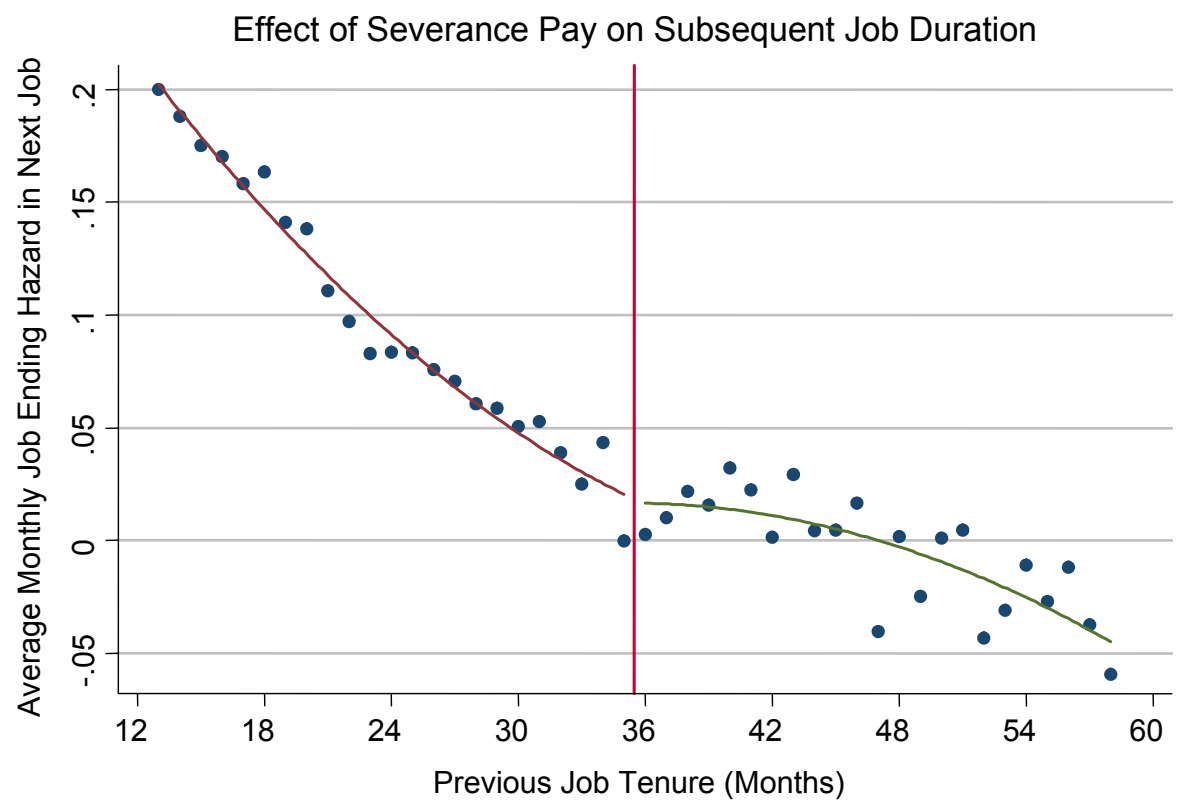

NOTE-Figure 10a plots average wage growth (difference in log annual wage between next job and the job from which the individual was laid off) in each tenure-month group. Figure $10 \mathrm{~b}$ plots coefficients from a Cox proportional hazards model for the duration of the next job with dummies for each job tenure category. The values can be interpreted as the percentage difference in the average job leaving hazard during the first five years of the next job between each job tenure group and the group with job tenure equal to 35 . The sample for both figures includes all individuals in the full sample observed in a new job. 
Figure 11a

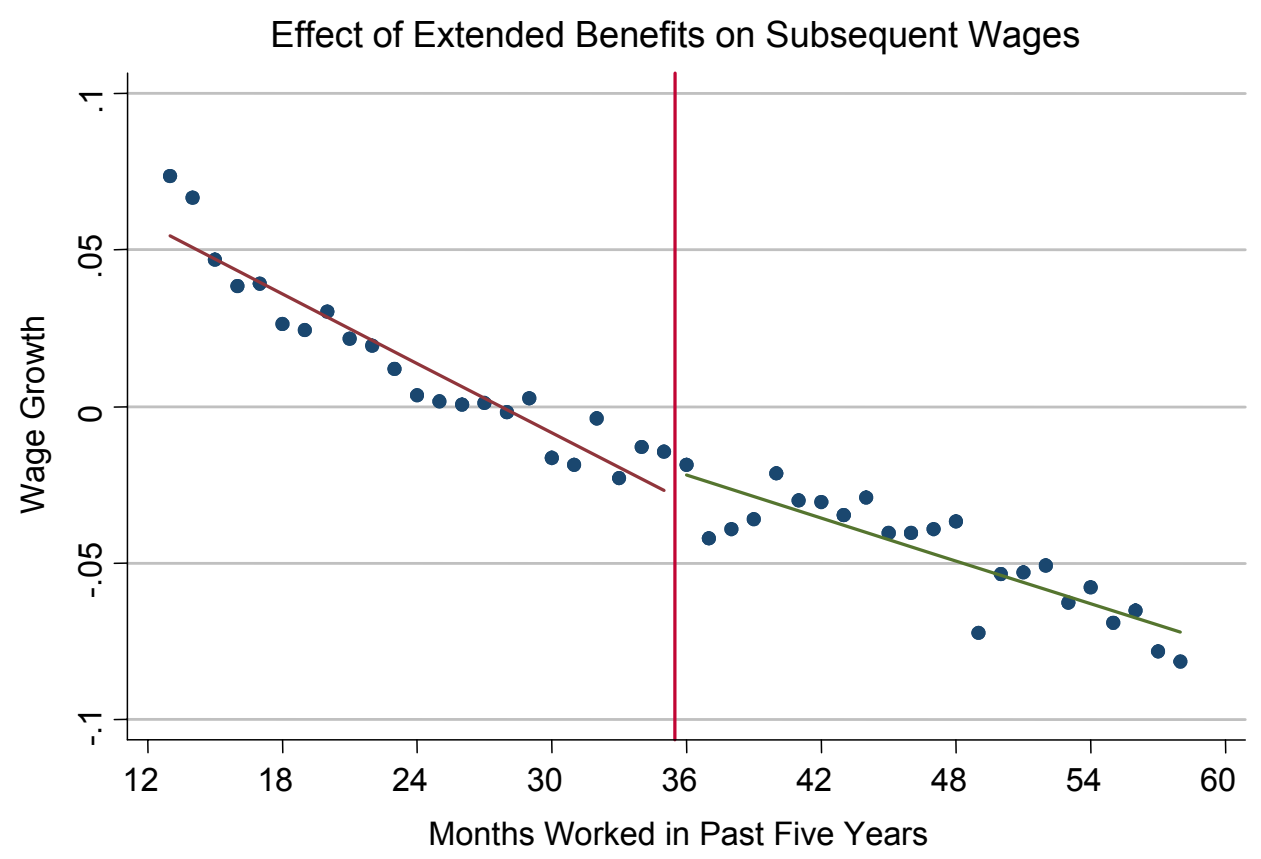

Figure $11 b$

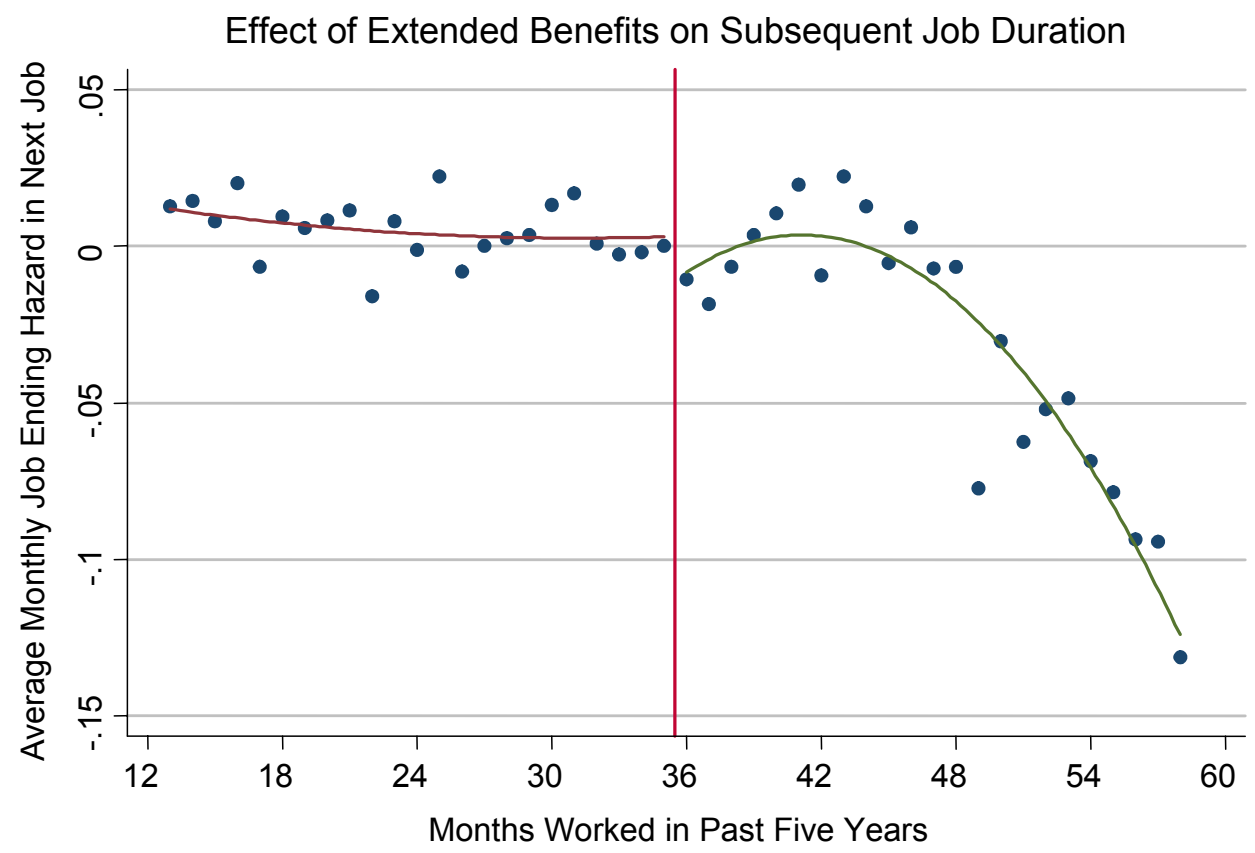

NOTE-These figures replicate Figure 10 using months worked as the running variable on the $\mathrm{x}$-axis. Figure 11a plots average wage growth in each months-worked group. Figure $11 \mathrm{~b}$ plots coefficients from a Cox proportional hazards model for the duration of the next job with dummies for each job tenure category. The values plotted can be interpreted as the percentage difference in the average job leaving hazard during the first five years of the next job between each months-worked group and the group with months-worked equal to 35 .

The sample for both figures includes all individuals in the full sample observed in a new job. 